University of Louisville

ThinkIR: The University of Louisville's Institutional Repository

Electronic Theses and Dissertations

$5-2017$

\title{
Parental opinions about prenatal genetic screening and selective abortion for Down Syndrome.
}

Laura E. Holt

University of Louisville

Follow this and additional works at: https://ir.library.louisville.edu/etd

Part of the Social and Behavioral Sciences Commons

\section{Recommended Citation}

Holt, Laura E., "Parental opinions about prenatal genetic screening and selective abortion for Down Syndrome." (2017). Electronic Theses and Dissertations. Paper 2675.

https://doi.org/10.18297/etd/2675

This Master's Thesis is brought to you for free and open access by ThinkIR: The University of Louisville's Institutional Repository. It has been accepted for inclusion in Electronic Theses and Dissertations by an authorized administrator of ThinkIR: The University of Louisville's Institutional Repository. This title appears here courtesy of the author, who has retained all other copyrights. For more information, please contact thinkir@louisville.edu. 
PARENTAL OPINIONS ABOUT PRENATAL GENETIC SCREENING AND SELECTIVE ABORTION FOR DOWN SYNDROME

\author{
By \\ Laura E. Holt \\ B.A., University of Louisville, 2009 \\ M.A., University of Louisville, 2017 \\ A Thesis \\ Submitted to the Faculty of the \\ College of Arts and Sciences of the University of Louisville \\ in Partial Fulfillment of the Requirements \\ for the Degree of \\ Master of Arts \\ in Sociology \\ Department of Sociology \\ University of Louisville \\ Louisville, KY
}

May 2017 
Copyright 2017 by Laura E. Holt

All rights reserved 

PARENTAL OPINIONS ABOUT PRENATAL GENETIC SCREENING AND SELECTIVE ABORTION FOR DOWN SYNDROME

\author{
By \\ Laura E. Holt \\ B.A., University of Louisville, 2009 \\ M.A., University of Louisville, 2017
}

A Thesis Approved on

April 18, 2017

by the following Thesis Committee:

Dr. David J. Roelfs

Dr. Robin S. Högnäs

Dr. Karen L. Christopher 


\section{DEDICATION}

This thesis is dedicated to

Garrick, my strong foundation,

and to Aleigha, my beautiful sky. 


\section{ACKNOWLEDGEMENTS}

I would like to thank my advisor, Dr. David J. Roelfs, of the department of sociology at the University of Louisville, for his tireless efforts in assisting me with this project. I would like to further thank Dr. Robin Hognas, of the department of sociology, and Dr. Karen Christopher, of the department of women and gender studies, both at the University of Louisville, for serving on my thesis committee and for their feedback and guidance. I would like to thank the parents who graciously participated in this study, taking the time to share their valued opinions and perspectives on this important topic. Finally, I would like to express my gratitude to my husband, Garrick, and my daughter, Aleigha, for their support and encouragement throughout my years of study and through the process of writing and researching this thesis. This accomplishment would not have been possible without them. 


\title{
ABSTRACT \\ PARENTAL OPINIONS ABOUT PRENATAL GENETIC SCREENING AND \\ SELECTIVE ABORTION FOR DOWN SYNDROME
}

\author{
Laura E. Holt
}

April 18, 2017

Recent advancements in the field of genetic testing have made it easier to prenatally identify the presence of Down Syndrome in a fetus. The purpose of this study was to examine the opinions of parents who are currently raising a child with Down Syndrome towards genetic screening and selective abortion for the condition, as well as any potential effects of this process on their families. A series of individual interviews with twenty parents was conducted. An inductive methodology was used to analyze interview data. The key findings indicate that parents' perspectives of the role of the physician in the genetic screening process, as well as their perceptions of threat to their children and families, each ranged from neutral to extremely negative. There was an association between these two perceptions. Parent advocates are engaged in a power struggle with physicians over influence on expectant parents at the time of fetal diagnosis. 
TABLE OF CONTENTS

PAGE

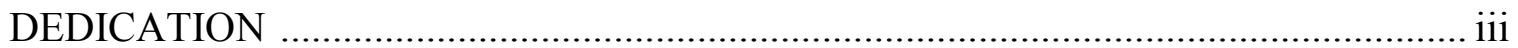

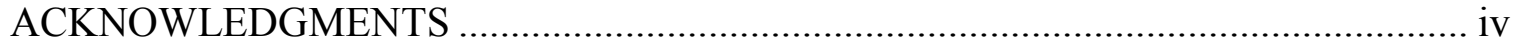

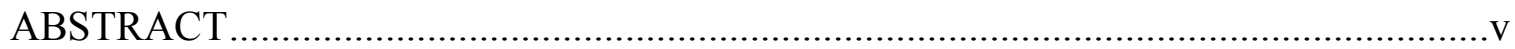

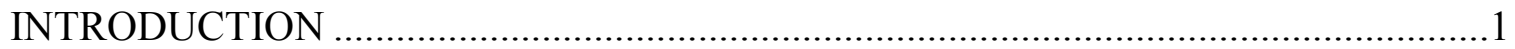

Review of the Literature ………….................................................................

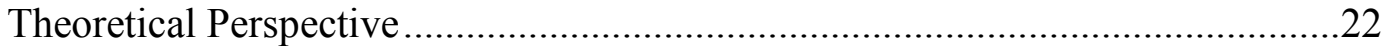

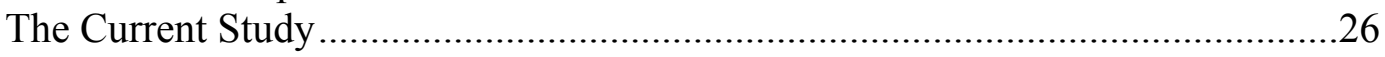

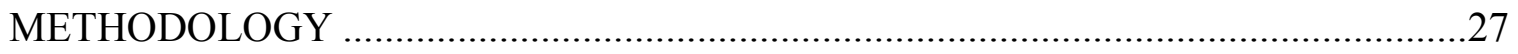

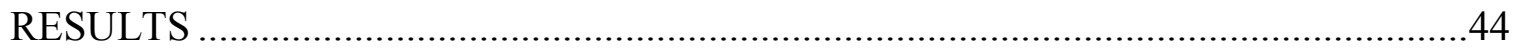

Expectant Couples, Advocacy groups, Physicians, and the Locus of "Reality" ...47

Perceived Effects on Individuals and Society..........................................................71

Association between Perceptions of Power and Perceptions of Threat..................84

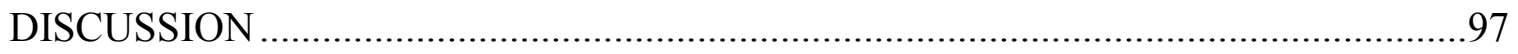

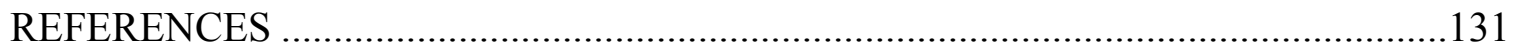

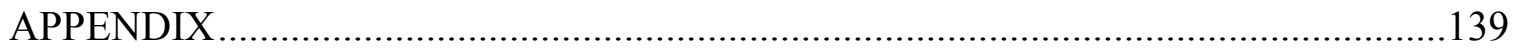

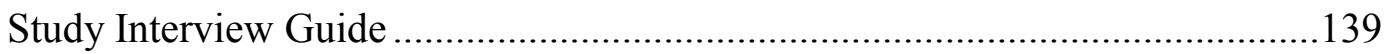

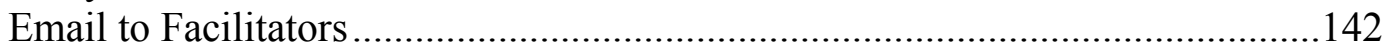

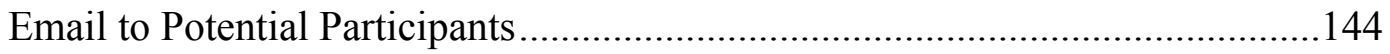

Participant Recruitment Flyer ...................................................................146

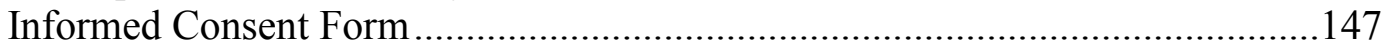

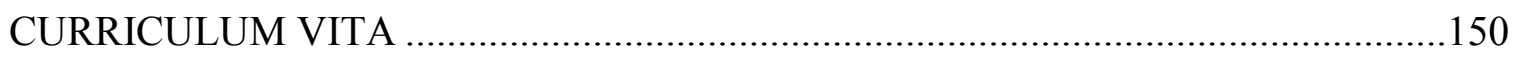




\section{INTRODUCTION}

The proposed study will examine the opinions of parents who are currently raising a child with Down Syndrome towards genetic screening and selective abortion for the condition. This is an especially salient topic for research because of the recent, rapid and extensive technological advancements in the science of genetic testing and enhancement and the discoveries made in the human genome project. Current technologies allow for the assessment of some forms of risk of physical or cognitive abnormality in a fetus, which may be followed subsequently by actions taken to repair the anomaly, or to terminate the pregnancy. There is also speculation on the availability of genetic engineering, soon to impinge on our consciences, which could allow eager parents to proactively alter or even construct a fetus, according to their wishes. All of these possibilities are plagued by moral and ethical issues of a profound nature. According to Ladelle McWhorter, "The issues of [genetic enhancement] are likely to become more rather than less pressing in the near future" (2009:413).

As Down Syndrome (also referred to as DS) is the single most frequently identified cause of mental retardation in North America, occurring at approximately 1 in 1,000 live births in the United States (Egan et al 2011, Galley 2005) it has come under particular scrutiny by physicians, disability advocates, and bioethicists. It has been the most common chromosomal abnormality which is associated with intellectual disability (de Groot-van der Mooren et al 2014). Rates of occurrence of Down Syndrome are stable 
across race, socioeconomic status and maternal health, but rise significantly with maternal age (Siffel et al 2004). Down Syndrome is characterized by certain facial features such as a flat nasal bridge and upwardly slanted eyes, short statures and shortened limbs, differing degrees of mental retardation, and comorbidity with certain heart, gastrointestinal, and respiratory conditions (Down Syndrome Fact Sheet). An additional chromosome, Trisomy 21 , occurs in $95 \%$ of cases of Down Syndrome. The remaining five percent consists of translocations (when part of chromosome 21 becomes attached to another chromosome) and mosaics (when only some cells have a third copy of chromosome 21 and the remaining cells are normal) (Siffel et al 2004).

The phenotypical presentation of individuals who are born with Down Syndrome varies greatly. Most individuals with DS have only mild to moderate cognitive impairment but some are affected more severely (Galley 2005). Congenital heart defects affect approximately $40 \%$ of children with Down Syndrome. Many of these defects can be now detected en utero or soon after birth and remedied appropriately (Galley 2005, Kozma 1995:65). In addition, the life expectancy for children with Down Syndrome has changed dramatically in the span of a few decades, with many living into their mid-fifties or beyond (Evans et al 2013, Galley 2005, Scott et al 2014). The health and cognitive abilities of children with Down Syndrome spans a wide range. This can make it difficult for pregnant couples to determine prenatally what to expect in parenting a child with DS (Rothman 1993).

Compounding the ethical controversies surrounding selective termination is that some studies suggest a discrepancy between the perceptions of disabilities held by expectant parents undergoing prenatal genetic screening, and the lived experiences of 
those with the disabilities and their families. This is, again, further complicated by the spectrum of health and ability exhibited by those with the condition. In addition, medicinal and technological advances can be made at a rate which outpaces public impression, in a process sociologist William Ogburn termed "cultural lag" (Godin 2010).

In the literature review that follows, the experience of parenting a child with Down Syndrome will be explored, along with parental and public perceptions of Down Syndrome and selective abortion. Various studies have unearthed the positive benefits of this unique parental experience, coupled with the available supports and resources, as well as the challenges and negative aspects. In addition, the literature review offers an explanation of the genetic screening options for Down Syndrome and insight into parents' perspectives on the genetic counseling process. Following that will be a brief discussion of a key theoretical perspective that will inform the present study, and a description of the methodology which was employed to investigate the research questions at hand.

\section{Review of the Literature}

\section{Education}

Since eugenics enjoyed its golden era in the early twentieth century, when thousands of disabled children in the United States and Europe were isolated in institutions or left to die from correctable maladies, starvation, or imposed exposure, many educational supports and resources have been mandated with the intention of incorporating disabled individuals into mainstream society. As an accompaniment to the women's and civil rights movements of the 1960s and 70s, American disability advocates 
succeeded at every level in securing equal rights and additional protections for citizens with cognitive, physical, and sensory impairments.

At the federal level, The Handicapped Children's Early Education Assistance Act of 1968 provided federal money for the development and assessment of early intervention programs for disabled children. In addition, the Vocational Rehabilitation Act of 1973 bolstered services for the educationally handicapped to promote their opportunities in employment and independent living. A critical portion of this act is Section 504, which remains in effect currently and allows for special appropriations and accommodations to be made for students who may not otherwise qualify under educational eligibility, but whose medical disability necessitates classroom or instructional modifications.

Critical court cases, occurring during the same time frame, also had a profound impact on the early development of the educational rights of children with disabilities. In 1972, the case of Mills v. Board of Education in the District of Columbia brought the issue of special needs education to the forefront. The case was pursued by seven special needs students who were denied education based on their disabilities. They used the argument of due process to assert that they had been denied education without a fair hearing. "The court found in favor of the children; thus began 'a free and appropriate education' for all children, regardless of their type of disability" (Hurwitz 2008:149). Also, in 1972, thirteen children with mental retardation (MR) sued on behalf of all children with MR, under the equal protection clause of the fourteenth amendment (PARC v. Pennyslvania). Through this case, the concept of "least restrictive environment" was applied to the educational arena, which means that students must be placed in a classroom environment with their neurotypical peers, to the extent their condition allows. 
In 1989, even those considered uneducable due to severe impairment were guaranteed the right to education, as determined in the case of Timothy W. v. Rochester. (Timothy W. was a severely cognitively disabled, blind, quadriplegic child.)

Regardless of the severity, federal mandates, such as the Americans with Disabilities Act of 1990, require the appropriate medical treatment and educational supports to assist all children with Down Syndrome to live their lives to the fullest of their ability (Cole 1999). It is unlawful in the United States to deny education to any child, regardless of disability. Currently, early screening programs exist in local communities, such as the First Steps program in Kentucky, which identifies the needs of children with DS and offer effective interventions at a young age, when potential for acquisition of skills and long-term progress is optimized.

\section{$\underline{\text { Medicine }}$}

Early medical screening and intervention programs are also in effect for the care of children with DS, many of which are implemented at birth (Fish 2008, Kozma 1995, Marshall et al 2014). Considerable advancements have been made in the treatment of comorbid medical conditions, which occur commonly in children with Down Syndrome. Because of these advancements, many children with DS are able to live healthy and functional lives relative to their typical peers (Down Syndrome Fact Sheet, Kozma 1995:64). Life expectancy for children born with Down Syndrome has extended from nine years in the 1930s to fifty plus years at the present time (Evans et al 2013, Galley 2005:45, Kozma 1995:64). Although it remains unknown how the presence of a twentyfirst chromosome in these individuals causes the health problems associated with Down 
Syndrome, most of the conditions, even some of the most serious, can now be detected and treated during infancy or the first few years of life.

Most children with Down Syndrome experience some level of sensory impairment and/or developmental delay, with a smaller percentage experiencing serious deformations to the heart, lungs, or gastrointestinal system. They may also exhibit dental or orthopedic problems. Vision problems, including strabismus, astigmatism, and blocked tear ducts, occur more commonly in children with Down Syndrome than in the general population, but the problems are typically no more severe (Kozma 1995:72). Hearing loss affects 40 to $60 \%$ of children with Down Syndrome. Proper treatment of any sensory impairments can also enhance the child's developmental progress.

Approximately 40 to 45 percent of babies with Down Syndrome are born with a congenital heart defect, which can usually be repaired in even the most severe cases (Kozma 1995:65). The most common deformations of the heart include atrioventricular canal defect and ventricular septal defect, both of which can lead to serious problems such as low blood oxygen levels, enlarged heart, high blood pressure, and pulmonary hypertension over time, if left untreated. Nowadays, echocardiograms are performed routinely on all children born with Down Syndrome, as soon as possible after birth, to identify malformations and plan treatment actions. Treatments may range from drugs used to control symptoms and reduce stress on the heart, to open heart surgery performed by a pediatric cardiologist. Most heart surgeries for children with DS occur in the first six months of life (Fish 2008:407, Marshall et al 2014). Survival rates for even the most intensive heart repair procedures fall upwards of $75 \%$, and the prognosis for the children 
who survive surgery is very good, although continual monitoring throughout the child's life is crucial (Kozma 1995:68).

Ten to $12 \%$ of children with Down Syndrome may also face gastrointestinal problems, the most common of which are duodenal atresia, imperforate anus, pyloric stenosis, trachea-esophageal fistula, and Hirchsprung's disease (Kozma 1995:69). These conditions are also generally identified soon after birth, and may become known due to the baby's feeding issues, vomiting or lack of stools, or pneumonia. As with the heart defects, these conditions are often readily identified and treated with surgical or other medical intervention. If left untreated, disruptions in the activities of the heart and stomach can lead to respiratory problems. Formerly, these issues were often fatal but now appropriate treatments for the primary causes are available.

Children with Down Syndrome face increased risk for seizures (5 to 10\%) and hypothyroidism, both of which can generally be controlled with medication (Fish 2008:507). Prompt identification and treatment are critical because, again, seizures and thyroid issues can be a causative factor in mental retardation and developmental delays, compounding problems for children who are already susceptible to these issues due to their genetics (Fish 2008:445). Careful and routine medical assessment of children with Down Syndrome is necessary to help parents avoid these problems before they start or early in their onset.

Children with DS face a substantially greater risk of leukemia than their typical peers (up to twenty-fold greater risk), with the presence of leukemia in the Down Syndrome population estimated at $1 \%$, and with treatment options including chemotherapy and bone marrow transplants. The survival rate is high (Kozma 1995:79). 
According to Fish, "Children with DS usually respond very favorably to standard treatment" (2008:504). They also face high rates of early onset Alzheimers disease and dementia (Carling-Jenkins et al 2012, Evans et al 2013).

Parents of children with Down Syndrome should be educated and made aware of all of these health problems. The majority of these health problems are surmountable, albeit with timely, ongoing, and potentially costly medical treatment, and, once adequately addressed with quality health care, may serve as no impediment to the child's healthy functioning later in life. The quality of life for children with Down Syndrome can be comparable to many of their peers, but it requires diligence and commitment on the part of parents and the medical and educational communities (Bauer 2008, Fidler et al 2000, Marshall et al 2014).

\section{$\underline{\text { Parental Rewards }}$}

Some studies on actual parents of children with Down Syndrome find that parenting such a child is personally enriching, and even joyful. Reilly and others reviewed five studies in the realm of parental and sibling grief over the loss of a child with a disability, all of which reported positive experiences associated with the presence of a disabled child in the family, even despite the grief resulting from the child's premature death (2008). Furthermore, Glidden and Jobe found in their longitudinal study of over 200 adoptive and biological parents of children with Down Syndrome, that biological parents initially showed high levels of depression, but levels of depression dropped soon after and remained low (2006). This suggests that once the initial shock has passed and the family has adjusted to the reality of raising a child with Down Syndrome, parents return to and maintain good mental health. 
Fidler, Hodapp, and Dykens took a comparative look at family and parental stress in their study of families of young children with Down Syndrome, Williams Syndrome, and Smith-Magenis Syndrome (2000). Their study revealed that families of children with Down Syndrome experience significantly less pessimism than the other two groups, and significantly fewer family problems than families of children with Smith-Magenis. The authors propose that the "behavioral phenotype" of children with Down Syndrome is less socially challenging than that of the other two syndromes, and that children with DS typically present parents with fewer maladaptive behavioral challenges than their peers with other genetic conditions. The differences in stress levels were not related to advanced maternal age or higher family income.

Following from family resilience theories, Boyraz and Sayger suggest that the presence of a child with a disability in a family may stimulate self-growth and enhance coping and interpersonal skills among parents and siblings. "Having a child with disability [sic] may require parents to develop additional coping resources to strengthen their belief in their ability to have positive influence in their child's life" (2011:293). Their research revealed higher self-acceptance among fathers of children with disabilities than among fathers of children without disabilities. The results "also provided evidence that rearing a child with a disability is not associated with lower levels of psychological well-being” (2011:293). Family cohesion, paternal self-efficacy and income were important factors in the psychological health of both groups.

\section{$\underline{\text { Parental Challenges and Stress }}$}

Other research demonstrates that, due to medical, educational, social, and financial challenges, the experience of parenting a child with intellectual disabilities can 
be more stressful than parenting neurotypical children (Hall et al 2012, Marshall et al 2014, Pillay et al 2012). Pillay and others state that "(h)igher instances of stress, anxiety, and depression have been reported in parents of children with an intellectual disability than in parents of typically developing children" (2012:1501). Cantwell, Muldoon, and Gallagher discovered a higher incidence of depressive symptomology in parents of children with intellectual disabilities, especially among those who perceived high levels of stigma and low levels of support from their communities (2015). In their study of nearly two hundred parents, they found that $33 \%$ of parents with an intellectually disabled child met the criteria for definite depression, compared to only $9 \%$ of the controls. The pressure of caring for a young child with multiple serious health conditions, coupled with social isolation and stigma, can lead parents, especially mothers, to report high levels of stress (Pillay et al 2012).

In addition, financial stress often results from the combination of increased medical and therapeutic costs and a reduced capacity to work outside the home. Marshall and others report that the medical costs to care for a child with DS from birth to age four are twelve to thirteen times higher than those of a typical child, and even greater in the presence of cardiac conditions (2014:365). Many parents find they must reduce their work hours, accept demotions, or relinquish outside employment altogether in order to meet the many medical, therapeutic, and educational needs of a child with an intellectual disability and associated health problems (Marshall et al 2014, Pillay et al 2012). The pressure can be even greater on single parents, or families raising more than one child with chronic health problems. 
Furthermore, Hall and others found in their mixed methods study that "a pile up of stressors, negative appraisals, and lack of resistance resources can lead to increased stress later" (2012:37). The research reveals that the challenges of parenting a person with Down Syndrome do not cease after eighteen years but extend throughout the lifespan (Carling-Jenkins et al 2012, Dyke et al 2013, Scott et al 2014). Interestingly, parental advocacy has shown to have great positive effect on the life opportunities of individuals with DS, but it comes at a great cost to the parents themselves. In order to secure satisfactory positions relative to employment, education, and recreation for their children, parents must devote many hours to advocacy (Marshall et al 2014, Scott et al 2014). These stressors often do not abate, but rather change in context, over the course of the life of an individual with DS.

Recent research has centered around three transitional periods that are especially prone to provoking parental stress: time of diagnosis (generally at birth or soon after), the progression of the young adult with DS out of the K-12 school environment and into the responsibilities of adulthood, and the development of dementia and Alzheimers disease in middle-aged and older individuals with DS. These transitions are associated with new roles, responsibilities, and worries for the parents of individuals with DS. The diagnosis experience is discussed later in this paper, but the other two times of transition merit discussion here, as they emphasize the extended role parents may adopt throughout the life of their intellectually disabled child.

Issues concerning independent living, employment, the development of social support networks and the initiation of sexual relationships surround the transition into young adulthood, not only for typically developing youth, but also for those with 
intellectual disabilities. However, research has shown that parents of adults with intellectual disability are often far more involved with their children's activities of daily living, recreation, and employment, and that young adults with Down Syndrome live with their parents longer than neurotypical adults (Foley et al 2012, Scott et al 2014). Adults with DS who are successful in obtaining employment and independent living opportunities often do so because of the intensive advocacy performed by their parents (Dyke et al 2013, Foley et al 2012). Both individuals with DS and their parents report stress and conflict during this time, as well as lack of needed support and information from the educational, medical and social institutions to which they belong (Dyke et al 2013, Foley et al 2012, Scott et al 2014).

Both groups also report relational tension at this time, which erupts because of the conflict between the authoritative stance of the parents and the desires of their children for autonomy and self-determination (Dyke et al 2013, Scott et al 2014). This tension is poignantly felt when it comes to the sexual relationships of those with DS. Drawing on a Foucauldian perspective, Simon Foley has explored the paternalism in parents' attitudes towards their adult children with DS, as it relates to sex (Foley 2014). Despite the parents' protests to the contrary, Foley asserts that the control parents exert over the social lives of the youth indirectly inhibits their ability to engage in mutually consensual sexual relationships with others.

Another exacerbating factor in the care needs of the adult with DS is the high incidence of dementia and Alzheimers found in this population. Individuals with DS experience earlier onset of Alzheimer's disease, with the average age of onset falling between 50 and 55 years of age (Evans et al 2013). Carling-Jenkins and others report 
that “(a)s many as $50-70 \%$ of people with Down Syndrome will develop Alzheimer's disease by the time they are aged 60 years" (2012:54). This comes at a time when the parents themselves are aging into their senior years. In their case study of three Australians with both Down Syndrome and Alzheimer's, they found that parents are unprepared for their adult children's neurological changes and that there is little outside support and few resources to assist them. The literature indicates that the care needs of individuals with DS are many, varied, and lifelong for their parents and primary caregivers.

\section{Perceptions of Abortion for Down Syndrome}

Studies conducted over the past thirty years have documented a wide expanse of feelings, beliefs, and experiences held by parents of children with Down Syndrome, with some regretting their decision to parent such a child and others finding it to be more rewarding than previously expected (Bauer 2008, Elkins et al 1986, Huyard 2012, Pillay et al 2012, Shepperdson 1983). The literature demonstrates a lower willingness to abort a fetus diagnosed with Down Syndrome among mothers who already have a child thus afflicted. In a study of mothers of children with Down Syndrome, Elkins and others found that only half went through with amniocentesis in a subsequent pregnancy, and only half of those indicated that a positive result would have led them to terminate the pregnancy (1986). The remaining mothers indicated they would not terminate a pregnancy for confirmed Down Syndrome and therefore chose not to undergo amniocentesis, or chose to undergo the procedure solely to prepare themselves sufficiently for the birth of another child with Down Syndrome. Of the 101 study participants, only one mother received a diagnosis of Down Syndrome for her fetus, and 
she did elect to terminate. Fourteen percent indicated that amniocentesis for the purpose of detecting Down Syndrome should be banned and approximately 35\% thought selective termination for the condition should be disallowed.

Shepperdson reported survey results from the same decade indicating a high level of support for the option to abort after diagnosis of Down Syndrome ( $77 \%$ of 78 parents of children with Down Syndrome). The authors also included comments from mothers denoting their personal choice not to abort a second pregnancy diagnosed with Down Syndrome (1983). Several expressed concerns about the eugenic nature of genetic screening and termination as well as euthanasia of disabled infants, with one mother remarking "It's like Hitler." Sixty-seven percent of parents also opposed euthanasia for children with an "average" phenotypical presentation of Down Syndrome. There exists a marked difference between what the mothers would choose for themselves and the options they feel should be made available to the public.

A meta-analysis of the literature reveals that selective fetal termination rates for diagnosed Down Syndrome fall at an average of around 90 percent in the United States and some European nations (Egan et al 2011, Mansfield et al 1999). Admittedly, these rates may be somewhat biased given that those who adamantly oppose abortion are unlikely to undergo invasive and painful diagnostic procedures, as well as to risk inducing a spontaneous miscarriage of a wanted pregnancy (Priest et al 1998). Conversely, those who are most concerned about the implications of having a child with DS would be most likely to undergo these procedures.

Recent publications in the field are quite saturated with research on the decision making process for selective abortion of fetuses diagnosed with Down Syndrome (Bell 
and Stoneman 2000, Lawson 2006, Yazbeck et al 2004). Lawson has found that it is the loss of expected parental payoffs, rather than the anticipation of increased parenting expenditures, that influences pregnant women's decisions to terminate a disabled fetus (2006). She also found that "parenting a child with Down Syndrome is viewed as less personally rewarding, but not more inherently costly, than parenting a child with a physical disability" (2006:54). Expectations for parental satisfaction and quality interpersonal relationships with children who have Down Syndrome are lower than for children who have physical disabilities or no disabilities.

A study conducted by McCoyd of thirty American mothers who chose to terminate a fetus diagnosed with Down Syndrome uncovered a high level of anxiety over the perceived burden of raising a child with a cognitive disability and a fear for the child's social acceptance and life chances (2008). "Respondents reported being swayed heavily by the thought of subjecting their children to the suffering (because of pain for some and stigma for others) they believed [disabled] people experience in U.S. culture" (2008:1492). Several women reported choosing abortion because others' rejection of their disabled children would be especially painful in light of their own unconditional love for their child. Other women expressed fear of raising a child with intellectual deficiencies, with one mother sharing, as an example, the sentiment of a co-worker who had said to her, "I just can't have a stupid child" (McCoyd 2008:1495).

Researchers in the Netherlands examined the motivations to terminate among seventy-one mothers who chose to abort their fetuses after they had been diagnosed with Down Syndrome (Korenromp 2007). Ninety-two percent cited "I believe the child would never be able to function independently" as a primary motivation, and $90 \%$ claimed the 
abnormality was too severe to consider carrying the child to term. Seventy-three percent of mothers felt the burden would be too heavy for their other children. Forty-five percent cited low respect for disabled persons among members of their community as an additional motivation for termination. It is important to note that in this study, mothers whose fetuses had lethal anomalies were excluded from participation; only the opinions of mothers to fetuses with no such anomalies were considered.

Parents' decision making is also impacted by their preconceived impressions of disabilities, perhaps acquired through direct contact, indirect associations or media portrayals. These assumptions, whether factually based or not, could play a crucial role in a mother's decision to terminate or bear to term a fetus with diagnosed Down Syndrome. Perceived social and familial support, adequate financial resources, and general esteem from others contributes to a mother's determination of her own ability to cope with, and parent well, a child with special needs (Boyraz 2011, Elkins 1986, Huyard 2012, Lawson 2006). Because of the potential impact on parents, both positive and negative, genetic screening is an available option to help parents identify the presence of Down Syndrome in their fetus and to make an informed decision about the pregnancy.

\section{Genetic Screening for Down Syndrome}

Genetic screening for Trisomy 21, also known as Down Syndrome or Down's Syndrome, is, at present, most frequently and definitively accomplished through the use of chorionic villus sampling (CVS) in first trimester or amniocentesis in second trimester of pregnancy (Prenatal Genetic Diagnostic Tests Fact Sheet). Through the process of CVS, tissue from the sac surrounding the fetus (what will later become the placenta) is obtained, either transcervically or transabdominally, and analyzed for risk of 
chromosomal and biochemical abnormalities. Amniocentesis, on the other hand, involves obtaining cells from the amniotic fluid surrounding the fetus, and conducting similar analysis.

Both procedures carry a risk of spontaneous miscarriage, which is why traditionally the procedure has been recommended only for women over the age of 35 (when the risk for Down Syndrome is highest) or who have screened to be of high risk from earlier blood or ultrasonography tests. Miscarriage from the CVS procedure can result from "accidental rupture of the amniotic sac, cervical infection, bleeding, or damage to the chorionic membrane" (Kolker and Burke 1998:20). Reports of babies born with severe jaw and limb deformities have been linked to CVS as well. However, according to Kolker and Burke, it can be difficult to establish causation in cases of miscarriage or fetal deformity because spontaneous miscarriages most frequently occur of their own accord around the same time CVS is performed, and deformities are rare and cannot be directly traced to the procedure (1998). The risk for miscarriage from amniocentesis is estimated at less than one-half of one percent in singleton pregnancies, and slightly higher for women carrying multiple fetuses. The risk associated with CVS is estimated at less than one percent higher than the risk of amniocentesis (Kolker and Burke 1998).

It has generally been held in the practice of obstetrics that the probability of carrying a fetus with Down Syndrome should be at least as high as the threat of spontaneous miscarriage from the diagnostic procedure in order to ethically recommend CVS or amniocentesis to a pregnant woman (Kuppermann et al 2004). Historically, this risk has been assessed through markers in an alpha fetoprotein (AFP) test conducted on 
the mother's blood sample. Abnormally high levels of AFP may indicate Down Syndrome (Kolker and Burke 1998). Ultrasonography is also used to identify potential markers for Down Syndrome, such as the enlargement of the nuchal translucency space in the back of the neck and the absence of the nasal bone. Women with abnormal screening results may then be referred for amniocentesis or CVS testing, along with all women over the age of 35 (Benn et al 2002, Koshnood et al 2006). It was reported in January of 2011 that not quite $2 \%$ of pregnant women in the United States undergo amniocentesis or CVS each year (Greely 2011).

The convergence of two factors may rapidly promote the ubiquity of prenatal genetic screening for Down Syndrome in the United States. In 2007, the American College of Obstetricians and Gynecologists changed its position to recommend genetic screening be offered to all pregnant women, regardless of age. Prior to 2007, they limited their recommendation to women over the age of 35 and those whose blood screening results indicated high risk (Egan et al 2011).

The second factor is that a blood test which identifies Down Syndrome in the DNA of a fetus, obtained directly through a sample of blood from the mother, arrived on the market in 2011 (Greely 2011). This type of testing is commonly referred to as noninvasive prenatal testing, or NIPT. The detection rate of the test, as reported by the manufacturer, Sequonom, Inc., is $98.6 \%$ (Roan 2011). In fall of 2013, a federal district court in California invalidated Sequonom's patent for the test, allowing other companies to develop and market the test (Marshall 2013). At present, there are four companies offering NIPT for Down Syndrome. An NIPT which can detect Down Syndrome "has 
long been considered the 'holy grail' of prenatal testing," according to a guest editorial by Louise Bryant in the Journal of Reproductive and Infant Psychology (2014:1).

In his comment on the potential impact of the new blood screening test, bioethicist Henry Greely estimates that screening tests will rise from 100,000 to three million per year in the state of California alone (2011). Because the testing technology is advancing at a rapid pace, more genetic anomalies can be detected prenatally. However, "because the effects of these genetic anomalies are sometimes uncertain, the test results may prompt difficult decisions for families who receive such diagnoses" (Check Hayden 2014:19).

This issue is distinctly sociological in nature. The doctrine of "free will" and individual choice is supposedly predominant in the field of genetic counseling, yet researchers have discovered that differences in how information is presented often sways parents' opinions, especially in times of vulnerability and stress (Bosk 1992, Dixon 2008, Reynolds 2003). In his multi-year study of a genetic counseling center, Charles Bosk found that differences in counselors' personalities, miscommunications among practitioners, and differing viewpoints on ethical standards for euthanasia resulted in varied and inconsistent outcomes for compromised newborns. Reynolds discovered that differences in how Down Syndrome is framed can create variance in ethicists' support for genetic screening techniques and abortion (2003). Researchers van Vliet, Grimes, and Smith uncovered a difference in understanding among genetic counseling patients when risk was presented as proportion rather than as a rate (2001). Although stated proportion of risk is standard practice among genetic counselors, statements of rate were found to be better understood by laypeople. 
Furthermore, medical sociologists have discovered that such patient characteristics as race, age, and gender can significantly affect physicians' treatment recommendations, even when clinical presentation and symptomology remain the same (Aronowitz 2008, McKinlay et al 1996). Cultural differences, associated with age, race, religion and socioeconomic status, are correlated with differences in abortion rate and support for abortion in cases of prenatally diagnosed Down Syndrome (Bell and Stoneman 2000, Khoshnood et al 2006, Kuppermann et al 2004, Siffel et al 2004). Researchers analyzing rates of Down Syndrome livebirths in the United States from 1989 to 2006 discovered that "a Down Syndrome fetus is more likely to be prenatally diagnosed and terminated in the West and least likely to be diagnosed and terminated in the Midwest," with the South and Northeast falling in between (Egan et al 2011:391). This study also revealed that "women with twelve years of education or less were less likely to either receive a prenatal diagnosis or to terminate an affected fetus" compared to more educated women and that black women experienced fewer DS livebirths than expected when compared to white women (37\% compared to $56.6 \%$, respectively) (Egan et al 2011:391).

How expectant mothers and their partners perceive the counseling experience can also differ. Some mothers whose fetuses were diagnosed prenatally reported pressure to terminate (Marshall et al 2014), whereas other mothers reporting feeling blame from their doctor for choosing to forego prenatal screening (Pillay et al 2012). In her review of ethical challenges facing the field of genetic counselling, Leah Richmond-Rakerd states that, "A direct infliction of therapist values is particularly harmful when it involves the individual and role differences that define and distinguish clients" (2013:33). 
Patients and practitioners report differing levels of satisfaction with the diagnosis disclosure process. In their study of 559 caregivers of children with disorders such as Down Syndrome and Fragile X Syndrome, researchers Goodwin and others found that "most[...]respondents rated the experience of being told the diagnosis as negative" and that "the amount and quality of information they received from healthcare professionals was unsatisfactory" (2014:482). Dutch researchers reported that pediatricians used positive adjectives $81.5 \%$ of the time when describing the first diagnosis discussion they had with parents, but they did not follow the established ethical guidelines for that discussion in all cases (de Groot-van der mooren et al 2014).

Clearly, women's decisions regarding the termination of fetuses diagnosed with Down Sydrome involves more than straightforward and rational decisionmaking. Sociological forces are at play in these medical encounters and in the influence of various actors shaping the experiences of expectant parents. Decisions made at this difficult time can lead to significant outcomes for families and society at large.

In his recent comment, Greely urged us to take immediate steps to address these ethical questions, as well as to standardize approaches to the NIPT and its results among physicians, midwives, and genetic counselors (2011). In her editorial, Louise Bryant states that "the relative ease with which NIPT can be conducted would require existing informed consent guidelines to be examined afresh" (2014:2). However, some would argue that a standardized approach could undermine individual autonomy and right to privacy, undervalue the diversity of experience, perceptions, and beliefs of expectant couples, and perhaps lack appropriate cultural sensitivities. Nevertheless, Greely states that whether we view prenatal genetic diagnosis "gladly as a way to reduce human 
suffering, warily as a step towards a eugenic dystopia, or as a mix of both [...] the better we prepare, the more likely we are to avoid the worst misuses of this potentially transformative technology" (2011:291).

Before describing the study in greater detail, I will detail a theoretical perspective which is relevant to the genetic disorder diagnostic and counseling process.

\section{Theoretical Perspective}

To better understand parental opinions on genetic screening and selective abortion for Down Syndrome, it can be useful to apply Foucault's theory of biopower. Prior publications discussing biopower have included an abundance of historical essays, especially on eugenics and Nazism. However, Foucault's work has been applied (albeit sparingly) to current research on sexuality and reproduction (Kuswa et al 2008). This research includes Simon Foley's look at the sexual relationships of adults with Down Syndrome (2014), as well as Ellen Feder's examination of recent attempts in modern medicine to uncover the biochemistry, present from birth, to blame for acts of antisocial behavior and violence (2007). I argue that Foucault's theory of biopower is particularly applicable to sociological research on genetic screening and counseling, because of biopower's focus on the corporeal and the physical subjection of bodies through normative means.

Foucault's theory of biopower posits a postmodern view of social stratification and hegemony in which there exists "an explosion of numerous and diverse techniques for achieving the subjugation of bodies and the control of populations" (1978:140). According to Foucault, the need to regulate and optimize human bodies was a strict accompaniment to capitalism. In contrast to the "right of seizure" of others' bodies for 
the defense of the governing faction, such as for the waging of wars during the feudal period, the right to extract labor from the human body became preeminent. The powerful desired no longer to lord over the weak with the threat of death, rather their desire lay in harnessing the productive life force necessary for the generation of ever-increasing quantities of capital.

In accordance with the technological advances of capitalism, advances in the acquisition and administration of demographic information and the development of public health programs enabled the systematic control and medicalization of human beings. Foucault claimed that, "The human body [was] brought into an increasingly dense and important network of medicalization that allowed fewer and fewer things to escape" (1994:135). This involved the formation of cartels Foucault termed "the medical police," which established methods of observation and documentation of sickness (following from the time of plague in Europe), as well as the standardization of medical power and knowledge (1994:140). It is a "power that exerts a positive influence on life," (in some circumstances, ironically, through the application of death), and "endeavors to administer, optimize and multiply it, subjecting it to precise controls and comprehensive regulations" (Faubion 1994:259, Macey 2009:187).

Internalization of social norms creates the moral imperative within individuals to comply with those means and objectives, designated by society for the social good; as Foucault calls it, “a 'private' ethic of good health" (Faubion 1994:281). Rather than residing in a governing body, power emerges in relationships, which encourages a complicity often unrecognized by the actors themselves (Macey 2009:196, Pollock 2003:248). This does not suggest an equitable distribution of power amongst the 
members of a society. Instead, members "participate in a hierarchy where all parties share in the construction of power" (Pollock 2003:248). A collective conscience develops which dictates the health and reproductive decisions of the populace.

These controls act at every level and through a diversity of social institutions, such as the family, schools, military, police, and medical facilities. Foucault states that "the family becomes the most constant agent of medicalization," due to its omnipresence in the lives of the youth, and its centrality to the rites of reproduction. The family is therefore "charged with maintaining a homeostasis of social health" (Feder 2007:67). Foucault discussed at length the unique responsibility of the family (and especially the mother), during the Victorian era, for the general good health of the offspring. Careful attention was turned at that time to the administration of appropriate hygienic practices in the home and the education of children in methods of proper cleanliness and self-care. Strict standards of chastity and guidelines for healthy sexual behavior were also imposed on the population.

Foucault argues that the aim of "the perfecting of the species inclined the whole problem toward an extremely exacting administration of sex" (1978:148). These strategies included "the art of determining good marriages, of inducing the desired fertilities, of ensuring the health and longevity of children" (1978:148). This science is to be based on sound knowledge and proven strategies. Biological existence "passed into knowledge's field of control and power's sphere of intervention” (1978:142).

Thus, the doctor began to be afforded the power and respect previously reserved for the king and the clergyman. It became the doctor's due responsibility and honor to observe the population, collect data about it, and to instruct the masses in the proper 
techniques of health and reproduction. According to Pollock, "(t)he doctor of reproductive technology does not simply learn from the preexistent female reproductive system but participates in its construction in order to mold it onto something socially useful" (2003:250). Unfortunately, these burdens, when tightly bound together, can become incestuous and self-reinforcing.

According to Macey, with the process of biopower, "prevention mutates into policing" (2009:197). The paternalism of the physician towards thefemale patients ensures their compliance with his or her dictums, as occurred with many young women who underwent compulsory sterilization in the US during the 1900s because of their supposed imbecility (Lombardo 2008). Propaganda in films and written publications further served to cement public notions of health and hygiene (Pernick 1996). Eugenicists of the earliest twentieth century recognized that a society must be naturally predisposed to continually purging itself of the degenerate unfit. "Government need not impose eugenic programs on normal people" (McWhorter 2009:419). When coupled with disdain for any aberration, the cultivation of an endless ambition towards genetic enhancement among members of society would ensure that "ordinary individuals could be counted on to make eugenic choices without any official compulsion" (McWhorter 2009:418).

Much of the sowing of these ideas among the populace was performed by doctors, according to Foucalt and others (Foucault 1978, Lombardo 2008, Pollock 2003). As geneticists and physicians advanced their crafts, vast realms of knowledge developed but remained largely within their sphere of control. Prospective parents had no option but to turn to their physicians for information and advice about the health and well-being of 
their pregnancies and children. And "if the authorities believed the birth of a deaf child or a dwarf' would be a family tragedy, no doubt many families would come to believe so as well” (McWhorter 2009:419).

This hyper-medicalization induces potential parents to accept abortion as "a responsible reaction to managing genetic risk" and as the only logical and humane choice (Silva 2011:24). Again, the woman's physician is held accountable to provide the scientifically based pathway for patient assessment of fetal risk. Foucault's theory of biopower provides an opportunity to understand genetic screening for Down Syndrome and the decision making process for abortion in the context of greater sociological forces.

\section{The Current Study}

What drives expectant parents to undergo genetic screening procedures such as amniocentesis and chorionic villus sampling? What causes some parents to abstain? Do parents of children with Down Syndrome support genetic testing and/or abortion for the condition? What advice would they share with other women facing the prospect of birthing a disabled child? What role does the doctor play in the diagnostic and decisionmaking process and what role should he or she play? What are the prospective consequences of fewer or more children being born with Down Syndrome, for society and for those families and individuals already affected? Would availability and accessibility of resources change in direct or inverse proportion to the number of individuals needing them? How could such a change affect prejudice or acceptance levels for individuals with all disability types? While the proposed research does not purport to fully answer these questions, they will be a guiding focus for the current study and will inform the methodology to be employed. 


\section{METHODOLOGY}

The purpose of the present study is to learn how parents of children with Down Syndrome feel about prenatal genetic screening and abortion for diagnosed genetic anomaly. The study will also investigate their perceptions of the potential effects of selective abortion of fetuses with Down Syndrome on society and on individuals born with the condition and their families. To date, little research has been done to examine the subjective perceptions, impressions, and beliefs of this important population. In light of the recent advances in genetic screening technology and availability, I argue that is important to study the perspective of individuals who have lived experience parenting a child with Down Syndrome (also referred to as DS). The present research strives to understand these perspectives.

The study consists of a series of individual interviews conducted with volunteer participants recruited from support groups around the Kentucky and Indiana area. The research is qualitative in nature and produces results that, while non-generalizable, illuminate the opinions and impressions of those with lived experience and daily familial contact with a child with special needs. I argue that quantitative methods, such as surveys, are inappropriate for the subject matter under study. As Patton explains, "The purpose of gathering responses to open-ended questions is to enable the researcher to understand and capture the points of view of other people without predetermining those points of view through prior selection of questionnaire categories" (2002:21). 
Although qualitative research techniques have been criticized for being too subjective, it is subjectivity itself I hoped to unearth in this study. As McCracken explains, qualitative research offers "an opportunity to glimpse the complicated character, organization, and logic of culture" (1988: 17). I wished to understand impressions, projections, and emotions situated within an ongoing historical context. This study captures a snapshot of a phenomenon at this critical juncture in our society's relationship with people who have Down Syndrome. I endeavored to understand how parents both resist and embrace prenatal genetic screening techniques for the condition of Down Syndrome, how they explain and rationalize their own and others' acceptances and prejudices, how they position themselves within our complex social system, and how they perpetuate or denounce the hegemony of the so-called "able-bodied" in contemporary discourse.

This form of study welcomes the subjectivity of the statements made by participants. A respect for subjectivity naturally flows from a foundational stance of ontological relativity, in which actors are understood to operate within a socially constructed, shape-shifting soup rather than a fixed and rigid reality (Patton 2002:96). Patton argues that such a stance "holds that all tenable statements about existence depend upon a worldview, and no worldview is uniquely determined by empirical or sense data about the world" (2002:97). The differences in support for abortion among those who hold and those who lack personal relationships with citizens with Down Syndrome substantiate this standpoint well.

As elucidated earlier, data analysis will be approached from the theoretical perspective of Foucault's concept of biopower. Does cognitive dissonance occur for 
those who feel that the lives of their children (whom they dearly love) are devalued by society or, as Foucault would argue, have these social norms been internalized? According to participants, who does and who should hold the bulk of the power in the decision making process when Down Syndrome is suspected (the woman's partner, doctor, family, social group, or perhaps the woman herself)? How do respondents perceive a society in which fewer or more children like their own are born? Do their statements reflect or refute a discord between the assumption of suffering and the genuine physical, social, and cognitive capacity of those with the condition? As with any qualitative research, it was impossible to predict in full the nature or direction of the data which the interviews would yield. However, questions were designed to better understand the balance of power in the decision-making process, as well as the extent to which our social mores, as uncovered in the literature, have been internalized by those who are uniquely acquainted with this condition.

Data collection was conducted with empathic neutrality and mindfulness, as described by Patton (2002:49). The researcher must endeavor to remain sensitive, openminded and nonjudgmental throughout the data collection and analysis process. The researcher does not deem himself, in these cases, an omnipotent authority with the power to condemn or exculpate his subjects. Yet, data can be examined with relation to the sensitizing concepts under study, and salient themes, trends, and inconsistencies revealed.

According to Patton, "The purpose of interviewing is to allow us to enter into the other person's perspective" (2002:341). The standardized open-ended interview is proposed as the optimal method for the current study. It allows the researcher to "step into the mind of another person, to see and experience the world as they do themselves" 
(McCracken 1988: 9). Furthermore, the careful execution of well-established methods of interviewing enables the researcher 'to capture the famous 'richness' of qualitative data without setting the investigator adrift on a featureless sea" (McCracken 1988: 65). It allows for the simultaneous focus and expansiveness of inquiry and data collection so fundamental to qualitative scholarship.

Given the sensitive nature of the study topics, the IRB was apprised of the questions to be asked, and adherence to a question list was necessary to achieve compliance. In addition, the use of a standard interview instrument increases consistency across interviews, enhances the ease of interviewing for the novice interviewer, and organizes data collected into a framework more readily accessed during data analysis. "For the purposes of the long interview, [the use of a questionnaire] is indispensable" (McCracken 1988: 24). Again, as discussed in McCracken's The Long Interview, a previously devised interview instrument allows the researcher to cover the same terrain with the same prompts and transitions across multiple respondents, channels the direction and scope of the discussion, and allows the researcher to focus his full attention on the responses of his informant (1998: 24-25).

The questions used in the interviews are questions of opinions and values. They were designed to solicit opinions and perceptions, not statements of fact or disclosures of behaviors or experiences. Neutral, hypothetical questions transform queries which could seem aggressive or offensive to the interviewee (Would you have an abortion if your fetus was diagnosed with Down Syndrome?) into a softer, less confrontational tone (What advice would you give a friend who is considering abortion after receiving a diagnosis of Down Syndrome during her pregnancy?) I felt that study informants would 
feel less threatened and more respected during the interview if questions about their opinions and standpoints were posed as hypotheticals and were not directed at them, their spouses or partners, or their children.

Transitional and prefatory statements were used to enhance the flow of the interview, and to reassure the informant that only opinions and perspectives are being sought, rather than statements of behavior or fact. In addition, expressions of appreciation for the participants' time and thoughtful responses to interview questions were made, as appropriate throughout the interview contact, to establish and maintain rapport with the participant. According to Patton, such recognition can enhance the quality of responses because it lets "the interviewee know from time to time that the purpose of the interview is being fulfilled" and that "the interview process is worthwhile" (2002:375). Patton also claims that, in accordance with the emergent nature of openended interviewing, a closing question, such as “Is there anything I didn't ask which you feel it is important I know?" shows respect for informants and may result in rich data $(2002: 379)$.

Although abortion and disability can be treacherous ground to traverse, several key considerations in this study design help to overcome the disadvantages of a sensitive discussion topic. Subjects were informed of the topic and delicate nature of the questions prior to giving their consent to participate. No personal medical information was solicited from participants nor required as a component of the study. In addition, participant selection was confined to parents of children with Down Syndrome who are involved with a support group for families of children with DS. I believe, from my review of the literature, that it would be naïve to assume that parents have not been 
confronted with these issues from their own personal experience and through their association with others in the disability community.

\section{$\underline{\text { Participant Recruitment and Informed Consent }}$}

I conducted this study through a series of twenty individual interviews. Participants were recruited through existing support groups for parents of children with Down Syndrome, already present throughout the states of Kentucky and Indiana. A total of five Down Syndrome support and advocacy organizations kindly distributed study recruitment materials to their members, and potential participants were asked to contact the researchers for more information or to indicate interest in participating.

Individuals holding a permanent parental role to a child or children with Down Syndrome were eligible to participate in the study. Both biological and adoptive parents were considered eligible. Foster parents, relatives such as grandparents, or others acting temporarily as parents to children with Down Syndrome were not eligible to participate. Individuals were required to be age eighteen or older at the time of the study to participate, and pregnant women were disallowed due to the sensitive nature of the study topic. I had concern that pregnant women would face additional psychological risk by discussing invasive genetic screening techniques and selective abortion, and I concluded that their vulnerability outweighs the potential contribution of their opinions to the study. I contacted local support group hosts to solicit their cooperation in forwarding a request for study participation to their support group members. I sent an email to these facilitators that describes the study, explains the need for participants, and asks for their permission and assistance to forward another email to group members. This email, addressed to the participants, also describes the purpose of the study, explains eligibility 
requirements for participants, provides a general description of the study, includes an informed consent document, and gives the contact information for the student investigator and the principal investigator. Interested participants were asked to contact the student researcher by phone or email. Several support group hosts requested a flyer and a link to an online version of the flyer, which they posted to their group's Facebook page and other social media sites. These documents, as well as the link, were provided electronically to all organization contacts, consistent with IRB guidelines.

I included a copy of the informed consent form with all initial points of communication I had, both with organization contacts and participants. I invited everyone with whom I corresponded to contact me and/or the principal investigator with any questions or concerns. I sent a final email to those who agreed to participate, as a friendly reminder of the date, time, and location of the interview. This email again included a copy of the informed consent form as an attachment, with instructions to contact the student researcher or principal investigator with any questions or concerns. Locations for interviews were selected with participant convenience and comfort in mind, or by phone if the participant preferred. Informed consent forms were collected for every participant, prior to the onset of the interviews. For interviews conducted in person, signed consent forms were collected from each participant upon their arrival for the interview. For interviews conducted by phone, participants were asked to print and sign a copy of the informed consent document. They were then asked to scan and email the signed form to the researcher, or to photograph the signed copy and either email or text this to the researcher. Participants were also granted the opportunity to ask questions of the student investigator, at the onset of the interview. 


\section{Study Sample}

Twenty respondents participated in the study. Of these, seventeen respondents were women (mothers) and three were men (fathers). Five respondents reported receiving a definitive or likely diagnosis that their child had Down Syndrome during the antenatal period, with the remaining fifteen respondents finding out their child had Down Syndrome after the child was born.

The age ranges of the respondents' children with Down Syndrome extended from one year old to adulthood. The age of the children skewed towards the younger end, with ten children falling between the ages of birth to five years old, five children between the ages of six to twelve, three children between the ages of thirteen to eighteen, and one adult. (One participant did not give the age of her child with Down Syndrome). The gender of the child with Down Syndrome was also heavily skewed, with fifteen of the respondents' children being male and the other five children being female.

I conducted eight interviews in person (at locations such as a coffee shop or deli) and the remaining twelve participants specifically requested interviews by phone. Thirteen respondents were recruited through Down Syndrome support groups located in medium to large sized cities, and the remaining seven participants were recruited though Down Syndrome support groups in smaller cities. Some respondents reported living several hours away from the city of the support group to which they belong. Therefore, the urban or rural residence of the various respondents cannot be assured based on their membership in a particular support group alone. However, participation was solicited through five different area support groups in an effort to expand the geographical 
diversity of the respondent pool, within the scope of the present study. Participant location information has been withheld to protect participants' privacy.

The participant list was randomized and participant names were replaced with pseudonyms. This list was then alphabetized by pseudonym. Participant information is summarized in the following chart: 
Table 1: Study Participants

\begin{tabular}{|llllll|}
\hline & Pseudonym & Gender & $\begin{array}{l}\text { Age of } \\
\text { Child }\end{array}$ & $\begin{array}{l}\text { Gender of } \\
\text { Child }\end{array}$ & $\begin{array}{l}\text { Point of } \\
\text { Diagnosis }\end{array}$ \\
\hline 638 & Amanda & Female & Preschool & Daughter & Post Natal \\
\hline 988 & Amber & Female & Infant & Son & Post Natal \\
\hline 264 & Andrea & Female & Elementary & Son & Post Natal \\
\hline 625 & Angela & Female & Elementary & Son & Post Natal \\
\hline 238 & Christopher & Male & Preschool & Son & Post Natal \\
\hline 057 & Danielle & Female & Preschool & Son & Prenatal \\
\hline 907 & Emily & Female & Teenager & Daughter & Post Natal \\
\hline 279 & Heather & Female & Preschool & Daughter & Post Natal \\
\hline 459 & Jennifer & Female & & Son & Post Natal \\
\hline 781 & Jessica & Female & Teenager & Son & Prenatal \\
\hline 647 & Lisa & Female & Preschool & Son & Post Natal \\
\hline 204 & Mary & Female & Teenager & Son & Post Natal \\
\hline 784 & Matthew & Male & Elementary & Daughter & Post Natal \\
\hline 583 & Melissa & Female & Elementary & Daughter & Post Natal \\
\hline 737 & Michael & Male & Preschool & Son & Prenatal \\
\hline 623 & Michelle & Female & Pre-Teen & Son & Post Natal \\
\hline 200 & Nicole & Female & Preschool & Son & Prenatal \\
\hline 816 & Rachel & Female & Preschool & Son & Post Natal \\
\hline 336 & Rebecca & Female & Adult & Son & Post Natal \\
\hline 029 & Sarah & Female & Infant & Son & Prenatal \\
\hline & & & & & \\
\hline
\end{tabular}

Age Ranges

Infant: Birth to Age 1 Preschool: Ages 2 through 5 Elementary: Ages 6 through 10

Pre-Teen: Ages 11 through 12 Teenager: Ages 13 through 17 Adult: Ages 18 and Over 


\section{$\underline{\text { Study Design }}$}

During the interviews, participants were asked to respond to questions posed by the interviewer during a private discussion. Approximately twenty open-ended questions were asked during the course of the interview, with follow-up and clarification questions asked, as necessary. The discussion questions are included with the study materials, , which are located in the appendix section. .

If, at the conclusion of the interview, or upon review of the discussion transcripts, it was determined that a participant's response was unclear or needed clarification, he or she may have been asked to engage in one follow-up individual interview with the researcher, not to exceed thirty minutes in length. This, however, was deemed unnecessary upon review of the transcriptions and no participant was contacted again. Interviews were recorded with an audio recorder, as outlined in the informed consent form. For interviews conducted by phone, the researcher was seated in a private room and the call was placed on speakerphone. Participants were informed of this at the onset of the call. The interview was then recorded by an audio recorder placed alongside of the phone. All participants were told that they could refuse to be recorded at any time during the interview, without affecting their eligibility to participate. In the absence of interview recordings, detailed field notes would have been taken. However, no participant refused to have their interview recorded, nor did any participant ask for the recorder to be turned off once the interview had commenced. The interview recordings were transcribed in full and were destroyed when the project was deemed complete. Fifteen of the twenty interviews were transcribed by the student investigator, with the remaining five interviews transcribed by the online transcription service, rev.com. Funds for the 
transcription service were covered by a grant from the Graduate Network in Arts and Sciences from the College of Arts and Sciences at the University of Louisville.

Identifying information maintained by the student researcher included participants' names, phone numbers, and email addresses. Only first names were used in the discussions, and all names were replaced with pseudonyms during transcription. Real names will never be used in any presentation of the research (written or verbal). Signed consent forms are kept in a locked cabinet accessible only to the student investigator. No medical information was solicited from informants in regards to themselves or their children, although discussions of personal experience were not directly discouraged, and many participants did willingly elect to share such personal experiences, of their own volition.

\section{$\underline{\text { Risks and Benefits of Participation }}$}

The anticipated risks of participation in the study were fully disclosed to potential respondents, in writing, at the point of first contact, at follow-up contact, and at the onset of the interview sessions. Participants were given multiple opportunities to review the informed consent document and to ask the student or principal investigator about any questions or concerns they may have had. They were required to sign the informed consent document as a condition of their participation in the study. All participants also received a copy of the informed consent document, signed by the student investigator, at the conclusion of the interviews. For interviews conducted over the phone, the student investigator printed and signed a copy of the informed consent document returned by the participant, and emailed it back to the participant, with the participant's consent. 
As with any research study, respondents may incur risks from their participation, some of which can be anticipated or expected prior to the onset. All precautions were taken to minimize the risks associated with study involvement, and for the protection of participants' privacy. This study was submitted to the Independent Review Board for the Protection of Human Subjects at the University of Louisville and the approval date of the application and study materials extends from October 21, 2016 to October 20, 2017. The application to the IRB would have been amended if any significant changes were made to the study design, and the IRB would have been apprised of any significant unexpected risks or problems that arise during the conduction of the study, in accordance with university policy. However, as of the point of data analysis, no amendments had been deemed necessary, nor submitted to the IRB for approval, and no unexpected risks or concerns arose during the collection of interview data.

Questions were asked during interviews, relating to pregnancy, babies and children with Down Syndrome, and abortion, all of which may be sensitive subjects for participants. In these situations, some informants may feel offended or uncomfortable because of the questions being asked by the interviewer. Because of this, study participants were informed, in writing and verbally, that they may choose to decline to answer any question posed by the interviewer, or to stop the interview at any time. There were no known, specific physical, legal, or economic risks to participants. Again, no medical records or protected health information were requested or collected from participants. They were not asked to share personal information about themselves, their children, or their families, although the disclosure of this information was not directly discouraged, and many participants did disclose this information of their own accord. 
Informants may have unresolved psychological issues regarding their role as parents to children with special needs or previous decisions they have made in relation to pregnancy, childbirth and/or abortion. A hotline number offering support referrals to individuals experiencing discomfort or distress was included on the consent form and will be additionally available upon request. Any and all expenses incurred in seeking followup care will be the responsibility of the participant, which is noted on the informed consent document. Respondents were informed of their right to withdraw participation at any time and to decline to answer any question. A standard script was used by the interviewer at the onset of each discussion session, to invite questions, to describe the study and to inform respondents of their rights. Participants will not suffer any repercussions from their refusal to participate, nor shall their participation in the support group be affected by their decision not to participate, to leave the discussion at any time, or to refuse a follow-up interview.

There was no direct benefit to those enrolled. However, the study will give voice to the parents of children with Down Syndrome, an underrepresented population in the current literature on genetic screening and selective abortion for fetal anomaly. With the rapid increase in the availability and use of genetic screening techniques, I assert that we must be informed of the opinions of parents who hold a unique relationship with individuals with Down Syndrome. We must also consider how the choices made during the genetic screening process may impact the lives of those who have a disability or are raising a child with a disability. 


\section{$\underline{\text { Data Analysis }}$}

Data resulting from the interviews was analyzed using an inductive coding methodology, with a social constructionist slant. Inductive coding allows themes to emerge from the data itself, rather than fitting results into prefixed and preconceived categories (Hesse-Biber and Leavy 2007). By conducting careful analysis and re-analysis of research data, the researcher becomes immersed "in the details and specifics of the data to discover important patterns, themes, and interrelationships" (Patton 2002:41). This analysis methodology partners well with social constructionism, which also allows for fluidity and flexibility in dissecting the narratives shared by respondents.

Social constructionism lies on the premise that reality is developed and interpreted in an ongoing process of action, reaction, and interaction. Patton describes the philosophical underpinnings of social constructionism as "built on the thesis of ontological relativity," in which "all tenable statements about existence depend on a worldview." This worldview is not fully empirically determined (2002:97).

Patton suggests that social constructionism begs the question, "What are [people's] reported perceptions, 'truths,' explanations, beliefs, and worldview?" (2002:96) This is precisely the research question under study in this project. What are these parents' reported perceptions and worldviews and how might they be shaped by their association with a child who has Down Syndrome? To operate from social constructionism is to embrace the subjectivity of respondents' experience and to respect the similarities and differences, consistencies and discrepancies, that dwell within them.

Patton argues that social constructionist research should be evaluated by dependability and authenticity. Dependability involves "a systematic process 
systematically followed" (2002:546). I strive for authenticity by acknowledging my own bias in the role of researcher, as well as the bias in sampling selection.

Social constructionism is interrelated with the practice of hermeneutics, especially in a study such as this, in which the data collected is largely verbal. The researcher must derive meaning from the expression of thoughts and predictions, and situate that meaning appropriately within a context natural to the informant. The data for this study will be examined with a respect for both the eugenic philosophies of our American past; as well as the successes of the disability advocacy movement.

Finally, the adoption of Weber's concept of verstehen will be a strength of this study. According to Patton, "The tradition of verstehen places emphasis on the human capacity to know and understand others through empathic introspection and reflection based on direct observation of and interaction with people" (2002:52). It recognizes that researchers can understand the phenomenon of interaction, behavior, and perspective in a distinctively human way. Verstehen imbues the researcher with great respect for his or her informants, and sensitivity to their standpoint. Given the delicate subject matter under study, verstehen will be a crucial guidepost for the ethical and dutiful collection of data.

\section{$\underline{\text { Limitations }}$}

This study examines opinions and beliefs, in contrast to actual behaviors. This is consistent with a social constructionist approach, in which the researcher seeks to understand how informants perceive and interpret their social world and their unique role within it. As with any study researching response to the hypothetical, it is impossible to know if respondents' predictions and predicted behaviors would manifest in actuality. 
However, I contend that attitudes and opinions are indicative of the internalization of social norms and mores, and suggestive of power structures inherent in the decisionmaking process associated with prenatal genetic screening.

It is important to note that, because the sample was drawn solely from parents of children who have Down Syndrome, the study results are not reflective of the opinions of the general population. The literature indicates that those individuals who have more positive and closer interpersonal relationships with people who have Down Syndrome are more likely to report positive feelings about them, and be less likely to support selective termination for fetuses diagnosed with the condition. In addition, the literature also reveals that parents, in general, are more likely to emphasize the positive aspects of parenting, and to gloss over the negative aspects, due to Americans' idealization of parenthood (Rizzo et al 2013, Simon 2008). The study has limited generalizability, and we may expect that other parents from different regions, religions or cultural backgrounds, or people who are not parents, may differ quite significantly in their reported opinions compared to the informants in this study.

Furthermore, given the scope of this study, it was not determined in advance if it would be possible to achieve saturation in the collection of data. The research was limited to data collected from individuals. Results were gleaned from the data collected, and any conclusions are tentative. This study is exploratory in nature and will hopefully illuminate what is somewhat lacking in the literature at the present time. It will provide suggestions for improvement in the study design and offer prospects for future research. 


\section{RESULTS}

Under examination in the present study is the locus of control in the genetic screening and selective termination process, as it relates to the condition of Down Syndrome, or Trisomy 21 (also referred to as DS). Although this matter has been explored by other researchers, there has been a paucity of literature to date which identifies the intersections of power in this process, as perceived by the parents of children with Down Syndrome themselves. Also understudied is the perceived effect, if any, of individual decisions regarding termination of a fetus diagnosed with Down Syndrome on individuals living with the condition and their families, as well as the special needs community and society at large. The present study has revealed some consistencies in beliefs and viewpoints among this group, as well as some variations, all of which will be explored in this section.

Foucault's theory of biopower puts forth a contemporary social structure in which doctors, as the arbiters of the physical body, further become the arbiters of the social body, and come to act as a moral compass and rudder for the health of the human population (1978:140). Foucault asserts that because doctors and medical professionals are exemplified as the authority on matters of health, longevity, and survival, they are in the position of power to influence an individual to make positive health choices which are presumably in the best interest of that individual. However, it cannot be denied that 
individual health decisions also have ramifications for others in the community, both at the time they are made and in the future. Examples would include the fluctuation of birth rates and the management of contagion. Therefore, doctors may have the desire, or some would say, the mandate, to encourage individuals to make choices which benefit the fitness and survival of the whole human species, particularly within a specific social environment.

There is little contention when the health decisions which benefit society are also considered by the individual to be of direct benefit to him or her. But when a person feels pressured to act in ways which defy their benefit, or when they consider the doctor to be prioritizing the benefits to society over their own rights and preferences, a power struggle can emerge. This precise scenario has been revealed in the screening and selective termination process surrounding the genetic condition of Down Syndrome.

As revealed by respondents' statements, the projected role of the expectant couple in this process is rife with contradiction. Respondents place heavy burden on pregnant mothers to have an incredible sense of self-awareness and steadfastness as they approach the genetic screening process, yet they largely absolve expectant parents of any responsibility or culpability if they do choose termination. In the view of these respondents, the decision to terminate is usually the unfortunate result of misinformation, lack of education, or undue persuasion by the doctor. In this case, the expectant parents are to be pitied and are assumed, by some, to later come to regret their decision. When it comes to termination for Down Syndrome, the agency of the expectant mother herself remains unaccounted for in the power dynamic between the physician and the advocate. 
Largely, study respondents rejected the idea of doctors having the right and responsibility to influence pregnant women in their decision making after a fetus has been diagnosed prenatally with Down Syndrome, substituting their own experience and counsel as paramount to that of the doctor, in nearly every case. The reasoning for this seems to lie behind a perception of physicians as having preconceived and ill-informed notions about the lives of those with Down Syndrome, a preoccupation with testing and test results which excludes the wishes and needs of the mother, and an agenda for termination. Where variability does exist is in the expectations of physicians' roles and responsibilities, and whether their presence in the post-testing process can be helpful in any way to expectant families. Some respondents were adamant that doctors should be excluded from the decision making dialogue, whereas others felt that physicians could rightfully offer informational support, provided any bias was checked at the door. However, almost all of the respondents asserted that the participation of the doctor should not preclude input from the parental advocates.

Participants' belief that the guidance of parents of children with Down Syndrome should be sought and considered over the advice of the medical profession is bolstered by their definition of the disability experience. These parents largely conceptualize the "reality" of Down Syndrome as falling fully and solely within their own domain. Study respondents believe that parents possess what they term "accurate" information about what it's really like to have Down Syndrome and, therefore, they are in the unique position to most adeptly educate expectant and new mothers about the condition. Many respondents felt that expectant couples should bear great responsibility for educating themselves in the "correct" way, which, to them, means speaking with families who are 
raising a child with Down Syndrome. In doing so, the expectant parents would naturally come to the "correct" conclusion, that they should continue their pregnancies and start preparing themselves for their own transformation, into parental advocates for their disabled children.

Upon full analysis of the data as a composite, an association was uncovered between respondents' attitudes toward the role of the physician and their feelings about possible outcomes from a reduction in the number of people born with Down Syndrome. These concerns were most poignantly centered on potential effects to people with Down Syndrome, their families, and Down Syndrome support groups. (Predictions about effects on the educational and medical arenas did not display the same variability.) Respondents who reported more neutral feelings about physicians were less likely to report a sense of threat to themselves and their children with Down Syndrome, from a decrease in the number of individuals with DS. Conversely, those who reported a strongly negative impression of physicians were more likely to feel a stronger sense of threat to themselves and their children. Furthermore, their intense level of personal and passionate engagement in others' genetic screening and selective termination journeys often led to feelings of grief, heartbreak, and rejection, as reported by these respondents. All of these findings will be discussed in great detail in the following sections.

\section{Expectant Couples, Advocacy groups, Physicians, and the Locus of "Reality"}

\section{Expectant Couples}

Concerning the power and agency of the mother-to-be, respondents placed a heavy weight on an expectant mother to know herself, to educate herself on available options, and to decide in advance what she would do, long before being faced with any 
decisions. Many participants said that the mother should know what screening tests are available to her, what the accuracy rates of the tests are, what the likely outcomes could be, and what she would do in the event a genetic abnormality was uncovered. She should know herself well enough, prior to becoming pregnant, to discern whether finding out if the child had any genetic disorders would bring anxiety or peace to her pregnancy, and whether she would rather receive the diagnosis while she is holding her newborn baby or while she is pregnant and can thus prepare. She should know her stance on abortion and be prepared to state and defend it at her first prenatal appointment, and then again whenever questioned, throughout her pregnancy.

Nearly all respondents supported a woman's right to choose to undergo or decline genetic screening tests and also to elect to abort a fetus with Down Syndrome. Even parents who considered themselves pro-life, and those who believed that abortion is murder, supported the right of a woman to make decisions about her own body during pregnancy. However, that meant, for many of them, that the woman had the obligation to educate herself, again with the "right" information, and to use the doctor as a tool available to her in navigating her own pregnancy, from start to finish. In contrast, they also largely excused expectant mothers from accountability for their own choices, seeing mothers who choose to abort their fetuses as more akin to victims, of misinformation, lack of information, or the negative agendas of their physicians.

When asked what advice study respondents would give to a woman who is deciding whether or not to undergo genetic testing while she is pregnant, a number of respondents stated that an expectant woman should know how she would use the results and how the results would affect her emotionally. Sarah said, "I just had someone come 
and ask me about [genetic screening], and my answer to her was, it depends on your personality, and who you are, and how your fears and worries and anxieties kinda dictate your pregnancy." She compared it to finding out the sex of the baby prior to the birth: that some people want to know ahead of time and that others prefer the surprise. Rachel said, "My advice would be to ask her if it's important. Like, would it change anything? And just to be honest with herself. [...] I guess I would just ask them to really do a lot of soul searching, of why did you get pregnant in the first place?" Amanda also shared that others had sought this very advice from her, saying:

I've actually had this conversation with several people. My advice is you need to figure out why you want to have genetic testing. Like what would you do if you got positive results, you know? If you have testing done and you find out your baby's going to have Down Syndrome, what then? Are you doing this so you can then terminate, are you doing this so that you can plan ahead and make sure you're in a hospital where you can get appropriate care for the baby when he or she's born? Is the stress of knowing your child has Down's Syndrome going to be too much for you to handle during the pregnancy? Is that something you'd rather have your baby there with you, to hold, when you get that first news? Those are the things I think people need to think about when they're considering genetic testing. [...] What are you going to do if it's positive or if your likelihood has increased and how are you going to be able to cope with that news?

Michelle also believed that a woman should prioritize her own emotional wellbeing when deciding whether or not to undergo genetic screening. "I would suggest, what is going to give her the most peace? What is going to either raise questions that maybe aren't even there, that she would need to struggle with? Or would just the wondering kind of drive somebody crazy? [...] So I think that each unique individual has to tap into and know who they are." She said that parents have the responsibility to educate themselves beforehand as to "what path they're choosing and why and what different paths might open up." 
Andrea agreed that the time to make those determinations is before the testing is done, not after. "Before you have the test, decide, what does the result mean to you?" she said. "Don't just have the test and then try to figure out, know what you would do before, because you have a limited time frame" to make decisions after the results come back. Before submitting to genetic testing, Jessica advised, "Make sure you're ready for the answer. [...] You have to know what you're going to do once you get that answer." Emily also said, "I think she has to talk to her husband and they have to have a decision as to what they would do if they tested and they were positive."

Once the pregnant woman is positioned firmly as the pilot of her own pregnancy, then she can access informational resources from her doctor, as she so chooses. Ideally, according to many study respondents, the mother will decide what genetic screenings she wants and either state her preferences upfront, or accept or decline the physician's suggested tests, according to her own determinations. As Danielle said, "That doctor is there as a tool to be used by the mother." Matthew expressed that because women need to be able to make the decisions that are right for her, "that's why it's important for a lady to choose a good physician." Amanda said, "I think it should be up to the woman which tests she receives, based on why she's having the tests done. I think women should investigate and figure out which test is right for them and then proceed accordingly. Like talk to their doctor about it and make sure that their doctor agrees." Michelle summed up well the opinion of many respondents:

I think for people that the results of the test would have an impact on their decision-making, their planning, their peace of mind, I think they should have the ability and right to. For those people that, their peace of mind is not testing, I think they should be respected for that too. I really think it's something each expectant mother has to decide on her own, what the right decision is for her. And I think that those [options] should be available, either or. 
Heather shared her impression that expectant mothers in an urban area of the country, where she previously lived, are aware of the early NIPT for Down Syndrome and are specifically requesting it from their obstetricians. These mothers, whom Heather described as "very ambitious, career oriented, [and] highly educated," "know about the test. They're aware of it. They know it's available now." She said these women want to know early in their pregnancies if their child has a disabling condition so they can terminate the pregnancy. This is because, "for a lot of them, they see it as something that would too adversely affect their lives, to continue a pregnancy with Down Syndrome." She felt that the availability of the NIPT made it easier for women to know early in their pregnancies if their child would be disabled and to terminate the pregnancy, because their pregnancies were not as visible or known to others. Lisa said the same thing, "I think the blood test makes it a lot easier to make that early decision to terminate the pregnancy and I think a lot of people do it." Although study respondents generally believed that expectant mothers should be able to exercise their right to abort their fetus for whatever reason, the decision to abort a fetus because of diagnosed genetic anomaly was seen as a tragic error. There seemed to be a sense among respondents that an expectant mother cannot be fully educated with current and balanced information about Down Syndrome, and hold people with the condition in high regard, and yet still choose abortion.

Again, parental perceptions of why people choose abortion, and how mothers could perhaps be persuaded otherwise, will be addressed at more length later in this section. It appears to be intertwined with parents' perception of the value society places on their children with Down Syndrome, how the abortions of fetuses with DS affect the special needs community and society at large, and how advocate parents become 
personally involved with the prenatal decision making process of others. At present, however, it is intriguing to note the contradiction between the agency afforded to the expectant mother during her pregnancy, versus the lack of accountability assigned to her in the event she chooses to abort.

When asked how she feels about a pregnant woman and her partner deciding to have an abortion after they receive a diagnosis of Down Syndrome during the pregnancy, Rachel replied, “It makes me feel sorry for them. It makes me feel they weren't given enough information." Nicole also attributed the decision to abort to lack of familiarity with Down Syndrome, saying, "I feel like if they knew enough about Down Syndrome, they might not do it." Angela said:

With the statistic being that $90-95 \%$ of children are aborted, it makes me sad because I don't think they realize what they're doing. If they were exposed to a child like that for any amount of time, I think it would change the way they look at it. I think fear is causing them to make decisions that maybe they shouldn't make, fear of the unknown. It's a shame there's not some way to expose people a little more to the special needs community so they can see there's a whole lot of worth there. There's a whole lot of joy there.

Many study respondents felt that these individual decisions stem from greater society's aversion to people with Down Syndrome, and that advocacy was needed to counter the misimpressions held by the ignorant public. As demonstrated by the study interview guide, no direct questions were asked about the role of parents raising a child with Down Syndrome in the prenatal genetic screening or counseling process. However, the opinion that expectant parents should seek advice and resources from this group was virtually omnipresent among the study respondents. (Only one of twenty respondents did not expressly state this opinion, although she did speak favorably of others seeking her advice, as a mother to a son with Down Syndrome, after receiving a diagnosis of DS in 
their fetuses.) One mother named Melissa stated, "I just really think that they should be connected with the local Down Syndrome agency[...]Because I feel like if anybody could give them resources, it's actually another parent with Down Syndrome." Another mother, Heather, responded, "I think that [the expectant couple] should get information on the local Down Syndrome society. I think they should be offered the opportunity to meet with parents who have a child with Down's Syndrome who would be willing to talk to them about their experience." The interpretation of the role of the physician as an intermediary between the expectant parents and advocate groups emerged multiple times, throughout many of the interviews.

\section{Physicians and Advocacy}

A number of respondents stated that they thought the doctor should provide material from Down Syndrome advocacy groups and/or contact information for local and/or national support groups for families of individuals with Down Syndrome. A mother by the name of Sarah stated that she planned to take literature on Down Syndrome to her obstetrician's office, for them to make available to expectant families, as part of her celebration of Down Syndrome Month. She stated that this is similar to what the advocacy group Down Syndrome Diagnosis Network does as part of their outreach efforts. According to one respondent named Michelle,

I believe the doctor should have up-to-date pamphlets that are from the National Down Syndrome Society, National Down Syndrome Congress, that are from a national organization, as well as the local organization. [...] Whatever it is, I would love for a doctor to be able to say, you know, here's some information from a national organization that's kind of general about Down Syndrome and here is some information from our local chapter if you would like to get in touch with them. 
In fact, as of 2013, it has been the law in the state of Kentucky that the Cabinet for Health and Family Services shall make such information available to any health facility or practitioner that "renders prenatal care, postnatal care, or genetic screening" and that such practitioners will have the obligation to pass this information on to parents who receive "a positive test result from a test for Down Syndrome." This is according to KRS 211.192. A very similar law, House Enrolled Act No. 1093ff, was enacted in the state of Indiana, effective July 1, 2015. Physician compliance with these laws is not known at present.

Nearly all respondents felt that doctors should be responsible to provide some form of information from advocacy groups to expectant parents, which is, again, consistent with current state law in Kentucky and Indiana. However, the point at which advocacy material should be introduced to a pregnant woman, the amount of effort which should be expended by the physician, and the degree to which the physician and his or her office staff should be involved as liaisons varied by respondent. A mother named Rachel described a ten minute video created by an advocacy group to which she belongs, that features parents of children with Down Syndrome discussing their testing, delivery, and parenting experiences. "A part of our advocating is that get into obstetrician's offices and it be shown to parents prior to genetic screening." Heather stated that, prior to doing any genetic screening, a physician should discuss the possibility that a baby may have a genetic anomaly or disability and should provide written information covering all of those potential disabilities. When further pressed about the likelihood that the schedule of a busy obstetrician would permit time for such a discussion with each and every patient, Heather replied that, "Pregnancy is such an important thing, maybe they shouldn't have 
such a limited time." A third mother, Mary, agreed that information about genetic conditions should be provided to all expectant mothers prior to screening. According to her, "Physicians should provide them with a lot of information about those specific disabilities, Down Syndrome or what have you, and just give them more support." She explained that this material should include the most common genetic conditions that exist, how often they occur, and what to expect with each of the disabilities.

Other parents felt that the educational component could be introduced after Down Syndrome had been diagnosed. However, the extent to which physicians involve themselves in the educational process and the extent to which expectant parents should have a say in the trajectory of that process differed among respondents. Several participants felt that parents would only seek support for the decision they had already preformed in their mind. For example, Heather reported spending her personal time on message boards related to Down Syndrome and abortion. She shared her impression that women who have received a prenatal diagnosis of Down Syndrome "actually really made up their mind before they choose which webpage to go to, whether they go to the Down Syndrome pregnancy page or they go to the support for termination for medical reasons page." A mother named Jennifer shared her concern that expectant parents are "so fearful of not having the perfect little child that I don't know how a doctor could convince them" not to have an abortion, and later said that "maybe a doctor could persuade them to keep the baby."

Study participants shared concerns that expectant couples may not have had any experience with Down Syndrome prior to the pregnancy and may be fearful of the unknown. Sarah said that a woman and her partner should "talk with other parents 
because at first it can be very scary, an unknown is always very scary." Therefore, some study participants felt it was impingent upon physicians to counter that fear and insist that expectant couples talk with family members or advocacy groups. This seems to follow Foucault's notion that people depend on direction from the doctor, at least until such time as they feel their own knowledge usurps that of the physician (Macey 2009). Heather said that oftentimes women online were not receptive to her direct attempts to correct their misperceptions of parenting a child with Down Syndrome, so she felt that the doctor should be informing them of the social networks available to them.

When asked who should be responsible for ensuring expectant couples connect with local advocacy groups, the doctor or the couple themselves, Jessica said, "I think a doctor should help them find the resources they need, because they're going to look to the doctor for help," and that "they should probably get them in touch with people who have accurate information," indicating Down Syndrome advocacy groups. A mother named Angela believed that physicians should "send them over to Down Syndrome at Global and let them talk to the people there," again stressing that expectant parents should be directed straight to advocacy groups for information. Christopher said, "If the [test results] came back Down Syndrome, the doctor needs to provide resources to Down Syndrome groups in the area." Sarah stated that doctors should be "educated on how to connect people and then resources are used." (How respondents defined "accurate information" and "education" will be addressed later in this section).

In addition to formal advocacy organizations, parents considered the possibility that physicians personally knew of families raising a child with Down Syndrome, that they could connect with expectant parents. One father, Christopher, stated that a 
physician could "connect them with [local support] groups[...]. Maybe if [that physician has] family that knows somebody that has a child with Down Syndrome, connect them with that family." Emily, a mother to a teenage girl with Down Syndrome, related a story of her own about the days after her infant daughter was diagnosed. "My doctor has a personal friend and she has a daughter with Down's Syndrome. And she immediately called her and they came to our house within a week. And [the mother] had this scrapbook and so we could see [her daughter's] life [...] So we could see kind of how our life was gonna be and it was like, oh, well this is okay." Other parents asked their obstetricians to pass their contact information to expectant parents. After her son was born with Down Syndrome, one mother, Nicole, claimed that she told her obstetrician's office, "If you get anybody with a prenatal diagnosis, you tell them to call me and this guy [referring to her son] [...] and so I left them my cell number and I was just like please, anybody, have them call me [...] I'm gonna tell them all about this guy."

One respondent, Danielle, thought that the physician had the obligation to make an affiliation between the expectant couple and the area Down Syndrome support group, even if that meant bypassing the expectant parents and their discretion altogether. Danielle felt very passionate that the local Down Syndrome organization should be provided with the name and contact information for every mother who receives a diagnosis of Down Syndrome (whether in her fetus or baby), even against the will of that mother. "Even though they said they don't want to be contacted, without fail, without fail, without question, without any delay, that person's name, that couple's name $[\ldots]$ is submitted to the local Down Syndrome organization, as, this is a potential couple that will be having a Down Syndrome baby." Danielle felt that this could be accomplished in 
a legal manner and was of benefit to the mother because "it's much easier to receive that call than to make that call." She also felt that the local Down Syndrome community was entitled to that information because it "keeps us cognizant of it," meaning the recent or impending births of babies who have Down Syndrome. She imparted that the director of her local support group frequently announced the births of babies with Down Syndrome at group meetings and other formal gatherings. According to Danielle, "when we go to our [group activities], the director will tell you, we've had two new babies born, a new baby born, so they're always up on it."

In summary, some respondents felt that physicians could potentially be an important component in educating and encouraging expectant families in their decisionmaking process. Suggestions for physician involvement ranged along a wide spectrum, from giving literature and written materials about Down Syndrome and other genetic conditions to their patients, to introducing them to personal friends who have experience raising a disabled child, to registering patient information with the local support group, even without patient permission. Participants did share individual examples of their own physicians taking these very steps for them, however it was not generally thought that this was the norm. Rather, participants largely expressed their impression that physicians were not reliably educating patients nor connecting them to support. Participants' impressions of the utility of the physician could be seen as ranging along a spectrum, from neutral (the doctor can be helpful in providing some informational support) to negative (the doctor cannot be trusted). 


\section{Physician Prejudice}

There was a distinction drawn in study responses between what a physician could ideally offer patients (such as books about Down Syndrome or information regarding neonatal care options available in the area) and what a doctor could realistically be trusted to offer expectant parents. When asked where a woman could access resources about Down Syndrome, one mother, Andrea, said, "I would like to say the medical community but a lot of that seems to be frequently biased towards a negative view." Many participants felt that doctors were operating with antiquated ideas about Down Syndrome and that they often portrayed Down Syndrome in negative ways. Angela, a mother to a son with DS, shared her thought that "a lot of times, doctors paint a picture of devastation when they talk about something like Down Syndrome." Stories of physicians presenting a "worst case scenario" of Down Syndrome cropped up several times in the interviews. Respondents claimed physicians "paint a picture of doom and gloom," tell expectant parents that their child will "never walk, never talk," "will never amount to anything," and will be a "vegetable." In turn, parents can expect that their lives will be "a living hell" if they carry that child to term.

Respondents shared with me what they had heard from other members in the community. Jessica said, "I know families that have a child that were told [by the doctor] when the child was born that he would never walk, he will never talk $[\ldots]$ and that is horribly bad information.” A parent named Amanda who performs outreach with expectant mothers stated, "I know that I've spoken with women, recently even, who found out they were having a baby with Down Syndrome and their doctors told them 'Your baby’s not gonna walk, is not gonna talk, they're not going to have a productive 
life, they're going to decrease your quality of life." She said, "I guess a lot of physicians out there still have this idea that children with Down Syndrome have no value and aren't really worth having, they're not viable life."

Parents also shared personal stories of their own experiences at the time their children were diagnosed. Sarah expressed her concern that at the time the diagnosis is discussed, "( $(t)$ he language is often very negative. I think they even used the word 'retarded' when I was given that." Another mother, Rachel, described an interaction that occurred, after her son's birth, with a genetic counselor that she felt was "possibly the worst person who could ever give us this sensitive, sensitive diagnosis. She threw a book at us and said, 'He will never be able to work or drive a car, he won't be like any other child.' She painted this picture of just absolute doom and gloom." Christopher described the medical team as being "unprofessional" when telling him and his wife that their newborn son likely had Down Syndrome, not offering them any support, resources, or information surrounding the condition.

A number of respondents felt that physicians were relying on old information, which does not reflect recent advances in the medical care and treatment options available to people with Down Syndrome, nor the enhanced quality of life enjoyed by people with disabilities who are no longer shunted off to institutions (Scott et al 2014). Sarah said "I think some of the information is outdated. I mean, a computer would have been null and void from information that's given at some doctors' offices" about Down Syndrome. Danielle felt that,

Doctors that try to give information about Down Syndrome [say], 'Well, they can't be educated, and they usually don't talk, and at some point in time you'll have to institutionalize them, and they're gonna have all kinds of medical problems, and they're never gonna be able to live on their own.' When was the 
last time [the doctor] read a book about Down Syndrome, 1952? You know, please, that's so antiquated information.

Jessica said if the physician "has the right information, that's great. They have to be able to get the right information. That's the bigger problem, is that they don't." When asked, as follow up to her statement, if she thinks that physicians are uninformed or misinformed, Jessica had the simple reply of "both."

Some study respondents cautioned mothers about the possibility of false positives and medical mistakes, which could lead to women aborting neurotypical fetuses that they had been told had Down Syndrome. Angela said that a family friend was originally diagnosed with Down Syndrome but did not turn out to have the condition. "You really need to make sure that you're not making a mistake because doctors, they're not God," she said. "They can only give you so much information. Sometimes they're wrong." Andrea said an expectant mother should be informed about "the false positives and false negatives, because it does happen. And you wouldn't want decisions made on a test that maybe wasn't even accurate, but in either direction." Rachel also stressed that there are, "I don't want to say mistakes, but false positives and false negatives on both sides." Respondents' emphasis on the possibility of erroneous test results could be a reflection of their mistrust in the medical profession and their hesitancy to embrace the physician as a deserved partner in the course of prenatal genetic screening.

Given many respondents' feelings that obstetricians are woefully ill-equipped to meet patient's informational and emotional needs at the time of diagnosis, I asked many of them if they felt that another specialist should be brought in specifically to confer with parents. This specialist would usually be a genetic counselor but could be a maternal-fetal medicine (MFM) specialist or other professional (Bosk 1992, Dixon 2008, Reynolds 
2003). Some respondents felt that a genetic counselor or MFM specialist could be helpful in terms of explaining how genetic anomalies occur and informing parents about the different genotypes of Down Syndrome. For example, Jessica said, "My doctor recommended that I speak to a genetic counselor just to get a better understanding of how it happened," although she did not answer, even when directly asked, if she thought this avenue should be made available to all pregnant women. Danielle responded, "If a geneticist says that they could help at that time, then definitely bring them in. [...] If they could tell you that they have a difference between Trisomy 21 and mosaic, there's a difference in those two." Lisa, Emily and Nicole each stated several times that they thought an expectant couple should have an opportunity to speak with a geneticist.

However, some of these participants responded that they felt these specialties were plagued by the same problems of bias and misinformation as the field of obstetrics. As reported above, Rachel felt that her experience with the genetic counselor was very negative, and that she and her husband later discovered that "all of those pictures she painted for us, not all of them, but a good majority of them, it's that it wasn't accurate." She felt that anyone giving the diagnosis, whatever specialty they may be, "should have training in giving that diagnosis in an effective, substantive manner." Heather shared her experience with genetic counselors she spoke with during her pregnancy: "I honestly found, out of the three geneticists I met, I found two appallingly unknowledgeable about my daughter's condition." She further expressed her concern that parents "may think the geneticist is an absolute authority on the condition, and that is not necessarily true. [...] They could be making these decisions, like enormously important decisions, talking with someone who doesn't actually know what they're talking about." When asked if a 
genetic counselor could be a beneficial addition to the prenatal decision-making process, Sarah replied,

Maybe and maybe not. [...] I think you're going to run into the same exact difficulty with the genetic counselor because they're freaking you out. They're giving you all of this genetic stuff, and your likelihood to have another baby with Down Syndrome. I mean, this is a child. They're still in this numbers game and screenings game. [...] And then other parents have said how great their genetic counselors were, like they really just put the book down and [said] a kid is a kid. And then others have just said it was devastating and traumatic and they almost chose not to have their baby because of their genetic counseling appointment. So I think it's the same issue no matter where you are. So whatever medical professional, it's their own bias.

Andrea shared the same sentiment, stating that "whoever's presenting the information, it just needs to be accurate and unbiased." Parents expressed concern over contempt for the condition of Down Syndrome among medical professionals, regardless of the specialty of the practitioner. This perception of contempt stemmed from what others told them, as well as what they encountered in their own pregnancy and diagnosis experiences.

\section{$\underline{\text { Prenatal Experiences }}$}

Some participants who reported receiving a prenatal diagnosis of Down Syndrome felt that their pregnancies were handled with prejudice after their genetic screening tests had been done. Five of twenty respondents in this study were informed, during the prenatal period, that their babies had Down Syndrome. Several of these five parents relayed their personal experiences in which they felt pushed by their obstetricians to undergo additional screenings when less invasive initial tests (such as ultrasounds and blood tests) suggested the possibility of Down Syndrome. Such additional testing included conducting an amniocentesis, which offers the most definitive results of all methods of prenatal testing, but which also carries risk of harm to the fetus and the risk of 
miscarriage of the pregnancy (Kolker and Burke 1998, Prenatal Genetic Diagnostic Tests Fact Sheet). Sarah said that once she received blood test results that showed potential markers for Down Syndrome, "Well then it was really, really pushed for an amnio. Like, over and over and over and over. Well, that had risk factors associated with it so there was no need for me to go further in the testing. But that was just like pushed [...] all the way up to my third trimester."

These parents reported sensing at this point that their doctors considered their pregnancies to be expendable, and that they deemed the risks of miscarriage from an amniocentesis to be acceptable in exchange for better certainty about the presence of Down Syndrome in the fetus. Danielle, who received a diagnosis during her pregnancy, shared the following:

I was eleven weeks pregnant at that time, and the high-risk doctor [...] took me into her office and showed me the ultrasound, told me the statistics, and really just said 'Okay, we're going to recommend that you have an amniocentesis $[\ldots]$ and it will really show us $[\ldots]$ what genetic issues that the child has. But I do want to at least,' just in an afterthought, 'Oh by the way [...] there's a 50/50 chance you'll miscarry.' I was like 'No, not happening.' And she was just all shocked that I wasn't going to have the amnio. She goes, 'Well, don't you want to know?' I was like, 'Whether I know or not, is not going to change whether I carry this baby full term, it's not going to change the love that I give to this child.'

Respondents felt they were treated differently in additional ways, as their pregnancies progressed, and that their doctors were primarily focused on testing and offering the option to terminate. Nicole claimed that at the time of the prenatal diagnosis of her son, the doctors "were mostly concerned about, 'Do you want him?'” Rachel was offered testing due to her advanced age at the time of her pregnancy, and she initially declined because the testing was not covered by insurance. Upon informing her doctor of her decision not to undergo the testing, she shared that, "He said, 'Well, you're probably 
going to feel differently about that if you're faced with the situation" of having a child with a disorder. So she and her husband discussed it further and still felt they would continue the pregnancy regardless of the outcome, and she persisted in declining testing. "But he was still strongly pushing it," she said. "So that definitely rubbed us the wrong way, that he was leaning more toward, 'You will definitely want to terminate this pregnancy if you find out that there's an anomaly.' [...] So it felt like out of the gates, like [my son's] life was not at all valued."

Sarah, who expressed frustration at her obstetrician's repeated offers of amniocentesis, also said that she was offered an abortion at every appointment, from the point of diagnosis until she passed the point in her pregnancy where abortion became prohibited by law.

I was told every single appointment, and I had that blood test at nine weeks. [...] Every single time what the latest time I could abort the child, or terminate my pregnancy would be. Every single time until I passed it. [...] I mean they didn't need to ask me every single time, 'Well, I just need to make sure you understand, by Kentucky law, you cannot terminate after twenty-two weeks.' I understand! You didn't tell me this for the other child, you know? Why is this getting extra attention for every single appointment?

Heather felt the same sense of dismissal of her viewpoint from her obstetrician, but in a different scenario. She explained, "When [my obstetrician] did find something on the ultrasound that she found a little unusual, she said, 'Oh, come back in two weeks and we'll look at it again.' And I said, 'Well, what is it?' And she's like, 'Oh, it's nothing.' And I said, 'No.' I said, 'You are my doctor, it is your job to answer my questions.' I couldn't believe that I even had to tell a doctor that." Although the scenarios are different, each of the anecdotes reveals a deep sense of frustration in parents. This frustration is centered in the notion that the obstetrician demonstrated an overreliance and 
fixation on testing and testing results, without considering the mother's emotional needs and feelings about her own pregnancy.

Other parents felt they were treated differently in their subsequent pregnancies. Matthew and his wife were told their daughter had Down Syndrome after she was born, and they later went on to have another child. He stated, "We were really, really, really, really taken back when we had our fourth child. [...] How many times they really, really want you to be tested, give you the option to terminate. [... ] To us, we were really, really, really surprised." When asked about the role of the doctor in the genetic testing process, Melissa said, "I know that should I ever become pregnant in the future, having my history, I know my doctor would recommend me to have certain testing. Probably just for his precautions, not so much as mine, just to have peace of mind to know what he's delving into."

Matthew felt explicitly that there were some in the medical and research fields who wished to exercise control and decrease the number of babies born with Down Syndrome and that although our society sees all doctors as good, there are good doctors and bad doctors. He also said that although he's supportive of women having options in their pregnancies, "( $(t) h e$ medical field is definitely not really a partner in being pro-life." Rachel stated, "I personally feel that there are some physicians that come in with an agenda." Amanda expressed,

I think that there's too many physicians who have very pre-conceived notions of what should happen when a woman is carrying a child with Down Syndrome and so I worry that those physicians are probably giving moms inaccurate information. [...] These are the words they are going to be hearing first, upon hearing that diagnosis or that possible diagnosis, that you're going to have a child that's not valuable, that will bring your quality of life down. And that, I think, is very unfortunate. 
Some parents clearly felt that doctors were exercising overt bias in their impartment of negative information about Down Syndrome to expectant parents. However, most felt that the doctors simply had the wrong information or could not be expected to convey the "right" information because they themselves had not borne nor raised a child with Down Syndrome. Andrea said, "I don't think it's a maliciousness on the doctor's part, but I think they're uneducated about the reality." This underscores the expressed idea of many participants that the reality of Down Syndrome can only be known by those who have raised a child with the condition.

\section{The Reality of Down Syndrome}

These expressions arose numerous times throughout the interviews, primarily in response to the questions "What questions, if any, should a woman and her partner ask her doctor when they're trying to make the decision whether or not to have an abortion after receiving a diagnosis of Down Syndrome during the pregnancy?" and "Is there anyone else a woman and her partner should speak to when they're making the decision?" In response to the former question, Sarah said, "Honestly, I think doctors do not have any information that is helpful," outside of logistical information about appointment dates and such. She later said, "I really say that source of information that's accurate, of parents, or local advocacy groups, are really the only people that are gonna give you a true image of having a child [with Down Syndrome] in your community at this time." Several parents also said that the perspective of parents raising a child with Down Syndrome should be valued the most by parents trying to make their decision.

Andrea shared advice that she would give a woman who is trying to decide if she will undergo genetic testing: "You should know the reality of what it is to have a child 
with Down Syndrome, not just what the doctor may portray to you or what people may

portray to you." She later explained that advocacy groups "can give you more real world, like realistic expectations." When asked what a woman should ask her doctor during the decision-making process, Amanda said,

In my mind, there are things that I think women need to know but I'm not sure that the doctor is the person that's going to have that information. I feel like women need to be asking, 'What kind of a future could my child have, what are adults with Down Syndrome doing now?' I think those things are important, like looking long-term. But I don't know, I think your standard physician is not necessarily going to be able to answer that, like [they] don't have patients with Down Syndrome or don't have that personal experience with it. So I'd say that, number one, they need to be asking for contacts to local support organizations.

Amanda stated that expectant parents should value the perspective of parents like

herself the most, when deciding whether or not to terminate.

I think that's something that's incredibly powerful. [...] That's a huge component, finding out what it's like, that person that's on the front lines, they're living it. You know, physicians, they have the medical knowledge, they can read about it, they can read the papers, but if they don't have a child with Down Syndrome, then they're just regurgitating other information. Parents are the ones who are gonna tell it like it is.

In response to the same question, another mother, Angela, said the physician “doesn’t really know anything about Down Syndrome except for the medical side of it.

He doesn't know what it's like to live with it." Jessica felt much the same way saying, "Unless a doctor has experience, I don't know that a doctor can give that information efficiently, effectively. I just don't know that a doctor can." She later said of her own experience, "For me, I reached out to support groups. [...] I had current, real, right information. I talked to people that are experiencing it right now. They knew what it was like right now and not what they've heard from a study that was done thirty years ago." Michelle said, “To be honest, unless the doctor has a child with Down's Syndrome, I 
don't think I would look to the doctor as a resource for the decision-making part." When asked about anyone else a woman and her partner should speak to, Michelle further stated," I would like somebody to speak to a parent of a child with Down's Syndrome. [...] They need the personal side of that dad to dad and mom to mom. In my ideal world, that's how that would go." Sarah would direct people to parent support groups, "so you can actually get the information and ask questions that, to me, doctors give wrong information about, because they're not really informed as the parent population is." Angela agreed, saying the doctor "would not be the person I would go to now, not the doctor. It would be other people who have family members, children with Down Syndrome, advocates for people with Down Syndrome. That's where I will get my information, not from the doctor." Lisa, Jennifer, Mary, Danielle, and Nicole also said expectant parents should seek out families who have a child with Down Syndrome as a critical resource.

Christopher stated that people cannot know what the real experience of Down Syndrome is unless they're intimately acquainted with someone who has it. Prior to having your child, "You have such a different idea of what the word Down Syndrome is, and I think it's much more negative than what the reality of Down Syndrome is. I would try to push them from that, because it's sad, really." "Because even doctors, they don't really, they just know what they've read," he said. "They don't have a child or family member or friend [with Down Syndrome]." According to Lisa, "If you don't know somebody with Down Syndrome, you don't really get it." Rachel also said that her impression of Down Syndrome changed drastically after her son was born with it. "We had preconceived notions in our head of what our lives would look like $[\ldots]$ and it is 
vastly different than the reality. It was very doomsday, our perceptions prior. And the reality of it is, it could not be any more opposite than what we envisioned it to be." She later shared her advice that "I would ask anyone who had a negative opinion about Down Syndrome what their direct experience with someone who had Down Syndrome was. Or if it was just merely like mine and my husband's, like we had seen Corky on Life Goes On. And then take those opinions with a grain of salt and seek out the opinions of those that have genuine experience."

Matthew stated that, soon after he was told his daughter had Down Syndrome, he called a friend from long ago who also had a child with DS. "We talked to them, and the things they said that night were ten times stronger than anything our family or friends could say. You have to remember, we were close to our family and friends. So the best thing a person can do is call someone that has been there, done that." Matthew expressed that a pregnant couple should be sure to seek the perspective of experienced parents, saying they should "find someone that has a child with a disability or Down Syndrome." Sarah said that she felt "a heavy weight" should be given to the perspective of families who have a child with Down Syndrome, out of all the voices an expectant couple could consider when making their decision whether or not to terminate.

Once the genetic testing and decision making process was explored during the interview, participants were then asked about any potential effects from an inflation or reduction in the number of people born with Down Syndrome. At this point, I will describe the numerous ways in which parents envisioned that individuals with Down Syndrome, the specials need community, and society at large, could be affected if more or fewer people are born with the condition. This includes participants' responses to the 
more pointed questions regarding the possible effects on the institutions of education, medicine, and health insurance.

\section{Perceived Effects on Individuals and Society}

A small minority of respondents did not anticipate much, if any, effect on society or disabled individuals, if this population's numbers were to rise or fall. These parents felt that their children with Down Syndrome did not self-identify as disabled to the extent that they would be aware of the presence or absence of others in the community like them, nor did they think society held enough regard for people with Down Syndrome to notice or regret their eventual elimination. However, the majority of parents of children with Down Syndrome felt that their children, the special needs community, and society in general would all benefit from an increase in the number of people born with the condition, and they saw few drawbacks to this proposition. Speaking broadly, the responses of parents in regard to this issue can be summed up in one succinct phrase: strength in numbers.

The perceived advantages to individuals with Down Syndrome included better educational techniques and opportunities, more and better research into medical conditions and care, and more kinship and increased social connections. The special needs community was thought to benefit from increased advocacy, more funds for lobbying, and a greater diaspora of community centers and support groups, especially in rural or less populated areas. The perceived benefits to society were a bit more intangible, including such things as more love, increased diversity, and better tolerance and inclusion of all people, disabled or not. Some participants acknowledged that, due to the propensity of people with Down Syndrome to have more medical and general care needs 
than the average person, there could be some financial strain on families and the government if the numbers were increased. However, they often felt these effects would be mainly negligible, and that people with Down Syndrome create no worse a financial burden on society than other segments of the population, such as the incarcerated or the autistic.

\section{$\underline{\text { Lack of Effects }}$}

A few parents, such as Jennifer, Emily, and Rebecca, did not feel that society would undergo dramatic changes if the number of people with Down Syndrome were to shift in either direction. Jennifer expressly stated her opinion that society would experience no effect. "I wish I could sit here and say it would be a sad society but I don't think anybody would notice or care, unfortunately, if the population had less of these people." She went on to say, "Our son is a great joy to everyone he meets but you know, it's just our circle, it's our tiny corner." She also said, "I don't think it will have any type of effect on society if there was more people with Down's Syndrome." Emily shared that society would simply "miss some really special kids," if the population was reduced, but she also felt that an increase in numbers would increase the financial burden, especially to the state. "Some of them do have special medical conditions, and [...] they do have to have Medicaid to help cover the health expense costs. [...] So there could be more financial costs to the family but also the state for helping to care for these children." Rebecca also thought that "society would miss out on a lot of happy people," but she bemoaned her impression that some in society "don't know how to react if they see" a person with Down Syndrome, and that others commonly "look down" on them, seeming to indicate that the disabled would not be missed by many. 
When asked about how individuals with Down Syndrome might be affected if there were more or fewer people with the condition, each of these mothers said they didn't think their children would recognize any change or influence on their own lives. Emily said, "I don't know that my daughter would know the difference," and "I still don't think that it would matter to her." Rebecca said that she personally would feel the loss of her adult son with Down Syndrome, but that he himself would not be affected if fewer people were born with Down Syndrome. Speaking of her son's self-perception (or lack thereof) as a member of the special needs community, Rebecca related, "I've told him and made him feel normal so much that, I think, he thinks they're different." Jennifer believed that the level of effect was directly related to the individual's intellectual abilities, stating that, "(f)or the people with Down Syndrome who are more developmentally aware, or higher functioning if you will, I think they would take great joy in knowing there were more people like themselves." However, she expressed her thought that others did not have the capacity to assess their social surroundings in this manner, saying of her son, "I don't think he would even be aware that there was less or more people like that in the world."

Jennifer did not feel there would be any changes to the educational or medical institutions if more or fewer people were born with Down Syndrome. She said, "Hopefully, there would be no change. Because they're human beings just like any other human being." However, Rebecca and Emily shared opinions on this matter that were similar to the responses of the remainder of the participants. Emily felt that fewer numbers could result in fewer educational and extracurricular opportunities, but that greater numbers could cause a financial burden to society. Rebecca also briefly stated her 
thought that fewer numbers could decrease resources for people with Down Syndrome, both medically and educationally. To synopsize, a small minority of respondents did not foresee much, if any, effect on individuals or society at large if numbers were to change, but almost all of the study participants conceived of some potential effect within the educational and medical arenas.

\section{$\underline{\text { Education }}$}

Many respondents felt that an increase in the number of children born with Down Syndrome would compel the educational system to improve the educations they provide to those with the condition. In response to the question about education, Christopher replied, "I feel like if more kids with Down Syndrome were born, I feel like education would have to get with the program, and create more educational programs for children, teenagers, and then more educational programs for adults. [...] They're just going to have to increase those educational opportunities." He felt the converse was true as well, that if fewer individuals with Down Syndrome are born, there will be less pressure on educational institutions to competently meet their needs. Nicole shared Christopher's opinion, stating, "If more people had the condition, they would be forced to come up with better programs." Jessica said, "I think they would have to put more effort into it than what they're doing," if the numbers were higher. Mary, Angela, and Matthew felt much the same way.

Heather shared, "I think maybe expectations could rise as people become more familiar with people with Down Syndrome," because they gain a stronger appreciation of the spectrum which exists in this population's capacity to learn. Michelle agreed with this statement, saying that teachers and administrators would learn to recognize that 
people with Down Syndrome have unique abilities, strengths, and weaknesses, like anyone else. Andrea felt that, "The education system needs to understand that children with Down Syndrome are very capable of learning," and that this would be more apparent if there were more kids in each classroom with the condition.

Some study participants, such as Rachel, Amanda and Melissa, felt that increased numbers would lead to increased inclusion for students with Down Syndrome in mainstream classes, which they saw as positive. Melissa said, "I know that schools now are a lot more inclusive of individuals with Down Syndrome and I think that's awesome. But I just feel like it would continue to get better, if there were more children with Down Syndrome." Sarah said that she thought, "integration would maybe be a little easier." And Amanda felt that, "More individuals with Down Syndrome could potentially push inclusive education even further."

Other study participants, such as Rebecca, felt that if there were more students with Down Syndrome in each grade, these students could be taught as a collective, largely segregated from other students, which they also saw as positive. Rebecca said that, "If there were more, they would have a certain class for them." She liked the idea of mainstreaming but worried about bullying, saying, "People are so mean that you kind of have to keep them together to keep people from being mean to them." Melissa felt that there could be more specialized classrooms and programs, tailored to a more diverse range of intellectual capabilities exhibited by children with Down Syndrome. "I feel like there would be more areas, instead of just having an FMD unit or an MMD unit, there might be somewhere in the middle of that," she said. "Where they're not just mild and 
they're not a full mental disability, but [there's an option] that's more equipped to handle kids with Down Syndrome and understand their way of thinking."

\section{$\underline{\text { Medicine }}$}

Much like with education, most study participants felt that medical research and treatment related to Down Syndrome would improve if more people were born with the disorder. Participants felt there would be more research, more specialists, and that insurance would be less averse to meeting coverage needs. Sarah works in services for the intellectually disabled, and she reported her impression that this population is medically underserved in comparison to their neurotypical peers. "'I've seen that with adults, maybe they don't get the same level of care in the medical field, anyone with an intellectual disability, and there's many factors to that. [...] So less people, more discrimination."

Amanda expressed her thought that, "The more people who have Down Syndrome, the more attention that it would get. Hopefully, the more research that people would get, and maybe be able to correct a lot of the medical issues associated with Down Syndrome." According to Christopher, "It's supply and demand. If there's greater supply and need for people who have Down Syndrome, [...], they'd have to increase healthcare, and research, and medical needs for people with Down Syndrome." Lisa stated, "There's always power in more, more numbers." Mary felt the same way. "If there are more people, then they will get more attention, because there is strength in numbers, and they will get better care if there are more of them, because people will have a bigger voice."

Melissa and Sarah felt that more specialists would be trained to meet the needs of a greater number of people with Down Syndrome, so that specialized medical care could 
be more widely available, even in less populated areas. Sarah felt that the clinic model of treatment could become more pervasive, "like the larger cities have Down Syndrome clinics where [people with Down Syndrome] can see all the specialists together and it's more of a comprehensive look." Danielle also expressed her frustration that travel to obtain necessary medical care for her son with Down Syndrome was a financial strain to her family as well as for others, and she indicated her desire for more medically-related expenses, such as gas and lodging, to be covered by health insurance.

Emily expressed her thought that if fewer people have Down Syndrome, insurance companies may feel less pressure to cover their healthcare costs. Melissa also felt that, "If more people are born, I could see insurance being more accepting." She recounted her attempts, which were ultimately unsuccessful, to obtain life insurance on her daughter with Down Syndrome. Melissa shared that she knew of several families who lost their children with Down Syndrome at a very young age, and these parents could have immensely benefited from some basic life insurance coverage to help cover their child's final expenses. She felt that if a sufficient numbers of parents could be pooled together, life insurance companies might consider a separate, but affordable, plan and premium for those families. She further stated her opinion that if fewer people are born with Down Syndrome, "Insurance companies are going to stray away from [coverage] because they're gonna be like, 'This is soon going to be something we're not going to have to worry about. So let's not worry about it right now.' So I feel like it would be almost impossible to get coverage, or like I said with life insurance, they're not going to want to pay." Again, study responses were fairly consistent in regard to potential effects on school systems and medical treatment and insurance options, but participants held 
widely different views on the direct effects on individuals with Down Syndrome, special needs communities and society at large. This spectrum ranged from no effect, addressed above, to significant effect, which will be described here.

\section{$\underline{\text { Social Opportunities and Self-Awareness }}$}

Some study participants were especially invested in the idea that people with Down Syndrome feel a shared kinship with others who have the condition, and that this connection would be forfeit if fewer people were born with it. Parents felt that their kids needed others in their social circle that could understand them and empathize with what they're going through (health problems, therapies, educational programs, etc.). Although many of them reported that their children had friendships with neurotypical children and family members, there was a unique quality to their friendships with other kids with Down Syndrome that could not be replicated in their other relationships. This again harkens back to their belief that one cannot truly know Down Syndrome unless they or a close family member have the condition.

When asked how individuals with Down Syndrome might be affected if fewer people were born with the condition, Nicole said, "Can you imagine living in a world where so many people don't understand what it's like to be you? Or to deal with what you deal with? [...] There are some drawbacks, you know there are things that they have to face and only other people with Down Syndrome understand." Christopher expressed much the same thing, saying of his two year old son,

I feel like when he's older, eventually he's going to realize, 'Yeah, there's something a little bit different about me than everyone else.' I think from relating to someone just on a different level, he's going to need someone that has Down Syndrome just, on a personal level. Like, 'Yeah, I get what you're going through. I get where you've been.' I think that's very important for people with Down Syndrome. 
Respondents shared stories of their children making friendships through club meetings, sports teams, and social events sponsored by Down Syndrome support groups in their community. Amber said, "I think that [gives] them opportunities to kind of be around other people like them and I think they could grow from that. [...] We have these events and see how kids have kind of gotten to know each other through these events. And you're so excited to see them. So it's lifelong connections." Michelle feared her child would have reduced social interactions if there were fewer advocacy organizations for Down Syndrome. "Local chapters would eventually have to close up and so now maybe your local chapter isn't thirty minutes away, now it's two hours away. And your family member with Down Syndrome only gets to go to the [group event] once a year, instead of going to the dance once a month. Just less social opportunity, more isolation, for the person with Down Syndrome and their families." Angela shared her belief that people with Down Syndrome would be overjoyed to know more people like themselves. She spoke of her experience volunteering at an annual dance for people with disabilities: "This would sound weird, but [people with Down Syndrome] run in packs, man. They converged on the dance floor, they knocked everybody else off of it, had a ball. I mean, they're very social beings. They love being with each other and other people. I think they would love it."

Andrea stated that society was denying her child the opportunity to make friends with like individuals, due to the approximately $90 \%$ termination rate of fetuses diagnosed prenatally with Down Syndrome. "I would just like everyone to think of ten of your friends and eliminate nine of them," she said. "Because that's what happens to my son. [...] You have eliminated a big pool of people he could connect with, or maybe fall in 
love with, or have a life with." Because there is an ethical uneasiness surrounding the sexual pairing of the cognitively disabled with the neurotypical (Foley 2014), several respondents were particularly concerned about the decrease in potential romantic partners for their children with Down Syndrome. Sarah stated, "Often [people with] intellectual and developmental disabilities find comfort in each other when it comes to intimate relationships."

Several parents felt that knowing others with Down Syndrome gave their own children a sense of self-awareness and a more secure place in their social surroundings. Melissa said, "My daughter is very aware of other individuals with Down Syndrome and if she starts to see a lack of that, she's gonna be like, 'Where are the kids like me?' Or, 'Where are the people like me?' So they're gonna just kind of feel like they don't matter." Jessica spoke of her fourteen year old son. "I think that when he is with others with Down Syndrome, there is a connection there that he is able to form quicker, more easily. We all want that connection, so I think not having the ability to have that connection would be difficult, harder on an individual with Down Syndrome.” Rachel felt that knowing others with Down Syndrome "would increase their own personal selfesteem. It would further solidify to them that people with their diagnosis absolutely can be successful and live full lives." Heather felt this had an effect across the life span of individuals with DS:

When an older person with Down Syndrome, whether they're eight years old or forty-five years old, or whatnot, when they meet a young person with Down Syndrome, a baby, they're happy. I mean, they're so excited. There's a kinship. It makes them feel proud of who they are, to see a younger generation coming along, to know that it validates that they're valued. So I think that [if fewer people were born with DS], it would make them sad. It would make them feel lonelier. 
Jennifer said, "I think they would take great joy in knowing that there were more people like themselves." Parents felt there was a myriad of ways in which their children could be affected if the birth rates of people with Down Syndrome were to be dramatically altered. Respondents further spoke of ways in which society both values and devalues the lives of people with Down Syndrome. This is thought to be the result of a confluence of social factors and individual decisions. This will additionally be explored later in this section.

\section{Effects on Special Needs Community}

In addition to the medical and educational effects previously outlined, respondents felt that advocacy groups and the special needs community would suffer from less funding, fewer lobbying efforts, and a lesser presence in the world, if fewer people were born with Down Syndrome. They also felt that many of the gains of the disability rights movement would be lost and that society could "go backwards" in their treatment of people with disabilities. These issues will be touched upon briefly here.

Again, following from the adage "there's strength in numbers," several respondents felt that a reduction in numbers would impede the efforts of advocates. Michelle said, "I think there [would be] less money for people and lobbyists advocating for them, whether it's Medicaid, whether it's IDEA, the department of education. There will be less advocating for them to be accepted and included, less advocating for them to have employment opportunities and fair housing opportunities." Matthew felt the community of families would have a harder time with their outreach efforts. "Right now already, we have a challenge already. We're pretty big into advocacy and awareness. 
There's some pretty awesome stories out there, there's a lot of great stories out there. But, the fewer the individuals with Down Syndrome, obviously the fewer the stories."

Other respondents, such as Danielle and Michael, felt that the rights and resources secured in recent decades for people with disabilities could be abolished if the need was lessened and fewer people were advocating for them. Melissa was concerned about people with Down Syndrome being perceived as "going into extinction. [...] So I feel like their resources will kind of shut down." Heather said she felt the stigma of parenting a daughter with a visible disability and expressed her grievance that, "with all these movements going on for equality, I see intellectual disability being left behind. And disability in general being left behind in the equality movement. And I think that's wrong." Danielle said, "All the forward moving laws that have been made, the advancements of the laws and the growth that had been made at colleges and in curriculums, or the certificate programs that they have put in, $[\ldots]$ the businesses that are owned by people that have Down Syndrome, [...] that would start going away. We'd be going back in time. Because it's supply and demand."

\section{Effects on Greater Society}

Greater opportunities for full inclusion and participation in society would, in turn, lead to better acceptance and appreciation for people with Down Syndrome and other differences throughout society, according to study participants. Although these benefits were intangible, they were seen as no less real or remarkable by parents of children with Down Syndrome. Parents often described their children as joyful beings bringing light, love, and diversity to the world around them. 
Michael expressed his belief that if there were fewer people with Down Syndrome in the world, there would be "less love" and "less joy." Mary said, "There will be less of compassion and understanding and less love toward one another." Matthew felt there would be "less love in the world," because they "bring more joy and happiness." Andrea expressed, "I've witnessed this, people with Down Syndrome give other people an opportunity to develop, especially siblings or others, to develop compassion, to develop acceptance of everyone." Amanda shared her thoughts:

I think that society would be a much less sympathetic place. I think that it's important that we accept differences in society and we love people who are not like us, who are different than us. And I think that people with Down Syndrome are a shining example of unconditional love and acceptance and I think it would be a much more boring world without them in it.

Nicole said, "I think it would be a miserable world [...because]people with Down Syndrome bring joy to the world." Many parents shared stories in which they felt their children personally touched the lives of others, and they expressed their pride that their children had gifts to share with their communities. They felt the world would suffer an irredeemable loss if Down Syndrome were to be systematically erased through widescale selective abortion.

Thus, in summation, a minority of respondents did not identify or sense any real threat to their children or society if the numbers were reduced, but the majority did. Upon further analysis of study data, I discovered that those who perceived little or no threat also held a more neutral stance on the role of physicians, while the opposite was true for many other respondents. This correlation will now be elucidated at length, followed by an examination of how parents in the latter group personally engage themselves and their children with the prenatal screening processes of others. As a result 
of this intimate level of engagement, they often appear to experience a sense of rejection and grief when others do choose abortion, and they feel the process as a whole devalues the lives of their children and others with Down Syndrome.

\section{Association between Perceptions of Power and Perceptions of Threat}

The key finding of the present study is that an association exists, in the study sample, between the perception of power in the prenatal screening process and the perception of threat to individuals with Down Syndrome, their families, and their collectives. Specifically, those respondents who held a more negative view of physician interaction in the genetic screening process, and who placed the greatest weight on the perspectives of people raising a child with DS in that process, were also those who felt the strongest sense of personal threat from a reduction in the number of people born with Down Syndrome. Conversely, those who held a more neutral stance on the physician also perceived far less threat to themselves and their children from other's decisions to abort.

As outlined earlier, Rebecca, Emily, and Jennifer fell most fully in the neutral/no threat group. Their responses were representative of a more neutral stance on the role of the physician and they perceived little, if any, effect on society or people with Down Syndrome, if the number of individuals born with the condition were to decrease. The neutrality of their viewpoints on the medical profession was encapsulated more in the absence of disparaging remarks regarding the doctor, rather than in expressions of allegiance to their expertise. These parents were also less adamant that expectant couples should speak to parents raising a child with Down Syndrome during the decision-making process. For example, Rebecca was the parent referenced previously, who was the sole study respondent not to directly state that expectant couples should speak to such parents, 
although, again, she did share that others sought her advice as a parent with lived experience raising a child with the disability. As quoted above, Rebecca felt that her son would not be aware nor be negatively affected if there were fewer people born with Down Syndrome, and she anticipated only vague effects on society, in that "society would miss out on a lot of happy people."

Jennifer responded much the same way, in that she did not express many negative thoughts about the role of the doctor nor the impact of a reduction of disabled individuals on her child or society. She said that her son was not sufficiently intellectual to recognize himself and others as differently abled and thus would not suffer from a lack of companions with the same disability that he has. Much like Rebecca and Jennifer, Emily also said, "I don't know that my daughter would know the difference," and that she doesn't "think it would matter to her."

Emily expressed a balanced approach in her vision of the roles of the various players in the prenatal screening and decision-making processes. In response to the question asking what advice she would give a woman and her partner when they are trying to decide if they will have an abortion once they receive a diagnosis of Down Syndrome during the pregnancy, Emily said the following:

I think that she would really need to talk with her doctor. I think that she would really need to talk to the genetic counselor but I think she really needs to make contact with someone that has a child with the genetic problem that [their child is] gonna have. And then I think she really needs to reach out to her church family and pray about it because it's a personal decision.

It is important to note that Emily did not disregard the role of the parental advocate, but she did place it on more equal terms with the role of the obstetrician, the genetic counselor, and the church. This stresses the finding from the study that the 
spectrum of feeling about the physician ranges not from emphatically positive to emphatically negative, but rather from neutral to emphatically negative. The same can be said of the spectrum of participant responses regarding perception of threat, which ranges not from positive effect to negative effect, but from no effect to extremely negative effect.

In my assessment of the study data, there exists significant peril in overstating the association between these spectrums as fixed and immutable, and I exercised caution against polarizing respondents into two distinct schools of thought. It is critical to recognize that study respondents cannot be concisely delineated into disparate groups. That, however, does not repudiate the existence of the association. Rather, I would propose an image of respondents as falling along a sliding scale, from insouciance to vehemence, both in their perceptions of physicians and in their perceptions of threat. A general position on one scale correlates to a general position on the second scale, for most respondents.

Emily, Rebecca, and Jennifer were the strongest representatives of the far end of the spectrum (neutral/no threat). Nicole and Lisa also fell further towards this end of the spectrum than the other. Nicole and Lisa posited an ideal power split between the physicians and the parental advocates, but both were also slightly more emphatic about parents reaching out to advocate groups as part of their education on Down Syndrome. They also spoke at greater length about perceived effects on society and their children, if fewer or more people are born with Down Syndrome. Nicole referenced less sense of connection and camaraderie, as quoted before, and Lisa mentioned better inclusion in educational programs and more medical research and treatment options. This group of 
five parents comprised the selection of respondents who most clearly fit within this far end of the associated spectrums.

On the opposite end of these spectrums were parents who felt passionately that doctors had a hostile agenda against people with Down Syndrome and should be bypassed entirely by expectant couples seeking advice and information after their fetuses were diagnosed with a genetic abnormality. These parents highly appraised the perspective of parents with lived experience raising a child with Down Syndrome and they ardently urged a connection be made between expectant and advocate parents. These parents also perceived a vivid and almost palpable sense of threat to themselves and their children from the selective abortion of fetuses with Down Syndrome. For several of them, this sense of threat extended to a feeling of persecution, rejection, and devaluation of their disabled children. These parents were among those using strong language regarding genetic screening and selective termination, with words like "extinction," "eugenics," "master race," and "elimination" arising in their responses.

The parents who fall most squarely on this end of the spectrum are Heather, Danielle, Sarah, Matthew, Rachel, and Amanda. Interestingly, these interviews were among those that ran the longest, with parents expounding at length on various scenarios they had personally encountered and also those that they envisioned. These parents were also heavily involved in advocacy on behalf of people with Down Syndrome and their families, and they each held professional roles (Amanda and Sarah), formal voluntary roles (Matthew and Rachel), or informal voluntary roles (Heather and Danielle) as advocates in their respective Down Syndrome support groups. 
Amanda holds a professional role in outreach to expectant and new parents in her area DS organization. As described above, she shared several stories with me about parents she had recently conversed with, in which the doctors had spoken very negatively about the condition. She expressed early in her interview that "there's too many physicians who have very preconceived notions of what should happen when a woman is carrying a child with Down Syndrome and so I worry that those physicians are probably giving moms inaccurate information." She spoke of the power inherent in an expectant couple connecting with an advocate couple and she said that this power flowed from the intense love a parent feels for their disabled child. "To have a parent that cares so much and loves their child so much that they want to be able to reach out and help other families experience that kind of love, I think that's pretty amazing." Amanda was a striking example of some respondents' willingness to invest themselves and their children heavily in the decision making processes of others, but it was clear from her account that this engagement was not without a substantial level of risk and cost to that advocate family. This will be discussed at length later in this section.

Danielle is very active in her local Down Syndrome support group and she told me that she is occasionally called upon by this group to speak with, and educate, mothers of newborns who have just been diagnosed with Down Syndrome. Danielle spoke exuberantly of her experience with her obstetrician and her impression of the medical field as a whole. A number of times, she shared her impression with me that doctors operate from archaic and biased viewpoints and that they should not allow their own morality to seep into conversations with their patients, nor should they be instrumental in the process of selective abortion. She said, "[The doctor should not] put forth his 
morality, his two cents' worth, into, 'Hey, $[\ldots]$ we put too much money into these kids over here that has this disorder and all it takes is this little blood test right here for us to weed out these kinds of kids so I really think you need to have this test.' Heck no. No, no, no, no, no. No. No. I'm gonna stand, I stand on that one." She is also the respondent that felt that obstetricians should be required to forward the contact information for all women who receive a diagnosis of Down Syndrome, either in their fetuses or babies, to the local DS advocacy group, even against the explicit wishes of the mother. In addition to numerous other ways in which she felt her son, the special needs community, and society could suffer from a reduction in the number of people born with Down Syndrome, she also felt a level of threat directly to herself and her husband as parents of such a child. She felt that with a greater number of people with the condition present in society, greater normalization of the condition occurs. In her mind, this is subsequently accompanied by less judgement against the parents as somehow causing the aberration themselves, through unhealthy preconception or prenatal exposures (such as to smoking, alcohol, drugs, radiation, etc). She said that parents experience this judgement as, "They're gonna think that I did something. There was something wrong with me that I had a child with Down Syndrome. There's still that thought, to this day." Danielle also felt an acute sense that the gains made by people with Down Syndrome and their families in recent years would undeniably be lost and that society would revert back decades in time, if fewer people were born with Down Syndrome. "Instead of being in the thought of the 1952 doctor that was saying he was gonna be institutionalized and all this other stuff, no," she said. “They're getting married, they're having babies, they're going to their businesses, 
and living on their own. That would start going away. We'd be going back in time.

Because it's supply and demand. I hate to say this, it's supply and demand."

Heather was the mother who shared with me that she often goes on public online message boards and websites to share her experiences and perspectives, as a mother to a young daughter with Down Syndrome. She strives to correct others' misperceptions and counter their fears about raising a disabled child, but she expressed her sadness that "Not once have I, I think, have I ever swayed a woman to keep her child with Down Syndrome. [...] But I don't think that's a reason to give up." She pointed out that while people are often aware of the health problems associated with Down Syndrome (greater risk of heart problems, leukemia, and developmental delays), the health benefits associated with DS are largely unknown.

Your child with Down Syndrome, yes will have trouble learning and they may have trouble with some social skills but things you can cross of the list are, your child is very unlikely to ever be involved in any criminal activity, drug abuse. [...] They're unlikely to run away, they're unlikely to contemplate suicide, even if they do happen to be bullied. [...] They are very unlikely to have mental conditions, such as schizophrenia, bipolar disorder. [...] That type of information is not shared, it's not widely known.

Heather said that she takes it upon herself to disseminate this information online and she was eager to discuss how the results of the present study could be used to influence social policy. She felt that the rights of the disabled are being left behind in comparison to other minority groups. She was keenly sensitive that the rise in the availability and use of the NIPT led to fewer expectant mothers soliciting the advice of parents like her online, choosing instead to elicit sympathy from others for "termination for medical reasons." She was very frustrated with her obstetrician and with several of the genetic counselors she met with after her daughter was diagnosed. She felt that many 
obstetricians do not take the requisite time to educate parents and that oftentimes she and other mothers are better informed than the medical professionals. She also perceived a very significant threat to individuals with disabilities, due to the increase in prenatal genetic screening, and that this threat was not just confined to the condition of Down Syndrome. "These tests are not just gonna eliminate people with Down Syndrome, they're gonna look for more and more of these genetic disabilities, they easier they find [disorders], they'll get added to the list. I do think we're possibly going into a slippery slope of eugenics."

Much like Heather, Matthew also experienced frustration with his wife's obstetrician and felt that doctors were not supportive of patients who are pro-life. He has a high-level, formal, voluntary position with a Down Syndrome support group in his area, whose members he described as "huge, huge advocates" for Down Syndrome. He stated upfront, "Definitely, we'd love to take the physician out of that choice" of pre-natal genetic screening. He characterized a society, in which selective termination for Down Syndrome is generally lauded, as a "throwaway" world, because, in his view, people would be discarded as easily as iPhones. He also says that it "shows we live in a broke world." He regarded physicians with suspicion, saying, "I really, really don't think some of them are there for the right reasons."

Rachel is also voluntarily involved in a Down Syndrome support group as a parent advocate, and she was the mother described earlier who wanted her organization's ten minute video to be shown in all obstetricians' offices prior to any genetic screening. She was also suspicious of the motives of physicians and related her disheartening experience with the genetic counselor as evidence of the insensitivity and ignorance she 
sees as emblematic of many in the medical profession. She believed that an increase or decrease in the number of people born with Down Syndrome could have profound effects on society at every level. She felt that if "there were fewer people with [Down Syndrome] around them, that it would make them feel further isolated. And I feel like it's kind of a step going backwards. The children with Down Syndrome were, until fifty years ago, when they were institutionalized because there was not a strong understanding of their abilities. So, to me, it's a step in the wrong direction." If there were a greater number of people with Down Syndrome, "it would increase their own personal self-esteem, it would further solidify to them that people with their diagnosis absolutely can be successful and live full lives."

Sarah is employed in the field of advocacy for individuals with intellectual disabilities and she said she felt such people experience discrimination from the medical field. She boldly stated that "you're gonna have to make your decision if you're going to have an abortion or not based on other information, that your doctor does not have," and that "doctors do not have any information that is helpful" to parents trying to make their decision. She was distressed that her obstetricians pushed her to undergo an amniocentesis and repeatedly told her the legal deadline to abort her baby. She said that, "Doctors are still trying to wrap their heads around how to address all of this new information that's coming" from the NIPT and other genetic screening rates. She shared that she does not trust reports of selective abortion rates, because she believes these reports are generated by the medical profession. "It almost makes me think that doctors or whoever's really collecting this information is looking at things skewed. I don't know, it's just like everyone's viewpoint is skewed until you actually get into these parent 
supports." She felt that the loss of any human life is a tremendous loss to the community and especially to others who share the same attributes. "Diversity in general heightens our community," she said. "And every person that enters this world has something to offer. So if more people are entering this world with a level of diversity, it just is going to make our community greater." She said that no matter the level of ability or disability, a person has an effect on humanity, and even if, "someone's in a coma, they still have brought meaning to people around them." Although she was aware of the financial cost to society to care for individuals with Down Syndrome, she felt the imperceptible costs to society of aborting them prenatally would be much greater.

It is important to note that this difference in perception of threat cannot readily be ascribed to a differing degree of connection between these parents and their special needs children, nor can it be ascribed to their children's level of interaction in the special needs community. All of the respondents from the neutral/no threat group professed their love for their children and detailed their children's involvement in the local DS support groups. Rebecca described her adult son with Down Syndrome as "pretty much my whole life," and said that she had a much closer relationship with him than with her other adult children. She shared with me that her son is very active with dance and exercise groups composed of adults with disabilities. Emily gave fairly short responses to my interview questions, but when asked if she had anything further to tell me that she thought I should know, Emily talked at length about her daughter's participation in the local Down Syndrome support group. She said that her daughter and her daughter's fellow support group friends participated together in hippotherapy, cheer squad, dance team, church activities, and life skills classes together. Jennifer expressed that her son with Down 
Syndrome "is just the sweetest little guy" who is "a great joy to everyone he meets" and that a "baby with Down Syndrome is the best gift and blessing [anyone] will ever experience in their lives." Their stories were indistinguishable from the expressions of love and pride that all study respondents shared when speaking of their children. Parents animatedly showed me pictures and videos of their children with Down Syndrome and spoke to me of their children's recent accomplishments in school and sports activities. It cannot be said that any of these study respondents love their children any less or neglect to engage them with others who have the same disability.

However, a distinction can be drawn in the level of fervor that parents exhibit in their advocacy efforts and their willingness to absorb themselves and their children in the decision making of others. Parents who fell on the negative view of physicians/strong perception of threat end of the scale were also generally more likely to feel a responsibility to persuade others to carry their babies with Down Syndrome to term and to feel their children were devalued by others' decisions to abort fetuses prenatally diagnosed. When asked, "How do you feel about a woman and her partner deciding to have an abortion after her fetus is diagnosed with Down Syndrome?" nearly all study participants said they would feel sad and that they think the parents would be missing out on a wonderful experience. But some parents took it more personally. For example, Christopher said, "Well, when you're a parent of a child with Down Syndrome, it's almost offensive." Amanda stated, "It makes me sad because I feel like I failed to convince them how great life can be, even though that's not my job. And it's not what I was setting out to do, but I feel sad about it." She said that, although she supports a woman in her right to choose genetic screening and abortion, she experienced some 
misgivings when a relative elected to undergo genetic screening. "There is a part of me, if I'm being incredibly honest, that thinks, are you doing this so you don't have a baby like mine? Like, what's wrong with my baby? Why would you not want to have a perfect, wonderful little girl like I have? It's a little part of me, but it's there. So I think that there's a piece of me that's offended." She said she relies heavily on her parental journey and love for her daughter when speaking to parents, which understandably leads to her feeling personal rejection on behalf of her family if, as she said, she fails to convince them how positive the child-raising experience can be.

Sarah said that, when she hears of a parent choosing abortion, "personally, I do mourn that loss." Angela said, "I think it's a terrible mistake. I think if they could see what I see in my little eight year-old, he is amazing." "It hurts my heart a bit," Amber said. "Because my kid's such a value. He's more of a value than a detriment." Heather also said that, "It disappoints me, it breaks my heart." She told me of numerous times in which she tried to convince parents that they were up to the challenge of raising a special needs child and to correct their misperceptions, based on her own parenting experiences. She felt that children with Down Syndrome were unfairly targeted for elimination and that this denigrates their position in society. "I'm not anyone special," she said. "But no one's questioning my existence." Furthermore, if the number of people born with Down Syndrome were to decrease, "It would be heart-breaking for [people with Down Syndrome]. I think it would make them feel less valued, maybe make them doubt their validity, of their existence." Although this was not the predominant finding of the present study, and does not bear belaboring, it does allude to the emotional wounds some parents 
have endured as an indirect outcome of the genetic screening and selective termination process. 


\section{DISCUSSION}

Testing for Trisomy 21 has been at the forefront of the genetic testing phenomenon, as Down Syndrome (also referred to as DS) has been the genetic disorder most commonly associated with intellectual disability (Acharya 2011, de Groot-van der Mooren et al 2014). According to Acharya, "prenatal testing has become synonymous with Down syndrome and Down syndrome [sic] has become synonymous with intellectual disability" (2011:27). As the threshold of genetic screening expands to include more options for testing, and with more conditions coming under scrutiny, much can be gleaned from past and present research on genetic testing for Down Syndrome and the power structure which pervades it. Furthermore, because minority segments of society can face unintended consequences which drift downstream from the actions of others, it is important to understand this power structure and how individuals with Down Syndrome and their families feel about it. This was the guiding force behind the present study.

Some of the data which emerged from the interviews was consistent with prior research and some of it deviated from what was formerly known about this population. The key findings of the study, the limitations and strengths of the study, the relationship of the present study to previous research, and the unanticipated results from the interview data will be discussed at length in the forthcoming sections. Additionally, I will discuss 
the relevancy of the theoretical perspective initially proposed for the present study, Foucault's biopower, to the resultant data from the interviews. I will also delve into other theories which could more adequately address areas where Foucault's ideas fall short, in relation to the findings which emerged. Finally, I will make suggestions for further research.

\section{$\underline{\text { Study Findings }}$}

There were several primary findings in this study. The first finding is that respondents impute great responsibility to expectant parents, to know themselves well and to educate themselves prenatally with what respondents consider to be the "right" information. However, they also often absolve parents of any accountability if they do choose abortion after their fetuses are diagnosed with Down Syndrome. Study respondents fear that the general public are ignorant of the "reality" of Down Syndrome, and that they are often inclined to choose prenatal genetic screening and selective abortion because of archaic prejudices against intellectual disability. Respondents feel that doctors are in the prime position to correct their misconceptions, but that doctors are often uninformed, misinformed, and/or prejudiced themselves.

Because of this, almost all respondents felt that expectant couples should speak to Down Syndrome advocacy groups, as well as to parents raising a child with Down Syndrome. The extent to which study participants felt physicians should be involved with this pross varied, from passing along pamphlets from local and national advocacy groups, to connecting expectant couples with families who have a child with Down Syndrome, to submitting patient information to advocacy groups, regardless if they have patient permission to do so. The position of parents toward the role of the physician ranged from 
neutral, (physicians can be a partner in the process, offering informational support and resources to expectant parents), to unequivocally negative (physicians have an agenda to influence patients to terminate, and therefore, they should be excluded entirely from the decision-making process.) Again, whatever the level of involvement of the physician, participants felt it was critical that expectant couples speak with parents who are raising a child with Down Syndrome, in order to understand the "reality" of Down Syndrome.

Many parents felt that, because they have a child with Down Syndrome, they are the only ones that possess the right information about Down Syndrome and can educate others on the condition. This information cannot be obtained in any alternate way, only through interpersonal contact with parents raising such a child, as well as DS advocacy groups. There was a sense that if expectant couples are in receipt of such contact and information, they can be relied upon to make the choice to continue their pregnancies and prepare themselves to become advocates for their disabled children. The idea that expectant parents could be fully and conscientiously informed by the appropriate parties and still elect to abort their fetus with Down Syndrome, for whatever reasons of their own, was not readily acknowledged by study participants.

Furthermore, some parents experienced a sense of threat to their children, their families, their support communities, and themselves from others' choices to engage in selective termination for the condition of Down Syndrome. A minority of respondents (around a quarter of respondents) did not perceive much, if any, threat to themselves or their children, if the number of children with Down Syndrome were to dramatically decrease. However, most of the respondents did perceive a threat, with approximately six 
respondents, in particular, portending very real and personal consequences to their families.

The most salient finding to emerge from this research is that an association exists between the perception of the role of the physician and the perception of threat to individuals with Down Syndrome and their families. Respondents fell along a scale from neutral to extremely negative in their impression of the obstetrician, which corresponded with a scale from neutral to extreme in their perception of threat to themselves and their children. In other words, participants who were more likely to envision the physician as a deserved partner in the decision-making process were also less likely to report feeling a sense of threat to themselves, their children, and the DS community as a whole, if the number of individuals with DS were to decrease. In contrast, respondents who reported more negative impressions of physicians were also more likely to report a stronger sense of threat. Out of those parents who experienced threat, a subgroup of them engage themselves and their children personally in the decision making processes of others, which leads to feelings of persecution, offense, and rejection if others do ultimately choose to abort.

The present study unearthed several important findings, generated through a qualitative mode of inquiry and analysis. As with any research endeavor, decisions must be made to ensure that, out of the many methodological approaches available to social scientists, the most effective and appropriate approach is undertaken. Also, parameters are put in place to ensure that the scope of the study is sufficiently concentrated, to allow the researcher to focus on what he or she truly wishes to know. Therefore, there are 
limitations to any methodological approach, and it is part of the integrity of research to duly recognize and address these limitations.

\section{$\underline{\text { Limitations }}$}

As described above, a number of interesting responses emerged from the interview data, which has been organized into several distinct themes. The data was collected and analyzed using qualitative methods, which were the most appropriate for this study, for the reasons I presented during the methodology section and will reiterate below. I assert that this approach is the best strategy for the nature of the subject under study and the research questions being posed. However, as with any study, there are limitations to this research, which will be acknowledged and discussed.

As non-random sampling techniques were employed to recruit participants, the study results are not widely generalizable. The study sample was comprised of volunteer participants, recruited from area Down Syndrome support groups over a four-month span of time. It is believed that saturation occurred with this study, as no new directions or themes arose after the seventeenth interview was conducted. Everyone who met the eligibility criteria for the study and expressed a desire to participate was permitted to do so, until the study was complete. It cannot be presumed that the exact same results would arise in another sample set. However, the sacrifice of generalizability was well worth the reward of the richness of data and the unique vantage point afforded to the researcher by the open-ended line of inquiry.

This sample was not necessarily representative of the larger population of families raising a child with Down Syndrome, as demographic factors (such as race, age, and 
religion) were not proportionately represented, nor was demographic information collected or assessed. The advocacy groups from which participants were drawn cover a fairly small area of the country, and it is possible that parents in other areas of the country, or in other countries, may feel and respond differently. Previous research has shown that demographic variables do have a correlation with different outcomes related to genetic screening and selective termination (Choi et al 2012, Egan et al 2011, Sherman et al 2007). It is not known how demographic factors, (such as those already listed, along with educational level, profession, sexuality, marital status, number of children, age of other children, etc.) may have affected the data collected.

There may be a difference in how parents who are not connected to a Down Syndrome support group may respond to the interview questions. Although a number of study respondents reported that their children had several medical ailments and/or had experienced multiple surgeries at a young age, none of the study respondents described their children as being profoundly debilitated or as suffering from any terminal condition. However, debilitating and lethal conditions can and do occur in conjunction with Down Syndrome. It is understandable that other parents, who may be facing a high and chronic level of family crisis due to their children's significant health challenges, may not regularly participate in advocacy groups nor elect to participate in voluntary studies. It is possible that such parents may feel differently from the parents who did elect to participate in the present study.

It is also logically probable that parents who actively participate in advocacy groups for their child's genetic condition are more prone to identifying as advocates themselves. They are likely to be more passionate about the role of the support group, 
and others with Down Syndrome, in the lives of their children. Parents who lack any connection to Down Syndrome support groups (for whatever reason)were not accessed for the present study and may feel differently than these study participants.

In addition, there is a mindset particular to advocacy groups that researchers have uncovered (Armstrong and Bernstein 2008). Because members of advocacy groups unite under common circumstances and with generally confluent aims, a shared narrative often arises among the group, which is then echoed and affirmed by individual members. In addition, an advocacy group may specifically target one institution on which to focus their efforts toward social change, because targeting multiple institutions simultaneously or in succession can be difficult (Armstrong and Bernstein 2008). There may be bias among present study respondents because of this tendency of groups, which are dedicated to social change, to develop a collective narrative, common target, and mutual identity as outsiders. This does not mean that what respondents reported is false or unreliable, just that, to some degree, they could be experiencing influence from a shared source (the advocacy groups to which they belong). This could have contributed somewhat to study respondents framing their children in similar ways and expressing their frustration with one specific institution, the medical profession.

From another angle, the community from which respondents were recruited could be considered a strength of the study. This is because the study targets the locus of control in the genetic screening process for Down Syndrome, as perceived by parents. Down Syndrome is frequently associated with prenatal genetic screening and selective abortion for genetic disabilities. So it is natural that Down Syndrome advocacy groups would seek to inform themselves and others about it, as well to influence the power 
hierarchy therein, especially if they feel that it currently works to their detriment. Independent Down Syndrome activists who feel the same would likely maintain some contact (at least indirectly) with area advocacy groups. This contact could include checking social media sites or receiving email blasts, and therefore these individuals would have received notification of this study and were eligible to participate.

It is important to consider that the majority of the study respondents have children with Down Syndrome who are relatively young; the study sample is skewed towards parents raising a young child with DS and there were far fewer participants whose disabled children were teenagers or adults. Due to problems which occur later in the lifespan of the person with Down Syndrome (such as transitioning to adulthood, and the onset of dementia) parents with older disabled children may feel differently, or feel that their perspectives have changed as their children have aged (Carling-Jenkins et al 2012, Dyke et al 2013, Evans et al 2013, Foley et al 2012).

While it could have been helpful to have a more even distribution in the children's age ranges among study participants, the fact that most of the study respondents had their disabled children within the last five years means that their recollection of their pregnancies is fresher and more emotionally vivid in their minds. Additionally, their experiences are more consistent with what contemporary mothers face. Because genetic testing and reproductive technology is a rapidly changing phenomenon, mothers of adult or teenaged children with Down Syndrome may not have faced the same challenges or had the same options as mothers to younger children. For example, one study respondent, a mother of two preschool aged children, said that her testing options were vastly different, although her pregnancies were only two years apart. As the study questions 
were about perceptions of the process as well as potential social consequences from that process, and not about direct personal experience, the perspectives of mothers to older children are still worthy of inclusion. However, I would assert that the study benefits from having a majority of study respondents whose pregnancies were more recent and therefore, more consistent with present circumstances.

The study sample was also heavily skewed towards mothers; it is possible that there are untapped sentiments more prevalent amongst fathers. There may also be a difference in parents of children with Down Syndrome and parents of children with other disabling conditions, especially conditions that are associated with greater behavioral problems or which primarily affect physical functioning (Hall et al 2012, King et al 2009, Pollard et al 2012). It is possible that there could be other characteristics or beliefs specific to my study participants, which were not made clear to me, which would not be common among other members of the same or similar populations.

As noted earlier, the literature indicates that parents, in general, tend to overemphasize positives experiences and emotions when discussing their children and their role as parents (Rizzo, 2013, Simon 2008). The informants in the present study did not report, as readily, the negative aspects of parenting their children with Down Syndrome, and they did not acknowledge that their own judgment could be clouded due to their abiding and unconditional love for their children. According to an article by Rizzo and others, Sharon Hays was the first to define the term "intensive mothering," which is often dominant in American culture and which includes, as two essential components, the ideology that mothering should be child-centered and that "children should be considered sacred, delightful, and fulfilling to parents" (2013:615). Due to this 
pervasive cultural dogma, parents in the present study might have been squeamish about sharing too many downsides to their parenting experience out of fear of being perceived as bad parents.

Again, the study results are not generalizable nor could I provide a statement of statistical significance in regards to these findings. However, according to Patton, qualitative studies are not judged by their statistical significance, but rather by their substantive significance (2002:467). Substantive significance can be assessed in four key ways. I will outline and respond to each of these four areas.

"How solid, coherent, and consistent is the evidence in support of the findings?" (467) I believe that the number and relevance of interview quotes, across all study respondents, attest to the clarity and consistency of the evidence I used to arrive at my findings. I noted where multiple parents expressed the same or similar ideas, and I noted where ideas might be outliers. I included quotes from the full range of parent perspectives to ensure that the data were adequately represented.

"To what extent and in what ways do the findings increase and deepen understanding of the phenomenon studied (verstehen)?" (467) Due to the open-ended questions in the interview guide, and the empathic neutrality I adopted in my stance as interviewer, I argue that the concept of verstehen was well employed in this study. Respondents were at liberty to share with me what defines the world they live in, rather than having to adapt their responses to pre-fixed questions or preconceived conclusions. I asked impartial follow-up questions, as necessary and appropriate, to better understand participants' responses and to allow them to clarify any points which were unclear, so 
that bias could not creep in on assumptions. I paid careful attention in my analysis of the data to what was said, how it was said, and also, what was not said.

"To what extent are the findings consistent with other knowledge?" (467) As discussed below, the participants in the present study share many common attributes with participants in other studies of a similar subject and nature. Several of the findings in this study, especially as relating to the testing and diagnoses experiences, are consistent with the findings in other research. Finally, the impressions and beliefs held by many of the study respondents have actual basis in the literature, lending credibility to their viewpoints.

Finally, "(t)o what extent are the findings useful for some intended purpose?" (Patton 2002: 467). This will be addressed in greater detail in the discussion section. However, I would like to note here that prenatal genetic screening and selective termination is a complex process which has been implemented in society relatively recently. It is certain that this process has an effect on who is born and who is not, but what is uncertain is how this will affect society over an extended period of time. Furthermore, although the perceptions about a power differential in the process and the predictions for a Down Syndrome-less society are presumptions, and not necessarily grounded in irrefutable fact, I would point to the sociological tenet of the Thomas theorem. "If men define situations as real, they are real in their consequences." If parents of children with Down Syndrome perceive a power struggle with physicians, and if they perceive threat to themselves and their families, how does this drive their beliefs, expectations, and actions, and what does this mean for themselves and others? In 
exploring these matters, the present study makes a significant contribution to the literature surrounding prenatal genetic screening and selective termination.

\section{Relation to the Literature}

As indicated above, much of the data resulting from this study is consistent with what others have denoted in the scientific literature. Many recent studies have revealed that parents experience joy in raising their children with Down Syndrome and that support from special needs communities and the greater social infrastructure is critical in bolstering their mental health and self-efficacy (Boyraz and Sayger 2011, Cantwell et al 2015, Huyard 2012, King et al 2009, Marshall et al 2014, Pillay et al 2012). Impressions of people with disabilities and what it means to raise a disabled child are often cultivated through media or other indirect means, which can cause the general public to develop expectations of the disabled which are not entirely in keeping with true and current lived experience (O’Brien 2011). Researchers have also reported that people with positive experiences with the disabled often express lower support for termination and more regret over the absence of such individuals in society (Antonak et al 1995, Lawson and WallsIngram 2010, Yazbeck et al 2004). Furthermore, researchers have uncovered a difference in what parents of disabled children would choose for themselves versus the rights and options they feel should be made available to all (Shepperdson 1983).

Other studies have examined the agency of the mother in the prenatal screening and diagnostic process, and they have revealed that oftentimes this process is dissatisfactory to expectant parents (de Groot-van der Mooren et al 2014, Goodwin et al 2015). Much like the respondents in the present study, parents have expressed frustration with the medical profession during their pregnancies, from feeling pressure to 
undergo genetic screening and diagnostic procedures, inducement to terminate, and blame if they refuse testing or termination. These experiences have led parents to feel that the lives of their disabled children are not valued, that their emotions and needs are ignored, and that doctors have an agenda to cull society of individuals with Down Syndrome, by means of prenatal genetic screening and selective termination. Each of these matters will be explored in turn.

As similarly reported by Bauer (2008), Boyraz et al (2011), Pillay et al (2012), and other researchers, the parents who participated in the present study expressed a strong sense of joy in raising their child with special needs. The pleasures and successes of their child-rearing experiences were largely emphasized, and the stresses and challenges were largely diminished, in their interview responses. Many parents seemed to echo the sentiment of Lisa, who said of the disorder, "It's just not that big of a deal. It's really not. And [my son] has brought so much joy to our lives and just a different perspective for our life." Several parents said that, in comparison to their other children, their child with Down Syndrome caused less them distress and daily struggle, due to the numerous other challenges that neurotypical children often face.

Where the difficulties lay for the average respondent was not within their disabled son or daughter, but in securing the appropriate rights and resources for their child to reach his or her potential. Their ability to parent well is dependent on their competence in initiating and obtaining the appropriate and necessary educational, medical, therapeutic, and social assets for their child. This means that their parenting experience does not exist in a vacuum, but is communally interwoven, both with other families 
raising a child with Down Syndrome, as well as with a number of other social institutions.

The existence of support and the ability to access it has an effect on parents raising a child with special needs (Cantwell et al 2015, Huyard 2012, King et al 2009, Marshall et al 2014). In a qualitative study, performed by King and others, on the belief systems of families of children with Down Syndrome, the researchers discovered that parents were not focused on "fixing their child" but rather, "(t)hey see their parenting role as one of creating a positive, tailored environment for their child- one that meets their child's needs" (2009: 58). Parents in the present study described their advocacy efforts and expressed their satisfaction, in large part, with the Medicaid waiver program, early intervention services, and the social networks available to them through the special needs community. However, they did express agitation with how hard they had to work within the educational system, to ensure their children were being integrated into the classroom and held to expectations which were commensurate with their neurotypical peers. They worried that, as their children aged, they would face more difficulty in ensuring they would receive rigorous educations, which could prepare them for independent adulthood, rather than being written off as incapable of higher learning and shunted into menial vocational training. This finding was mimicked in research by Dyke and others (2013) and Foley and others (2012). Again, parents worried that educational resources would decline in tandem with the number of individuals needing and demanding them.

Parents were plagued by their fear that society holds archaic impressions concerning the disorder of Down Syndrome and that the disdain of others would negatively affect their children. As Amber said, “Especially as abortion's happening, it 
makes them seem as though they're not valued. And that they're less than others. And I don't think that's fair. And to walk around and have that idea about themselves, that's sad." They repeatedly insisted that the public (and expectant couples) should be informed as to the true reality of Down Syndrome and they believed that the public's opinions of disabled people would improve as a result. There is research to support this impression. In accordance with intergroup contact theory, Lawson and Walls-Ingram found that "high-quality" personal contact with individuals who have Down Syndrome was related to more positive attitudes toward them (and less willingness to terminate in the hypothetical event of prenatal Down Syndrome diagnosis) (2010). "High quality" in this study was defined as an emotionally close and personally comfortable relationship. In addition, participants reporting such comfortable personal relationships "perceived significantly more personal enrichment or psychological rewards (e.g. happiness, enjoyment, fun, pride) inherent in [hypothetically] parenting a child with DS" than those who did not (2010:570). Yazbeck, McVilly, and Parmenter uncovered the same trend in their study of Australian students, disability service professionals, and members of the general population. "Respondents reporting prior personal knowledge of a person with intellectual disabilities consistently indicated that they held more positive attitudes [towards them] than did respondents without such knowledge" (Yazbeck et al 2004:108). Researchers have further discovered a relationship between previous contact with disabled individuals and attitudes towards selective abortion.

Participants in the present study said, time and again, that if expectant couples had the opportunity to speak with parents like themselves, as well to meet a child with Down Syndrome, they would gain a better appreciation for the gifts of raising a child 
with the condition and would be less likely to consider terminating their pregnancy. As Nicole said, "I feel like if they knew enough about people with Down Syndrome, they might not do it." This belief is also supported by the literature. Studies suggest that the presence of prior, positive relationships with individuals with disabilities correlates with lower willingness to abort for Down Syndrome. Antonak and others found in their study of university students that "endorsement of eugenic principles was inversely related to [...] familiarity with people with mental retardation" (323:1995). Their study also showed that general members of the public are not cognizant of the subtle gradations of impairment characteristic of the condition of DS, but rather consider only two classifications of cognitive impairment, mild and severe. Bell and Stoneman discovered that those who held more positive attitudes toward individuals with Down Syndrome were less likely to choose abortion in a hypothetical situation (2000). Researchers have also conducted studies showing a lower willingness to abort a fetus diagnosed with Down Syndrome among mothers who already have a child with Down Syndrome (Elkins et al 1986), as well as among female siblings of people with Down Syndrome (Bryant et al 2005).

As stated in the results section, although study respondents did not ethically support selective termination for the condition of Down Syndrome, and stated they would not have chosen termination in their own pregnancies, they did support the legal right of a woman to make choices over her own body, which includes prenatal genetic screening and abortion. A father named Michael from the present study said, "I think it's a woman's choice, whether it's termination or not termination. It's her body. [...] With the government and everything else, they need to butt out of it $[\ldots]$ " Regarding a woman 
seeking prenatal genetic testing, Andrea (who stated she is pro-life) said, "That's her right. I wouldn't judge her for that right or for exercising that right. But it's not something that I would recommend." This was in accordance with the findings of Shepperdson, that although the majority of parents believe that abortion due to Down Syndrome is unethical, they support the rights of others to make that choice for themselves (1983).

Several of the parents in the present study reported their exasperation with the medical professionals they engaged with during pregnancy. They reported feeling pressure to undergo intrusive screening tests (such as amniocentesis), after less invasive screening tests suggested the possibility of Down Syndrome, and in subsequent pregnancies. One parent was repeatedly given the option to terminate her pregnancy at every prenatal appointment, until it was no longer legal. According to Barbara Katz Rothman, "Women who choose not to have amniocentesis are often at odds with the expectations of their own medical providers" (1993: 63) and that "(d)oing the unexpected requires people to be ready to account for themselves, to defend and explain the reason for their actions" (1993:65). Several authors, such as Barbara Katz Rothman and Rayna Rapp, have researched extensively and written books about prenatal testing and selective abortion. They report that some expectant mothers and their partners feel spurned and de-humanized when obstetricians and genetic counselors prioritize testing and termination over the feelings and beliefs of their patients (Ettorre 2002, Rapp 1999, Rothman 1993,). A comprehensive review of the literature reveals that the experiences of my study respondents are not uncommon in the world of genetic screening and counselling. 
In addition, prior research has revealed that many parents, much like the respondents in the present study, are unhappy with their diagnosis experiences. For example, both Christopher and Rachel reported negative interactions with their child's medical team at the time their child was diagnosed. Goodwin and others conducted a study on 559 parents and caregivers of children with genetic developmental disorders, and claimed that, "Across all groups parents reported that the diagnosis experience was negative and often accompanied by a lack of support and appropriate information" (2015: 474). In another study of Australian mothers of children with Down Syndrome, researchers found that, "These mothers described their dissatisfaction with the approach of the medical professionals who delivered their child's diagnosis. They felt that the medical staff were not emotionally equipped to handle such a task and were very blasé or clinical in their approach" (Pillay et al 2012:1503). Skotko reports that, "Mothers from the USA, Spain, and the Netherlands who have received a prenatal diagnosis of DS and chose to continue their pregnancies have indicated that their physicians often provided incomplete, inaccurate, and, sometimes, offensive information about DS" (2009: 824). Again, many of the responses from the present study are accordant with what has been suggested in the wider literature, concerning the process of genetic screening and selective abortion for Down Syndrome.

\section{$\underline{\text { Unanticipated Results }}$}

Where the present data diverges from the existent literature is in the exploration of perception of threat, resulting from a hypothetical decline in the Down Syndrome birth rate, and the association between this perception of threat and the perception of the role of the obstetrician. While it cannot be known for certain if any of the projected 
consequences of a reduction in the number of individuals with Down Syndrome would come to fruition, the fact that parents perceive and predict these consequences is worthy of examination. Not only does this allow us a unique insight into the power structure of prenatal screening as conceptualized by parents, but it also allows us a glimpse into the power structure of the Down Syndrome community within society at large.

This discussion of the findings will center around four primary ideas. First, parents have not internalized society's norms when it comes to their disabled children. In fact, this community could be considered a counterculture, in that they reject the standard norms of society and actually wish to uproot and replace those norms. Secondly, as birthrates decline, advocacy groups, and their power to supplant social norms, are decreased and diminished. Because of this, whoever holds the power of influence over expectant parents (who will give birth to future individuals with Down Syndrome) has the ability to shape the presence of Down Syndrome in society. This leads to the third point, that respondents perceive a power struggle, between the physicians and themselves, over the expectant parents who receive a prenatal diagnosis of Down Syndrome in their fetuses. Study data reveals that those who characterize the physicians as the most villainous are also those who fear the most for the future, and who feel that they and their families have much to lose. Finally, through their voices and actions, many of them are leveraging a social resistance against abortion for the condition of DS. However, due to the extensive web of knowledge and power influences in the sphere of reproductive technology, and the historical trends of selective termination for the condition of Down Syndrome, it is difficult to determine whether this resistance will be successful. 
A number of questions were posed, prior to conducting the study, which laid out the investigational framework for the interviews. These questions were as follows: Does cognitive dissonance occur for those who feel that the lives of their children (whom they dearly love) are devalued by society, or, as Foucault would argue, have these social norms been internalized? Do their statements reflect or refute a discord between the assumption of suffering and the genuine physical, social, and cognitive capacity of those with the condition? According to participants, who does and who should hold the bulk of the power in the decision making process when Down Syndrome is suspected? How do respondents perceive a society in which fewer or more children like their own are born?

In response to the first question, and to expound on the first point of discussion, it does not appear that the majority of respondents experience cognitive dissonance in terms of how they assess their children versus what they think society expects of them and their families. They do not share the same opinions on the lives of their children as they suspect society does. Rather, they outright renounce others' opinions and place their own as preeminent. A popular bromide comes to mind, first spoken in a 1984 film and repeated by television personality Adam Savage on the show Mythbusters, "I reject your reality and substitute my own." This concept moves beyond mere dismissal of others' ideas and expertise, as simply wrong or unworthy of much time or attention. The rejection of someone's "reality" extends to thoroughly discarding that other person's entire viewpoint, such that their opinions, experiences, knowledge and beliefs have no ontological basis whatsoever, and should be regarded as fully without substance, merit, or validity. 
Study respondents' dismissal of others' perspectives on the condition of Down Syndrome includes society at large and, more specifically, obstetricians and genetic counselors. Lisa said, if you don't personally have a child with Down Syndrome, "You can't really fathom it, you can't understand it." As Christopher said, and quoted above, doctors “just know what they’ve read, they haven't experienced” Down Syndrome. Michelle went so far as to state that even those who have formal employment with Down Syndrome advocacy groups, or those who professionally research and study the condition and the lives of people who have it, cannot truly know the condition. Therefore, they should not be in the position of speaking with expectant parents. She expressed to me, "You, yourself, are doing a study, you don't have a child with Down Syndrome. So just because somebody works at [local Down Syndrome advocacy group] doesn't mean they have a child with Down Syndrome. So they can't even provide the perspective [...]" on Down Syndrome, that an actual parent can provide. No credible frame of reference in regards to Down Syndrome exists aside from that of the parent, according to most study respondents.

As such, parents perceive themselves and their communities less as a subculture, and more as a counterculture. To Heather, people who choose to continue their pregnancies after a diagnosis of a disability are rebels. As she expressed, "My husband and I almost feel like, there's really almost nothing more rebellious you can do these days, than to knowingly have a child with a disability." To Melissa, children with Down Syndrome are the standard, everyone else is impaired in some way, and people who have children with DS have been hand-picked to raise them because of their own exceptional attributes. "I know that God only gives special kids to special people," said Melissa. 
"Really, we're the disabled ones, they're not." Several parents characterized their children with Down Syndrome as spiritually superior and otherworldly. Rachel said, "I like to joke that that extra chromosome that he was blessed with, and it truly is a blessing, is a little piece of heaven left over that the rest of us don't get. And it's true. Like he is an absolute angel and a blessing to every single person that he meets." Although many parents insisted that their disabled children were kids like any other, they also often made statements which seemed to set themselves, their children, and the Down Syndrome support groups apart.

The norms of greater society have not been internalized by these study participants, as Foucault might assume, but one could argue that the social norms of the support groups have been absorbed. The themes of nobility in advocacy, strength in numbers, and the surreal, often seraphic descriptors of children with Down Syndrome came up repeatedly throughout the study interviews. These themes also arise on the Down Syndrome advocacy group websites, to which participants frequently referred me. Parents of children with Down Syndrome and their support groups create and contribute to a shared vision of the condition that they then present to the world.

Yet, there is a sensation of strain between parents' fervent love for their children and their fear that their child's position in the world is immensely vulnerable. As befits their status as comrades in a counterculture, many parents described distinct threats to their children, family, and support groups, that were not faced by others outside their social system. Some of these threats stem from genetic testing methods, which singles out Down Syndrome and a few other disorders, but which cannot identify the bulk of disabling conditions which may afflict a fetus. (As reported by Acharya in 2009, 90\% of 
intellectual disability is due to causes other than Down Syndrome.) Many parents felt that their lives and the lives of their children are threatened and devalued if fetuses with Down Syndrome are uniquely identified and targeted for elimination. They also fear that the longevity and success of advocacy groups working on their behalf is tenuous and dependent on fluctuating factors, such as membership size. Because of this fear, it seemed at times that some of their statements belied a sense of desperation, that Down Syndrome be viewed only in a positive light, as if admitting any challenges would lend credence to the opinions of their opponents.

Parents and advocacy groups feel they must remain united and continue to approach and influence others by way of outreach and lobbying efforts. They strive to increase the opportunities for members of general society to experience close and mutually rewarding relationships with Down Syndrome and to understand the "reality" of Down Syndrome, as they define it. They work to ensure that expectant parents can reach out to them for information, guidance, and support at a difficult time in their lives. Yet, the advocacy groups themselves may suffer from a decreasing number of people born with the condition, if study respondents' predictions are accurate. According to Michelle (as partially quoted above), if fewer people are born with Down Syndrome,

I think there's less money for people and lobbyists advocating for them, whether it's Medicaid, whether it's IDEA, the department of education. There will be less advocating for them to be accepted and included, less advocating for them to have employment opportunities and fair housing opportunities. Local chapters would have to eventually close up [...] Just less social opportunity, more isolation, for the person with Down Syndrome and their families.

If what Michelle forebodes is true, then advocacy groups could be facing an uphill battle. If the continued inclusion of people with Down Syndrome in society is indeed 
dependent upon a steady influx of new members to the fold, then the recent advances in prenatal genetic testing for Down Syndrome could potentially have drastic consequences for this community. Already, the number of people born with Down Syndrome is decreasing. According to Brian Sotko, of the Children's Hospital of Boston,

Birthing trends worldwide suggest that women are waiting longer to have children. Because advanced maternal age is associated with increased chances of having a child with DS, the birth incidence of DS would have been expected to climb. However, the worldwide birth incidence of DS has actually decreased from what it could have been by $2-18 \%$ per year. For example, in the USA, there would have been a 34\% increase in the number of babies born with DS between 1989 and 2005 , in the absence of prenatal testing. Instead, there were $15 \%$ fewer babies born, representing a $49 \%$ decrease between the expected and observed rates. [...] Trends like these, in the USA, UK, and abroad, are mostly attributable to the availability of prenatal testing and maternal preference for selective termination. (2009: 823)

This decline was already taking place, prior to the changes in screening recommendations made by the American College of Obstetricians and Gynecologists and prior to the development of the NIPT. Until 2007, screening procedures were not universally recommended, nor were they made available to all segments of the pregnant population. At that point, more women began undergoing prenatal screening because it was suddenly being offered to all. Egan and others noted, in their 2011 study, "most of the recent increase in the utilization of prenatal diagnosis occurred in women 15 to 34 years old" (2011:393). This means that more fetuses with Down Syndrome were and will be identified, and more mothers will face the option to terminate. This trend accelerates even faster with the recent development of the NIPT, the genetic screening test which uses a sample of blood drawn from the mother to identify the presence of chromosomal abnormalities in a fetus. 
Skotko asserts that, due to three distinct factors, the number of infants born with Down Syndome can be reasonably expected to continue to decline (2009). The first factor is that the NIPT testing is conducted earlier in the pregnancy than previous diagnostic techniques, so that expectant mothers can choose to terminate before their pregnancies are known to others. The second factor is that the NIPT is far less invasive, less costly, and the blood for the test can be drawn at the same time that other routine labwork is performed. This makes the NIPT less aversive to pregnant women than the pricey, invasive, painful, and time-consuming procedures of amniocentesis and CVS. This is supported by data referenced by Acharya, (acquired in a 2001 study done by Halliday and others), which indicated that " $82 \%$ of women who refused amniocentesis would agree to noninvasive prenatal testing, regardless of their stance on abortion" (2011: 30). The third factor identified by Skotko is that the test will be made available to all women, not just women who are at high-risk for Down Syndrome or whose previous test results raise suspicion. There will be far fewer women "falling through the cracks" of testing, (as it was described by several of my study respondents).

It is possible that women will still elect to continue their pregnancies even after a diagnosis of Down Syndrome, and that their acquiescence to the NIPT will simply be for informational and preparative purposes. However, the literature shows a high willingness to abort for fetuses diagnosed with disabilities, especially with the condition of Down Syndrome. Kuppermann and others conducted a study which demonstrated pregnant women preferred to have a miscarriage of a neurotypical child provoked by a screening procedure than to have a child with Down Syndrome (2004). In addition, $76 \%$ of pregnant women accepting a recommendation to undergo amniocentesis in Montana 
"said the most important consideration was knowing if the fetus had Down Syndrome" (Priest et al 1998). All of the women choosing amniocentesis in that study expressed concern over the possibility of the fetus having Down Syndrome, as well as concern for their own lack of ability to provide adequate care to such a child. In a similar study, Learman and others found that $76.3 \%$ of pregnant women at less than twenty weeks' gestation supported abortion for Down Syndrome, $73.2 \%$ supported abortion for unspecified mental disability and 70.3\% for unspecified physical disability (2005).

When looking at actual rates of termination for DS, the percentages are even higher. Historically speaking, “(i)t is estimated that $85 \%$ to $90 \%$ of pregnancies in which Down Syndrome is diagnosed end in abortion" (Bauer 2008: 247). According to Skotko, "In an international meta-analysis using data from the USA, UK, New Zealand, France and Singapore, approximately $92 \%$ of women who receive a definitive prenatal diagnosis of DS choose to terminate their pregnancies" (2009: 823). Whether these statistics hold steady remains to be seen, but enough longitudinal data exists that it could be considered a safe assumption. It is hard to imagine that, in the future, a vast majority of the women will lack the motivations or resist the pressures that, at present, cause almost every woman who receives a diagnosis of Down Syndrome during her pregnancy to abort.

Again, many study respondents felt that a decrease in the number of babies born with Down Syndrome would endanger the ability of advocacy groups to secure rights and resources for their children. So if these parents feel vulnerable to threat, it begs the question, who is it exactly, in their minds, that's threatening them? As queried prior to the study, who do parents of children with Down Syndrome think holds the power in the prenatal screening process and who should hold this power? If some intervention is 
necessary to stem the tide of selective abortion, who can intervene, and how? In the minds of study participants, who has the power to change the course of the Down Syndrome community and spare it from the fate of extinction?

It certainly seems from the interview responses that physicians could be one group wielding the scepter. Participants' responses alluded to the idea that at least some of them initially put their faith in the expertise and guidance of their obstetricians. However, with time, the majority of study respondents found that their personal beliefs and objectives ran counter to those of the medical doctors. This impression was developed through their own experiences and/or through learning of the experiences of others. Therefore, they rejected the physician and put forth themselves as the ultimate authority instead. This suggests that participants still believe in the necessity of a power hierarchy in prenatal screening. Expectant couples should rely on the guidance of others, independent of their own agency, to discern the correct trajectory of their pregnancies. However, the authority of parents raising a child with Down Syndrome is hegemonic in this hierarchy, rather than the authority of the physicians.

This is somewhat consistent with Foucault's theory of biopower, which was presented as a sensitizing concept, informing the collection and analysis of this study's data. I wrote above (in the theoretical perspective section), that as geneticists and physicians advanced their crafts, vast realms of knowledge developed but remained largely within their sphere of control. Prospective parents had no option but to turn to their physicians for information and advice about the health and well-being of their pregnancies and infants. This is compatible with the present study, as many participants do see the physician as holding the majority of the power in the prenatal screening 
process. As Amanda stated, the words of the physician "are the words [expectant parents] are going to be hearing first, upon hearing that diagnosis or possible diagnosis." In the opinions of parents like Andrea, who said the medical community "is frequently biased towards a negative view," obstetricians are portraying Down Syndrome as an incontrovertible hardship, best to be avoided. Therefore, it is understandable that advocate parents would distrust them and wish to downgrade their position of power.

Furthermore, it could still be said that reproductive technology and prenatal decision-making is under "knowledge's field of control and power's sphere of intervention" (Foucault, 1978:142). The influence of knowledge and power in the prenatal screening process is fairly undeniable, as evidenced by research into the process (Bosk 1992, Rapp 1999, Rothman 2007). Testing and termination options have to be known and understood (at least on a basic level) to be exercised. These options are only available through the medical profession; pregnant mothers cannot choose to receive genetic testing or terminative services without involving a physician.

However, according to Ettorre, “(k)nowledge of reproductive genetics is developed in networks by a multiplicity of actors who have their own knowledge interests concerning the role of genetics in our bodies, lives, and societies" (2002:42). This knowledge is not centralized to one institution or profession. Knowledge is now created and vastly diversified through print and digital media. Expectant parents can access a limitless bounty of expertise and experience through both tangible material and online, and they can take the initiative to educate and inform themselves, if they so choose. This, again, moves beyond Foucault's vision of the physician as being the sole possessor of the knowledge parents need to make an informed decision. Parents are not 
reliant upon their obstetrician, or any other expert, to advise and define the process for them. And one could argue that with transfer of knowledge comes the potential for transfer of power.

Study participants are aware of the various avenues for the acquisition of information. For example, Heather described her observations of message boards on popular websites, where parents commiserate and console each other over their reproductive decisions. She asserts that women are informed of available testing and are electing to undergo it, for their own ends. Many participants in the present study said that expectant parents should read books or go online and learn for themselves, and not depend on the physician as their sole source of information. Danielle said, "Google it. [...] They say, everybody googles their life, well, this time, Google it. And get informed."

Because of the more equitable saturation of knowledge throughout different segments of society, there is a wresting of control away from the "medical expert" and a re-defining of the hierarchy of power in the prenatal genetic screening and selective termination process. Perhaps knowledge can be seized and norms transformed. I would argue that, based on present study data, it is in this power struggle that parents of children with Down Syndrome and DS advocacy groups are eager to mount a resistance and interject their voices. Respondents insisted that physicians should have pregnant mothers watch advocacy videos, give them books, pamphlets, and brochures, connect them with people they may know who have Down Syndrome, and refer them to advocacy groups, thereby shifting the influence away from the physicians and towards themselves, at the point that Down Syndrome is diagnosed. 
To that aim, advocacy groups have successfully fought for their viewpoints to be heard during the process of prenatal genetic screening, by way of state laws that require their information to be disseminated to pregnant mothers. The law (in the states of Kentucky and Indiana) requires pamphlets from these advocacy groups to be given to expectant parents at the time the diagnosis or likelihood of diagnosis is disclosed to them. Indiana law mandates the following criteria for this material: "The information includes a brief description and contact information for state and local advocacy organizations that advocate for people with intellectual and other developmental disabilities, including Down Syndrome and other conditions diagnosed prenatally.” Kentucky state law obligates health professionals to provide patients with "contact information regarding support programs and services for expectant and new parents of children with Down Syndrome, including [...] national and local Down Syndrome organizations such as Down Syndrome of Louisville, Down Syndrome Association of Central Kentucky, Down Syndrome Association of South Central Kentucky, Green River Area Down Syndrome Association" and others.

However, due to the complexity inherent in social norms surrounding pregnancy, birth, and parenting, mounting a successful resistance against selective abortion for Down Syndrome may require more than printing up pamphlets. As noted by Rothman (1993), Rapp (1999), Bosk (1992), and others, reproductive rights and "freedom of choice" are not always as they seem. This can explain why envisioning the physician as the ultimate authority, (whose rule can be overthrown), may be an oversimplified understanding of the power structure in reproductive technologies. This is also where others' more 
contemporary work could be seen as an appropriate adjunct to the theories of Michael Foucault.

As Barbara Katz Rothman states, in the United States, (ideologically speaking), a woman cannot be forced to continue pregnancies she doesn't want, nor can she be forced to abort pregnancies she does. However, she states,

This does not mean that women are not forced by circumstance into these very situations and eventualities. It only means that the society will not use the official power of the state to force her. Women are in fact prevented from having abortions they might want by family pressure, by economic circumstances, by religious and social pressures. And women are forced into having abortions they might not want to have because of poverty, because of lack of services for children and mothers, because of lack of services for disabled children and adults. By offering amniocentesis to identify fetuses who would have disabilities, and by cutting back on services for disabled children and their families, we effectively force women to have selective abortions. (390)

It is true that the state, at present, lacks jurisdiction over the bodies of women, as Foucault and Rothman discuss, and rightfully so, according to study respondents. However, social norms surrounding disability are prevalent throughout society, and do not necessarily have to be propagated by the physician to reach the populace. I would argue that it is the vast and complex array of norms and social circumstances that Rothman describes that must truly be changed, if Down Syndrome advocacy groups are to be successful in largely abolishing selective termination for the condition. This could be an immensely complex, difficult, and time-consuming undertaking. It is beyond the scope of the present study, or even this discussion, to do justice to the myriad of ways that social norms are created or demolished. But suffice to say, again, these norms are not isolated to the physicians nor are they easily rendered obsolete. 
In closing, advocacy groups in the area can now rest assured that their contact information will be passed along at the time expectant parents receive the news that their child will likely have Down Syndrome. This is one victory for the advocate parents in their power struggle with physicians over the influence on expectant parents. Undoubtedly, advocacy groups will continue their forays into wider society, with fundraisers, outreach, and awareness endeavors. However, are their efforts sufficient to curtail the present trends in selective abortion, especially in the wake of the advent of the NIPT?

It seems that our society has found itself at a significant crossroads in that, as Bauer says,

[...] the historical moment in which science has become really proficient in detecting Down Syndrome prenatally is exactly the moment in which those who have intellectual disabilities have begun to benefit from political and social forces like early educational intervention, inclusion, improved healthcare, and better educational opportunities and are doing better than ever before. (2008: 247)

It cannot yet be known exactly how this advancement in reproductive technology will be used, by whom, and for what end, and how the scientific information now at our fingertips will intersect with inevitable human fallibility and social prejudice. Already, physicians face the possibility of wrongful birth lawsuits from mothers who give birth to a child with Down Syndrome (Howlett et al 2002, Silva 2011). Will doctors face increased pressure to coerce their patients into testing and termination, due to the growing number of testing options and the possibility of being drawn into litigation concerning babies born with Down Syndrome? How will mothers react, if they eliminate their fetus with Down Syndrome, only to have another child that suffers from a different intellectual 
disability? Where will people with Down Syndrome find kinship and camaraderie in a world that has eradicated them? Will Down Syndrome eventually be eliminated, or is it true, as Heather said, that "( $\mathrm{t}$ )here will always be people who choose to have a child with Down Syndrome"? In a society where disability is deemed "electable," what responsibility could social welfare programs, insurance companies, and communities at large hold for the well-being of these citizens? Finally, how are these life and death decisions made, and by whom? The answers to these questions could speak volumes about our society's definition of life, humanity, and the progression of our species, to the benefit of some and the detriment of others.

\section{$\underline{\text { Suggestions for Further Research }}$}

There are a number of areas where continued research is needed, to guide the development of public policy. It is clear from present study data, and other studies which have been conducted, that many parents find the diagnosis and disclosure experience dissatisfactory. Several researchers have outlined steps physicians can take at the time of diagnosis, which can help to ensure that expectant couples are in receipt of balanced, accurate information concerning the condition of Down Syndrome (Bosk 1992, Skotko 2009, van Vliet et al 2001). These researchers have uncovered inconsistencies in the recommendations made by those in the medical profession, regarding genetic tests and screening results, and this is troubling. Whether these inconsistencies result in systematic or unfounded biases against certain racial, disability, or other minority groups remains unclear at this time, and further research into this matter seems warranted. Given the complexities of human cognition, communication, and interpersonal interaction, such 
biases seem unavoidable, in the absence of global standardization, routinization, and established science in the practice of genetic counseling.

In addition, it is not known at present how best to train physicians and their staff in effective and equitable communication techniques, and how often training should be updated to incorporate new testing technologies and the health and lifestyle gains attained by individuals with various disabilities. Nor is it known if a standardized guide can be truly sensitive to the many cultural, spiritual, and personal differences which exist among mothers of various demographic and regional characteristics. More research should certainly be conducted in these areas.

Finally, while the present study illuminates some important perspectives in the realm of prenatal genetic screening and selective termination, especially as it relates to Down Syndrome, there are many other areas which remain unexplored or insufficiently explored. For example, it would be advisable to examine physician compliance with the laws concerning the distribution of advocacy material at the time of diagnosis, as these laws are fairly new to the states of Kentucky and Indiana. It would also be prudent to collect data on how many expectant couples are reading this material, and using the contact information they have been provided to reach out to advocacy groups and families raising a disabled child. It would be extremely helpful to know if expectant couples are incorporating this material (and any interpersonal contact they receive) into their decision-making process, and, furthermore, if this has any influence on their decision to terminate or continue their pregnancies. 


\section{REFERENCES}

Acharya, Kruti. 2011. "Prenatal Testing for Intellectual Disability: Misperceptions and Reality with Lessons from Down Syndrome." Developmental Disabilities Research Reviews 17: 27-31.

American College of Obstetricians and Gynecologists. "Prenatal Genetic Diagnostic Tests." Fact Sheet. American College of Obstetricians and Gynecologists. Washington, D.C. 2016. Web.

Antonak, R.F., J.A. Mulick, F.H. Kobe, and C.R. Fielder. 1995. "Influence of Mental Retardation Severity and Respondent Characteristics on Self-Reported Attitudes toward Mental Retardation and Eugenics." Journal of Intellectual Disability Research 39(4): 316-325.

Armstrong, Elizabeth A. and Mary Bernstein. 2008. "Culture, Power, and Institutions: A Multi-Institutional Politics Approach to Social Movements." Sociological Theory 26(1): 74-99.

Aronowitz, Robert. 2008. "Framing Disease: An Underappreciated Mechanism for the Social Patterning of Health." Social Science and Medicine 67(1):1-9.

Bauer, Patricia E. 2008. “'Tell Them It's Not So Bad': Prenatal Screening for Down Syndrome and the Bias Toward Abortion." Intellectual and Developmental Disabilites 46(3): 247-251.

Bell, Martie and Zolinda Stoneman. 2000. "Reactions to Prenatal Testing: Reflection of Religiosity and Attitudes toward Abortion and People with Disabilities." American Journal on Mental Retardation 105(1): 1-13.

Benn, Peter A. 2002. "Advances in Prenatal Screening for Down Syndrome: II First Trimester Testing, Integrated Testing, and Future Directions." Clinica Chimica Acta 324: $1-11$.

Bosk, Charles. 1992. All God's Mistakes: Genetic Counseling in a Pediatric Hospital. University of Chicago Press: Chicago, IL. 
Boyraz, Guler, and Thomas V. Sayger. 2011. "Psychological Well-Being among Fathers of Children With and Without Disabilities: The Role of Family Cohesion, Adaptability, and Paternal Self-Efficacy." American Journal of Men's Health 54(4): 286-296.

Bryant, Louise. 2014. "Non-Invasive Prenatal Testing for Down's Syndrome: Psychologically Speaking, What Else Do We Need to Know?" Journal of Reproductive and Infant Psychology 32(1): 1-4.

Bryant, L., J.D. Hewison, and J.M. Green. 2005. "Attitudes towards Prenatal Diagnosis and Termination in Women Who Have a Sibling with Down's Syndrome." Journal of Reproductive and Infant Psychology 23(2): 181-198.

Cantwell, J. O. Muldoon, and S. Gallagher. 2015. "The Influence of Self-Esteem and Social Support on the Relationship between Stigma and Depressive Symptomology in Parents Caring for Children with Intellectual Disabilities.” Journal of Intellectual Disability Research 59(10): 948-957.

Carling-Jenkins, Rachel, Jennifer Torr, Teresa Iacono, and Christine Bigby. 2012. "Experiences of Supporting People with Down Syndrome and Alzheimer's Disease in Aged Care and Family Environments." Journal of Intellectual and Developmental Disability 37(1): 54-60.

Check Hayden, Erika. 2014. "Prenatal-Screening Companies Expand Scope of DNA Tests." Nature 507: 19.

Choi, Hyunkyung, Marcia Van Riper, and Suzanne Thoyre. 2012. "Decision Making Following a Prenatal Diagnosis of Down Syndrome: An Integrative Review." Journal of Midwifery and Women's Health 57: 156-164.

Cole, Peter. 1999. "The Structure of Arguments Used to Support or Oppose Inclusion Policies for Students with Disabilities." Journal of Intellectual \& Developmental Disability 24(3): 215-225.

de Groot-van der Mooren, M.D., R.J.B.J. Gemke, M.C. Cornel, and M.E. Weijerman. 2014. "Neonatal Diagnosis of Down Syndrome in the Netherlands: Suspicion and Communication with Parents." Journal of Intellectual Disability Research 58(10): 953961.

Dixon, Darrin. 2008. "Informed Consent or Institutionalized Eugenics? How the Medical Profession Encourages Abortion of Fetuses with Down Syndrome." Issues in Law and Medicine. 24: 3-59.

Dyke, Paula, Jenny Bourke, Gwynnyth Llewellyn, and Helen Leonard. 2013. "The Experiences of Mothers of Young Adults with an Intellectual Disability Transitioning from Secondary School to Adult Life.” Journal of Intellectual and Developmental Disability 38(2): 149-162. 
Egan, James F.X., Kathleen Smith, Diane Timms, Jay M. Bolnick, Winston A. Campbell, and Peter A. Benn. 2011. "Demographic Differences in Down Syndrome Livebirths in the US from 1989 to 2006." Prenatal Diagnosis 31: (389-394).

Elkins, Thomas E., Thomas G. Stovall, Sidney Wilroy, and John V. Dacus. 1986. "Attitudes of Mothers of Children with Down Syndrome Concerning Amniocentesis, Abortion, and Prenatal Genetic Counseling Techniques." Obstetrics and Gynecology 68(2): 181-184.

Ettorre, Elizabeth. 2002. Reproductive Genetics, Gender and the Body. Routledge: New York.

Evans, Elizabeth, Anjali Bhardwaj, Henry Brodaty, Perminder Sachdev, Brian Draper, and Julian N. Trollor. 2013. "Dementia in People with Intellectual Disability: Insights and Challenges in Epidemiological Research with an At-Risk Population." International Review of Psychiatry 25(6): 755-763.

Faubion, James D. ed. 1994. Essential Works of Foucault. Vol. 3. New York: The Hew Press.

Feder, Ellen. 2007. "The Dangerous Individual('s) Mother: Biopower, Family and the Production of Race.” Genealogies 22(2): 60-78.

Fidler, Deborah J., Robert M. Hodapp, and Elisabeth M. Dykens. 2000. "Stress in Families of Young Children with Down Syndrome, Williams Syndrome, and SmithMagenis Syndrome.” Early Education and Development 11(4): 395-406.

Fish, Kim and Qadoshyah, ed. 2008. Down Syndrome: What You Can Do. Qadoshyah Fish.

Foley, K.R., P. Dyke, S. Girdler, J. Bourke, and H. Leonard. 2012. "Young Adults with Intellectual Disability Transitioning from School to Post-School: A Literature Review Framed within the ICF." Disability and Rehabilitation 34(20): 1747-1764.

Foley, Simon. 2014. “A Foucauldian Reading of Mothers' Views on the Paternalism/Autonomy Debate in Relation to the Sexual Practices of their Intellectually Disabled Adult Sons and Daughters.” Irish Journal of Sociology 22(2): 64-85.

Foucault, Michael. 1978. The History of Sexuality. Volume I: An Introduction. Vintage Books: New York.

Foucault, Michael. 1994. Power. Essential Works of Foucault 1954-1984. Volume 3. The New Press: New York. 
Galley, Ray. 2005. "Medical Management of the Adult Patient with Down Syndrome." JAAPA: Journal of the American Academy of Physician Assistants 18(4): 45-50.

Glidden, Laraine M. and Brian M. Jobe. 2006. "The Longitudinal Course of Depression in Adoptive and Birth Mothers of Children with Intellectual Disabilities." Journal of Policy and Practice in Intellectual Disabilities 3(2): 139-142.

Godin, Benoit. 2010. "Innovation without the Word: William F. Ogburn's Contribution to the Study of Technological Innovation." Minerva: A Review of Science, Learning and Policy 48(3): 277-307.

Goodwin, J., K. Schoch, V. Shashi, S.R. Hooper, O. Morad, M. Zalevsky, D. Gothelf, and L.E. Campbell. 2015. "A Tale Worth Telling: The Impact of the Diagnosis Experience on Disclosure of Genetic Disorders." Journal of Intellectual Disability Research 59(5): 474-486.

Greely, Henry T. 2011. "Get Ready for the Flood of Fetal Genetic Screening." Nature 469: 289-291.

Hall, Heather R., Susan L. Neely-Barnes, J. Carolyn Graff, Taylor E. Krcek, and Ruth J. Roberts. 2012. "Parental Stress in Families of Children with a Genetic Disorder/Disability and the Resiliency Model of Family Stress, Adjustment, and Adaptation." Issues in Comprehensive Pediatric Nursing 35: 24-44.

Hesse-Biber, Sharlene Nagy, and Patricia Lina Leavy. 2007. Feminist Research Practice. Sage Publications: Thousand Oaks, California.

Howlett, M.J., Denise Avard, and B.M. Knoppers. 2002. "Physicians and Genetic Malpractice." Medical Law 21: 661-680.

Hurwitz, Kathleen. 2008. “A Review of Special Education Law.” Pediatric Neurology 39: 147-154.

Huyard, Caroline. 2012. "Decision-making after Prenatal Diagnosis of a Syndrome Predisposing to Intellectual Disability: What Prospective Parents Need to Know and the Importance of Non-Medical Information." Journal of Intellectual and Developmental Disability 37(4): 315-323.

Khoshnood, Babak, Catherine De Vigan, Veronique Vodovar, Gerard Breart, Francois Goffinet, and Beatrice Blondel. 2006. "Advances in Medical Technology and Creation of Disparities: The Case of Down Syndrome.” American Journal of Public Health 96(12): 2139-2144.

King, Gillian, Donna Baxter, Peter Rosenbaum, Lonnie Zwaigenbaum, and Anita Bates. 2009. "Belief System of Families of Children with Autism Spectrum Disorders or Down Syndrome." Focus on Autism and Other Developmental Disabilities 24(1): 50-64. 
Kolker, Aliza and B. Meredith Burke. 1998. Prenatal Testing: A Socoiological Perspective. Bergin and Garvey: Westport, Connecticut.

Korenromp, Marijke J., Godelieve C.M.L. Page-Christiaens, Jan van den Bout, Eduard J.H. Mulder, and Gerard H.A. Visser. 2007. "Maternal Decision to Terminate Pregnancy after a Diagnosis of Down Syndrome." American Journal of Obstetrics and Gynecology 196: 149.e1-149.e11.

Kozma, Chahira. 1995. "Medical Concerns and Treatments." Pp 63-94 in Babies with Down Syndrome: A New Parents' Guide, $2^{\text {nd }}$ Ed., edited by K. Stray-Gunderson. Bethesda, MD: Woodbine House.

Kuppermann, Miriam, Robert F. Nease Jr., Elena Gates, Lee A. Learman, Bruce Blumberg, Virginia Gildengorin, and A. Eugene Washington. 2004. "How Do Women of Diverse Backgrounds Value Prenatal Testing Outcomes?" Prenatal Diagnosis 24: 424429.

Kuswa, Kevin, Paul Achter and Elizabeth Lauzon. 2008. "The Slave, the Fetus, the Body: Articulating Biopower and the Pregnant Woman." Contemporary Argumentation and Debate 29:166-185.

Lawson, Karen L. 2006. "Expectations of the Parenting Experience and Willingness to Consider Selective Termination for Down Syndrome." Journal of Reproductive and Infant Psychology 24(1): 43-59.

Lawson, Karen L. and Sheena A. Wall-Ingram. 2010. "Selective Abortion for Down Syndrome: The Relation Between the Quality of Intergroup Contact, Parenting Expectations, and Willingness to Terminate." Journal of Applied Social Psychology 40(3): 554-578.

Learman, Lee A., Eleanor A. Drey, Elena A. Gates, Mi-Suk Kang, A. Eugene Washington, and Miriam Kuppermann. 2005. "Abortion Attitudes of Pregnant Women in Prenatal Care.” American Journals of Obstetrics and Gynecology 192: 1939-1947.

Lombardo, Paul. 2008. Three Generations, No Imbeciles. The John Hopkins University Press: Baltimore.

Macey, David. 2009. "Rethinking Biopolitics, Race and Power in the Wake of Foucault." Theory Culture Society. 26: 186-205.

Mansfield, C., S. Hopfer, and T.M. Marteau. 1999. "Termination Rates after Prenatal Diagnosis of Down Syndrome, Spina Bifida, Anencephaly and Turner and Klinefelter Syndromes: A Systematic Literature Review." Prenatal Diagnosis 19(9): 808-812. 
Marshall, Eliot. 2013. "California Moves Shake Up Prenatal Gene Testing Market." Science 342: 680.

Marshall, J., J.P. Tanner, Y.A. Kozyr, and R.S. Kirby. 2014. "Services and Supports for Young Children with Down Syndrome: Parent and Provider Perspectives." Child: Care, Health and Development 41(3): 365-373.

McCoyd, Judith L. 2008. “'I'm Not a Saint': Burden Assessment as an Unrecognized Factor in Prenatal Decision Making." Qualitative Health Research 18(11): 1489-1500.

McCracken, Grant. 1988. The Long Interview. Sage Publications: Newbury Park.

McKinlay, John B., Deborah A. Potter, and Henry A. Feldman. 1996. "Non-Medical Influences on Medical Decision-Making." Social Science and Medicine 42(5): 769-776.

McWhorter, Ladelle. 2009. "Governmentality, Biopower, and the Debate over Genetic Enhancement." Journal of Medicine and Philosophy. 34: 409-437.

National Down Syndrome Society. "Down Syndrome Fact Sheet." National Down Syndrome Society. Web.

O'Brien, Gerald V. 2011. "Eugenics, Genetics, and the Minority Group Model of Disabilities: Implications for Social Work Advocacy." Social Work 56(4): 347- 354.

Patton, Michael Quinn. 2002. Qualitative Research Methods. $3^{\text {rd }}$ Ed. Sage Publications: Thousand Oaks, California.

Pernick, Martin S. 1996. The Black Stork: Eugenics and the Death of "Defective" Babies in American Medicine and Motion Pictures Since 1915. Oxford University Press: New York.

Pillay, Divia, Sonya Girdler, Marie Collins, and Helen Leonard. 2012. “'It's Not What You Were Expecting, but It's Still a Beautiful Journey': The Experience of Mothers of Children with Down Syndrome." Disability and Rehabilitation 34(18): 1501-1510.

Pollard, Corey A., Carolyn McNamara Berry, Brian H. Freedman, and Beth A. Kotchick. 2013. "Relationship Quality as a Moderator of Anxiety in Siblings of Children Diagnosed with Autism Spectrum Disorders or Down Syndrome." Journal of Child and Family Studies 22: 647-657.

Pollock, Anne. 2003. "Complicating Power in High-Tech Reproduction: Narratives of Anonymous Paid Egg Donors.” Journal of Medical Humanities 24: 241-263.

Priest, Jean H., Joan M. Fitzgerald, Mary M. Haag, Karen Streets, Marie Vanisko, and John P. Johnson. 1998. "Acceptance of Amniocentesis by Women in the State of 
Montana Who Are Screen Positive for Down's Sydrome.” Journal of Medical Screening 5: 178-182.

Rapp, Rayna. 1999. Testing Women, Testing the Fetus. Routledge: New York.

Richmond-Rakerd, Leah S. 2013. "Modern Advances in Genetic Testing: Ethical Challenges and Training Implications for Current and Future Psychologists." Ethics and Behavior 23(1): 31-43.

Reilly, Deirdre E., Richard P. Hastings, Frances L. Vaughan, and Jaci C. Huws. 2008. "Parental Bereavement and the Loss of a Child with Intellectual Disabilities: A Review of the Literature." Intellectual and Developmental Disabilities 46(1): 27-43.

Reynolds, T.M. 2003. “Down's Syndrome Screening is Unethical: Views of Today's Research Committees.” Journal of Clinical Pathology 56: 268-270.

Rizzo, Kathryn M., Holly H. Schiffrin and Miriam Liss. 2013. "Insight into the Parenthood Paradox: Mental Health Outcomes of Intensive Mothering." Journal of Child and Family Studies 22: 614-620.

Roan, Shari. 2011. "Prenatal Test for Down Syndrome Available." LA Times, October 19. Retrieved February 21, 2012 (http://articles.latimes.com/2011/oct/19/news/la-heb-downsyndrome-test-20111019).

Rothman, Barbara Katz. 1993. The Tentative Pregnancy: How Amniocentesis Changes the Experience of Motherhood. W.W. Norton and Company: New York.

---. 2007. "Beyond Mothers and Fathers: Ideology in a Patriarchal Society." Pp 390-407 in Maternal Theory: Essential Readings, edited by Andrea O'Reilly. Demeter Press: Toronto, Canada.

Scott, Melissa, Kitty-Rose Foley, Jenny Bourke, Helen Leonard, and Sonya Girdler. 2014. "'I Have a Good Life': The Meaning of Well-Being from the Perspective of Young Adults with Down Syndrome." Disability and Rehabilitation 36(15): 1290-1298.

Shepperdson, Billie. 1983. "Abortion and Euthanasia of Down's Syndrome ChildrenThe Parents' View.” Journal of Medical Ethics 9: 152-157.

Sherman, Stephanie L., Emily G. Allen, Lora H. Bean, and Sallie B. Freeman. 2007. "Epidemiology of Down Syndrome." Mental Retardation and Developmental Disabilities 13: 221-227.

Siffel, Csaba, Adolfo Correa, Janet Cragan, and C.J. Alverson. 2004. "Prenatal Diagnosis, Pregnancy Terminations and Prevalance of Down Syndrome in Atlanta." Birth Defects Research (Part A): Clinical and Molecular Teratology 70: 565-571. 
Simon, Robin. 2008. “The Joys of Parenthood, Reconsidered." Contexts 7(2): 40-45.

Silva, Vesta T. 2011. "Lost Choices and Eugenic Dreams: Wrongful Birth Lawsuits in Popular News Narratives." Communication and Critical/Cultural Studies 8(1): 22-40.

Skotko, Brian G. 2009. "With New Prenatal Testing, Will Babies with Down Syndrome Slowly Disappear." Archives of Disease in Childhood 94(11): 823-826.

van Vliet, H.A., D.A. Grimes, B. Popkin, and U. Smith. 2001. "Lay Persons' Understanding of the Risk of Down's Syndrome in Genetic Counselling." BJOG: An International Journal of Obstetrics and Gynaecology 108(6): 649-650.

Yazbeck, Marie, Keith McVilly, and Trevor R. Parmenter. 2004. "Attitudes toward People with Intellectual Disabilities: An Australian Perspective." Journal of Disability Policy Studies 15(2): 97-111. 


\section{APPENDIX}

\section{Interview Guide}

- Do you think all pregnant women should undergo initial screening tests for genetic problems, such as blood tests?

- If not, should any pregnant women undergo the tests? If so, who and why?

- What do you think the role of the woman's doctor should be in the genetic screening process?

- What, if anything, should a woman's doctor talk to her about, before doing the screening?

- What advice would you give a woman who is trying to decide if she will undergo genetic testing while she is pregnant?

- How do you feel about a woman deciding to undergo genetic testing while she is pregnant?

- What information, if any, should a doctor give to a woman and her partner, if they receive a diagnosis of Down Syndrome during the pregnancy?

- What advice would you give to a woman and her partner who are trying to decide whether or not to have an abortion after they receive a diagnosis of Down Syndrome during the pregnancy? 
- What questions would you tell a woman and her partner to ask her doctor when making the decision?

- What questions would you tell a woman and her partner to ask their family and friends when making the decision?

- Is there anyone else a woman and her partner should speak to when making the decision? If so, who and why?

- Whose perspective should a woman and her partner value the most when making the decision?

- How do you feel about a woman and her partner deciding to have an abortion after her fetus is diagnosed with Down Syndrome?

- What effects could there be on society if fewer people are born with Down Syndrome? (Problems, Benefits)

- What effects could there be on society if more people are born with Down Syndrome? (Problems, Benefits)

- How do you think people who have Down Syndrome could be affected if fewer people are born with Down Syndrome? (Problems, Benefits)

- How do you think people who have Down Syndrome could be affected if more people are born with Down Syndrome? (Problems, Benefits)

- How do you think education for children with Down Syndrome could change if more or fewer people are born with Down Syndrome? 
- How do you think medical care and insurance coverage for children and adults with Down Syndrome could change if more or fewer people are born with Down Syndrome?

- Is there anything I have not covered in this discussion that you feel it is important I know? 


\section{Email to Facilitators}

UofL Institutional Review Boards

IRB NUMBER: 16.0930

IRB APPROVAL DATE: 10/21/2016

Subject Line: Participants being sought for a sociological research study on Down Syndrome

Dear ,

My name is Laura Holt and I am a graduate student in the department of sociology at the University of Louisville. I am looking for participants for my research study. I will be conducting a series of individual interviews on the subject of genetic screening for Down Syndrome. You are receiving this email because you were listed as the contact for a local support group for parents of children with Down Syndrome. A review of your website information suggests your members may be eligible to participate in this study.

This study is about prenatal genetic screening for Down Syndrome, and abortion, as well as the effects of individual's choices about both, on the community and the lives of those who have the condition and their families. It is important that we gain a better understanding of how parents who are raising a child with Down Syndrome feel about prenatal genetic screening techniques and selective abortion for the condition. The perspectives of families affected by Down Syndrome are an important consideration in the development of public policies. Participants will be asked to answer questions in one individual interview, not to exceed ninety minutes in length. These discussions will be conducted at a time and place convenient for those willing to participate, or by phone if a participant prefers. The interview(s) will be recorded with a voice recorder; however, participants may direct the investigator to turn off the recorder at any time during the interview(s), without affecting their ability to participate in the study. Participants may also be asked if they are willing to participate in one individual interview for follow-up clarification, not to exceed thirty minutes in length.

Information collected during interviews will be kept confidential. The signed informed consent forms will be kept in a locked storage box accessible only by myself and the primary investigator. Real names will be replaced with fake names during the transcription of the voice recordings from the interviews. The voice recordings will be destroyed after they have been transcribed. If the research from this study is made public, the identities of the participants will not be revealed. The study will be conducted over the course of the next six months. To be able to take part in the study, participants must be eighteen or older, not pregnant at the time of the interview, and be a permanent parent to a child with Down Syndrome (not be acting temporarily as a caregiver, but having permanent custody as a parent or guardian).

I have attached a copy of the email of invitation for participants and the informed consent document. I would like to ask if you would please forward the participant email on to your support group members, who may contact me directly if they wish to participate. I would also be happy to provide you with hardcopies of the email of invitation for distribution at your next meeting, if you prefer.

Please let me know if I can answer any questions or address any concerns that you and/or your members may have. I may be reached at leholt01@cardmail.louisville.edu.

Version Date 10/13/2016 
UofL Institutional Review Boards

IRB NUMBER: 16.0930

IRB APPROVAL DATE: 10/21/2016

In addition, should you have any questions or concerns, you are welcome to contact my

graduate advisor who is acting as the principal investigator for this study, Dr. David J.

Roelfs, PhD at (502)852-8038, or at david.roelfs@louisville.edu.

Dr. David Roelfs

130 Lutz Hall

Department of Sociology

University of Louisville

Louisville, KY 40292

Thank you for your help.

Sincerely,

Laura Holt, BA

Version Date 10/13/2016 


\section{Email to Potential Participants}

UofL Institutional Review Boards

IRB NUMBER: 16.0930

IRB APPROVAL DATE: 10/21/2016

Subject Line: Invitation to participate in a sociological research study on Down Syndrome

Dear, My name is Laura Holt and I am a graduate student in the department of sociology at the University of Louisville. I am looking for participants for my research study. I will be conducting a series of individual interviews on the subject of genetic screening for Down Syndrome. You are receiving this email because you were included as a member of a local organization for parents of children with Down Syndrome. Your organization facilitator has graciously forwarded my invitation to you, as you may be eligible to participate in this study.

This study is about prenatal genetic screening for Down Syndrome, and abortion, as well as the effects of individual's choices about both, on the community and the lives of those who have the condition and their families. It is important that we gain a better understanding of how parents who are raising a child with Down Syndrome feel about prenatal genetic screening techniques and selective abortion for the condition. The perspectives of families affected by Down Syndrome are an important consideration in the development of public policies. Participants will be asked to answer questions in one individual interview, not to exceed ninety minutes in length. These discussions will be conducted at a time and place convenient for those willing to participate, or by phone if preferred. The interview(s) will be recorded with a voice recorder; however, you may direct the investigator to turn off the recorder at any time during the interview(s) without affecting your ability to participate in the study. If you participate in the interview, you may also be asked if you are willing to participate in one additional interview for followup clarification, not to exceed thirty minutes in length.

All information collected will be kept confidential. The signed informed consent forms will be kept in a locked storage box. Real names will be replaced with fake names during the transcription of the interview recordings. The voice recordings will be destroyed after they have been transcribed. If results of the study are made public, your identity will not be revealed. The study will be conducted over the course of the next six months. To be able to take part in the study, you must be eighteen or older and not pregnant at the time of the interview. You also must be a permanent parent to a child with Down Syndrome. Biological and adoptive parents can participate. If you are acting on a temporary basis as a parent to a child with Down Syndrome, you cannot participate. For example, foster parents and relatives, such as grandparents, that have only temporary custody of a child with Down Syndrome are ineligible.

I have attached a copy of the informed consent document. Please look over the form and contact me at leholt01@cardmail.louisville.edu if you would like to participate. I would also be happy to address any questions or concerns that you may have.

Version Date: 10/13/2016 
UofL Institutional Review Boards IRB NUMBER: 16.0930

IRB APPROVAL DATE: 10/21/2016

In addition, should you have any questions or concerns, you are welcome to contact my graduate advisor who is acting as the Principal Investigator for this study, Dr. David J.

Roelfs, PhD at (502)852-8038 or david.roelfs@louisville.edu or

Dr. David J. Roelfs

130 Lutz Hall

Department of Sociology

University of Louisville

Louisville, KY 40292

Thank you for your consideration.

Sincerely,

Laura Holt, BA

Version Date 10/13/2016 


\section{Participant Recruitment Flyer}

\section{Participants being sought for a sociological research study on Down Syndrome}

My name is Laura Holt and I am a graduate student in the department of sociology at the University of Louisville. I am looking for participants for my research study. I will be conducting a series of individual interviews on the subject of genetic screening for Down Syndrome. If you are a parent to a child with Down Syndrome you may be eligible to participate in this study.

This study is about prenatal genetic screening for Down Syndrome, and abortion, as well as the effects of individual's choices about both, on the community and the lives of those who have the condition and their families. It is important that we gain a better understanding of how parents who are raising a child with Down Syndrome feel about prenatal genetic screening techniques and selective abortion for the condition. The perspectives of families affected by Down Syndrome are an important consideration in the development of public policies.

Participants will be asked to answer questions in one individual interview, not to exceed ninety minutes in length. These discussions will be conducted at a time and place convenient for those willing to participate, or by phone if a participant prefers. The interview(s) will be recorded with a voice recorder; however, participants may direct the investigator to turn off the recorder at any time during the interview(s), without affecting the participant's ability to participate in the study. Participants may also be asked if they are willing to participate in one individual interview for follow-up clarification, not to exceed thirty minutes in length.

Information collected during interviews will be kept confidential. If the research from this study is made public, the identities of the participants will not be revealed. The study will be conducted over the course of the next six months. To be able to take part in the study, participants must be eighteen or older, not pregnant at the time of the interview, and be a permanent parent to a child with Down Syndrome (not be acting temporarily as a caregiver, but having permanent custody as a parent or guardian).

Please contact me if you are a parent to a child with Down Syndrome and you would be interested in participating. I am available by email at leholt01@cardmail.louisville.edu. Also, please let me know if I can answer any questions or address any concerns that you may have.

In addition, should you have any questions or concerns, you are welcome to contact my graduate advisor who is acting as the principal investigator for this study, Dr. David J. Roelfs, PhD at (502)852-8038, or at david.roelfs@louisville.edu

Dr. David Roelfs

130 Lutz Hall

Department of Sociology

University of Louisville

Louisville, KY 40292 


\section{Subject Informed Consent Document}

\section{Parental Opinions about Prenatal Genetic Screening and Selective Abortion for Down Syndrome}

Investigator(s) name \& address: Dr. David J. Roelfs 130 Lutz Hall Department of Sociology University of Louisville, Louisville, KY 40292

Site(s) where study is to be conducted: Sites convenient for participants, to be determined, or by phone

Phone number for subjects to call for questions: (502)852-8038

\section{Introduction and Background Information}

You are invited to participate in a research study. The study is being conducted by David $\mathrm{J}$. Roelfs, PhD, principal investigator and Laura Holt, BA, student investigator. The study is sponsored by the University of Louisville, Department of Sociology. The study will take place at sites to be determined, which are convenient for participants, or by phone. Approximately 20 subjects will be invited to participate.

\section{Purpose}

The purpose of this research study is to learn how parents of children with Down Syndrome feel about prenatal genetic screening, selective abortion for the condition, and how individual's choices about these matters impact society, as well as the people living with the condition and their families.

\section{Procedures}

In this study, you will be asked questions during one individual interview about the topics listed above. This interview will not exceed ninety minutes in length. You may decline to answer any question the interviewer may ask you. If you are willing, you may also be invited to participate in one individual follow up interview with the researcher, for the purpose of clarifying information you may have shared during the initial interview. This interview will not exceed thirty minutes in length. The interview(s) will be recorded with a voice recorder, however, you may direct the investigator to turn off the recorder at any time during the interview without affecting your ability to participate in the study.

\section{Potential Risks}

There are no foreseeable risks other than possible discomfort in answering personal questions. There may be unforeseen risks. If you feel at any time before, during, or after the study that you are experiencing distress or need a referral to a medical professional, you may contact the National Down Syndrome Society Helpline at (800)221-4602. All expenses related to such a referral will be your responsibility.

Page 1 of 3 Version Date: 10/13/2016 


\section{Benefits}

The possible benefits of this study include a better understanding of how parents who are raising a child with Down Syndrome feel about prenatal genetic screening techniques and selective abortion for the condition. The perspective of families affected by the condition is an important consideration in the development of public policies. The information collected may not benefit you directly. The information learned in this study may be helpful to others.

\section{Compensation}

You will not be compensated for your time, inconvenience, or expenses while you are in this study.

\section{Confidentiality}

Total privacy cannot be guaranteed. Your privacy will be protected to the extent permitted by law. If the results from this study are published, your name will not be made public. While unlikely, the following may look at the study records:

The University of Louisville Institutional Review Board, Human Subjects Protection Program Office

\section{Conflict of Interest}

This study does not involve a conflict of interest.

\section{Security}

Your information will be kept private by the following methods: Signed copies of this informed consent form will be kept in a locked storage box. Real names will be replaced by pseudonyms ("fake names") during the transcription of the voice recordings from the interviews. The voice recordings will be destroyed after the data has been transcribed.

\section{Voluntary Participation}

Taking part in this study is completely voluntary. You may choose not to take part at all. If you decide to be in this study you may stop taking part at any time. If you decide not to be in this study or if you stop taking part at any time, you will not be penalized or lose any benefits for which you may qualify.

You will be told about any changes that may affect your decision to continue in the study.

Contact Persons, Research Subject's Rights, Questions, Concerns, and Complaints

If you have any concerns or complaints about the study or the study staff, you have three options.

You may contact the principal investigator, Dr. David J. Roelfs, at (502)852-8038 or at david.roelfs@louisville.edu. 


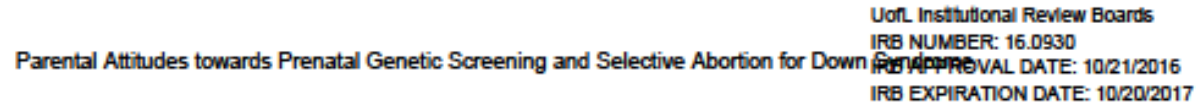

If you have any questions about your rights as a study subject, questions, concerns or complaints, you may call the Human Subjects Protection Program Office (HSPPO) (502)

852-5188. You may discuss any questions about your rights as a subject, in secret, with a member of the Institutional Review Board (IRB) or the HSPPO staff. The IRB is an independent committee composed of members of the University community, staff of the institutions, as well as lay members of the community not connected with these institutions. The IRB has reviewed this study.

If you want to speak to a person outside the University, you may call 1-877-852-1167. You will be given the chance to talk about any questions, concerns or complaints in secret. This is a 24 hour hot line answered by people who do not work at the University of Louisville.

\section{Acknowledgement and Signatures}

This informed consent document is not a contract. This document tells you what will happen during the study if you choose to take part. Your signature indicates that this study has been explained to you, that your questions have been answered, and that you agree to take part in the study. You are not giving up any legal rights to which you are entitled by signing this informed consent document. You will be given a copy of this consent form to keep for your records.

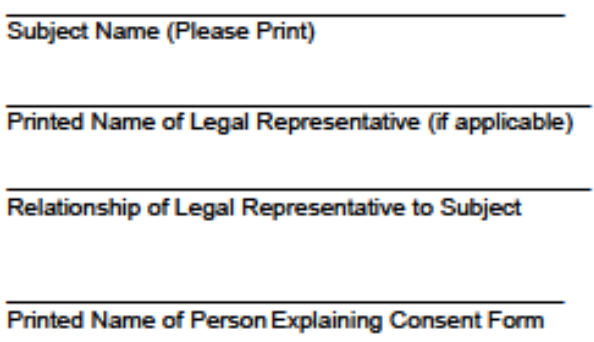

Printed Name of Investigator

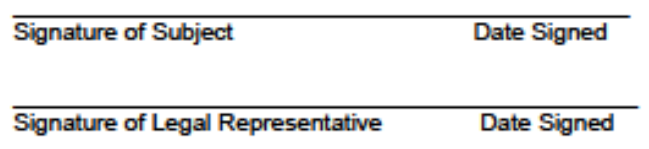

Signature of Legal Representative

List of Investigators:

David J. Roelfs, PhD

Laura Holt, BA

Phone Numbers:

(502)852-8038

Signature of Pers
Consent Form (if
Signature of Inves
Phone Number
(502)852-8038
(502)852-8038

Page 3 of 3 Version Date: 10/13/16 


\title{
CURRICULUM VITA
}

\author{
Laura Holt
}

\section{Education}

University of Louisville, Louisville, KY

Master of Arts Degree in Sociology, May 2017, GPA: 4.0

University of Louisville, Louisville, KY

Bachelor of Arts Degree in Sociology, magna cum laude, May 2009, GPA: 4.0

Honors: Harold C. Yeager Award 2008-09, Dean's Scholar 2008, Spring 2009

University of Kentucky, Lexington, KY

Completed 39 hours of coursework toward Bachelor of Arts degree, double major in English and Sociology, 1999 to 2001, GPA: 4.0 in double major, 3.8 cumulative

\section{Professional Experience}

\section{Community Living Supports Provider}

Present

- Adhere to established goals and behavioral support plan in supporting clients in community living environments.

- Provide timely and detailed feedback to plan representative and collaborate to develop modifications to support plan.

\section{Employer and Representative for Michelle P Waiver Program}

2010 to 2016

- Recruit and assemble highly qualified, goal oriented behavioral and community living support team. Train employees in effective, evidence based behavioral practices, incorporating principles of person-centered planning.

- Organize and chair efficient, focused team meetings. Foster collaboration among support personnel and support broker. Develop strategies for enhancing plan efficacy. Apprise team members of plan needs and changes.

- Provide diligent oversight and supplemental training to team members, to ensure they demonstrate continued proficiency in executing plan of care. Collect, review, and submit employee contracts, documentation, and timesheets. Implement program with mindfulness of desired outcomes and strict adherence to state guidelines. 
Certified Childbirth Doula, Self-Employed

2001 to 2013

- Discuss childbirth options with clients during the prenatal period. Design functional birth plans targeted to the specific desires, needs, and anticipated challenges of each expectant woman and her partner.

- Render mental, emotional, and physical support to women in labor and their families. Provide reliable and continual support in a rapidly changing and high pressure work environment.

- Maintain sensitivity to ethnic, cultural, and religious differences among families of diverse backgrounds.

Graduate Teaching and Research Assistant, Department of Sociology, University of Louisville Spring 2010

- Created teaching aids, student assessments, and enrichment exercises for undergraduate Introduction to Sociology course, in collaboration with Associate Professor.

- Taught two recitation sections of the course, facilitated student discussions on contemporary sociological topics, and tutored students during office hours. Assigned, managed, and reported student grades.

- Conducted independent research and reviews of existing literature for Associate Professors. 